\title{
Measuring the Services of Durables and Owner Occupied Housing
}

W. Erwin Diewert and Chihiro Shimizu, ${ }^{1}$

March 20, 2019

Discussion Paper 19-04,

School of Economics, University of British Columbia,

Vancouver, B.C.,

Canada, V6T 1 Z1.

\begin{abstract}
This paper provides an update to the chapter on the treatment of durables in the Consumer Price Index Manual (2004). The most important durable is housing, which typically accounts for approximately $20 \%$ of total consumption services. A large fraction of total housing services consists of the services of Owner Occupied Housing $(\mathrm{OOH})$. The main approaches to measuring the services of $\mathrm{OOH}$ are (i) the acquisitions approach; (ii) the rental equivalence approach and (iii) the user cost approach. Two other approaches are sometimes used: (iv) the opportunity cost approach and (v) the payments approach. A main purpose of this paper is to present the main approaches to the treatment of $\mathrm{OOH}$ and to discuss the benefits and costs of the alternative approaches. The paper also discusses the problems associated with forming imputations for the services of "ordinary" consumer durable goods.
\end{abstract}

\section{Journal of Economic Literature Classification Numbers}

C23, C43, C81, D12, E31.

C43, C82, E01.

\section{Key Words}

Durable goods; Consumer Price Index; Owner Occupied Housing; hedonic regression models; rental equivalence approach; user cost approach, acquisitions approach, opportunity cost approach.

\footnotetext{
${ }^{1}$ W. Erwin Diewert: School of Economics, University of British Columbia, Vancouver B.C., Canada, V6T $1 \mathrm{Z1}$ and the School of Economics, University of New South Wales, Sydney, Australia (email: erwin.diewert@ubc.ca) and Chihiro Shimizu, Nihon University, Setagaya, Tokyo, 154-8513, Japan, (email: shimizu.chihiro@nihon-u.ac.jp). The first author gratefully acknowledges the financial support of the SSHRC of Canada. The authors thank Paul Armknecht, John Astin, Corinne Becker-Vermeulen, David Fenwick, Dennis Fixler, Brian Graf, Jill Leyland, Jens Mehrhoff, Paul Schreyer, Nigel Stapledon and Valentina Stoevska for helpful comments.
} 


\section{Table of Contents}

1. Introduction

Page 3

2. The Acquisitions Approach

Page 6

3. The Rental Equivalence Approach

Page 8

4. The User Cost Approach for Pricing the Services of a Non-Housing Durable Good

5. The Opportunity Cost Approach

Page 11

Page 17

6. A General Model of Depreciation for Consumer Durables

Page 18

7. Geometric or Declining Balance Depreciation

Page 20

8. Straight Line Depreciation

Page 23

9. One Hoss Shay or Light Bulb Depreciation

Page 25

10. The Relationship Between User Costs and Acquisition Costs

Page 27

11. Calculating User Costs for Unique Durable Goods

Page 29

12. Decomposing Residential Property Prices into Land and Structure Components

Page 32

13. Decomposing Condominium Sales Prices into Land and Structure Components

14. Demand Side Property Price Hedonic Regressions

Page 42

Page 49

15. Price Indexes for Rental Housing

Page 54

16. Valuing the Services of OOH: User Cost versus Rental Equivalence

Page 58

17. The Payments Approach

Page 63

18. Summary and Conclusion

Page 73

References

Page 78 


\section{Introduction}

When a durable good (other than housing) is purchased by a consumer, national Consumer Price Indexes typically attribute all of that expenditure to the period of purchase, even though the use of the good extends beyond the period of purchase. ${ }^{2}$ This is known as the acquisitions approach to the treatment of consumer durables in the context of determining a pricing concept for the CPI. However, if one takes a cost of living approach to the Consumer Price Index, then it may be more appropriate to take the cost of using the services of the durable good during the period under consideration as the pricing concept. There are two broad methods for estimating this imputed cost for using the services of a durable good during a period:

- If rental or leasing markets for a comparable consumer durable exist, then this market rental price could be used as an estimate for the cost of using the durable during the period. This method is known as the rental equivalence approach.

- If used or second hand markets for the durable exist, then the imputed cost of purchasing a durable good at the beginning of the period and selling it at the end could be computed and this net cost could be used as a estimate for the cost of using the durable during the period. This method is known as the user cost approach.

The major advantages of the acquisitions approach to the treatment of consumer durables are:

- It is conceptually simple and entirely similar to the treatment of nondurables and services and

- No complex imputations are required.

The major disadvantage of the acquisitions approach compared to the other two approaches is that the acquisitions approach is not likely to reflect accurately the consumption services of consumer durables in any period. Thus suppose that real interest rates in a country are very high due to a macroeconomic crisis. Under these conditions, purchases of automobiles and houses and other long lived consumer durables may drop dramatically, perhaps to zero. However, the actual consumption of automobile and housing services of the country's population will not fall to zero under these circumstances: households will still be consuming the services of their existing stocks of motor vehicles and houses. Thus for at least some purposes, rather than taking the cost of

\footnotetext{
${ }^{2}$ This treatment of the purchases of durable goods dates back to Alfred Marshall (1898; 594-595) at least: "We have noticed also that though the benefits which a man derives from living in his own house are commonly reckoned as part of his real income, and estimated at the net rental value of his house; the same plan is not followed with regard to the benefits which he derives from the use of his furniture and clothes. It is best here to follow the common practice, and not count as part of the national income or dividend anything that is not commonly counted as part of the income of the individual."
} 
purchasing a consumer durable as the pricing concept, it will be more useful to take the cost of using the services of the durable good during the period under consideration as the pricing concept.

The above paragraphs provide a brief overview of the three major approaches to the treatment of consumer durables. In the remainder of this introduction, we explore these approaches in a bit more detail and give the reader an outline of the detailed discussion that will follow in subsequent sections.

Since the benefits of using the consumer durable extend over more than one period, it does not seem to be appropriate to charge the entire purchase cost of the durable to the initial period of purchase. If this point of view is taken, then the initial purchase cost must be distributed somehow over the useful life of the asset. This is the fundamental problem of accounting. ${ }^{3}$ Hulten (1990) explains the accounting problems that arise from the purchase of a durable good as follows:

"Durability means that a capital good is productive for two or more time periods, and this, in turn, implies that a distinction must be made between the value of using or renting capital in any year and the value of owning the capital asset. This distinction would not necessarily lead to a measurement problem if the capital services used in any given year were paid for in that year; that is, if all capital were rented. In this case, transactions in the rental market would fix the price and quantity of capital in each time period, much as data on the price and quantity of labor services are derived from labor market transactions. But, unfortunately, much capital is utilized by its owner and the transfer of capital services between owner and user results in an implicit rent typically not observed by the statistician. Market data are thus inadequate for the task of directly estimating the price and quantity of capital services, and this has led to the development of indirect procedures for inferring the quantity of capital, like the perpetual inventory method, or to the acceptance of flawed measures, like book value.” Charles R. Hulten (1990; 120-121).

Thus the treatment of durable goods is more complicated than the treatment of nondurable goods and services due to the simple fact that the period of time that a durable is used by the consumer extends beyond the period of purchase. For nondurables and services, the price statistician's measurement problems are conceptually simpler: prices for the same commodity need only be collected in each period and compared. However, for a durable good, the periods of payment and use do not coincide and so complex imputation problems arise if the goal of the price statistician is to measure and compare the price of using the services of the durable in two time periods.

As mentioned above, there are 3 main methods for dealing with the durability problem:

\footnotetext{
3 "The third convention is that of the annual accounting period. It is this convention which is responsible for most of the difficult accounting problems. Without this convention, accounting would be a simple matter of recording completed and fully realized transactions: an act of primitive simplicity." Stephen Gilman $(1939 ; 26)$. "All the problems of income measurement are the result of our desire to attribute income to arbitrarily determined short periods of time. Everything comes right in the end; but by then it is too late to matter." David Solomons $(1961 ; 378)$. Note that these authors do not mention the additional complications that are due to the fact that future revenues and costs must be discounted to yield values that are equivalent to present dollars. For more recent papers on the fundamental problem of accounting, see Cairns (2013) and Diewert and Fox (2016).
} 
- Ignore the problem of distributing the initial cost of the durable over the useful life of the good and allocate the entire charge to the period of purchase. As noted above, this is known as the acquisitions approach and it is the present approach used by Consumer Price Index statisticians for all durables with the exception of housing.

- The rental equivalence approach. In this approach, a period price is imputed for the durable which is equal to the rental price or leasing price of an equivalent consumer durable for the same period of time.

- The user cost approach. In this approach, the initial purchase cost of the durable is decomposed into two parts: one part which reflects an estimated cost of using the services of the durable for the period and another part, which is regarded as an investment, which must earn some exogenous rate of return.

These three major approaches will be discussed more fully in sections 2, 3 and 4 below. ${ }^{4}$ There is fourth approach that has not been applied but seems conceptually attractive that will be discussed in section 5: the opportunity cost approach. This approach takes the maximum of the rental equivalence and user cost as the price for the use of the services of a consumer durable over a period of time. Finally, there is a fifth approach to the treatment of consumer durables that has only been used in the context of pricing owner occupied housing and that is the payments approach. ${ }^{5}$ This is a kind of cash flow approach, which will be discussed in section 17 after we have discussed the other approaches in more detail.

The main three approaches to the treatment of durable purchases can be applied to the purchase of any durable commodity. However, historically, it turns out that the rental equivalence and user cost approaches have only been applied to owner occupied housing. In other words, the acquisitions approach to the purchase of consumer durables has been universally used by statistical agencies, with the exception of owner occupied housing. A possible reason for this is tradition; i.e., Marshall (1898) set the standard and statisticians have followed his example for the past century. However, another possible reason is that unless the durable good has a very long useful life, it usually will not make a great deal of difference in the long run whether the acquisitions approach or one of the two alternative approaches is used. This point is discussed in more detail in section 10 below.

A major component of the user cost approach to valuing the services of Owner Occupied Housing $(\mathrm{OOH})$ is the depreciation component. In section 6, a general model of depreciation for a consumer durable is presented and then it is specialized in sections 7-9 to the three models of depreciation that are widely used.

\footnotetext{
${ }^{4}$ It should be noted that in principle, the user cost and rental equivalence approaches should be much the same: the owner of a rental property needs to construct a user cost for the current period (using its opportunity cost of capital as the interest rate that appears in the user cost formula) so that the resulting user cost can be used as the rental price that will just allow the owner to make the target rate of return on the property investment. In practice, the exact equality does not hold due to various market imperfections which will be discussed later.

${ }^{5}$ This is the term used by Goodhart (2001; F350-F351).
} 
The general model presented in section 6 assumes that homogeneous units of the durable are produced in each period and it also assumes that used units of the durable trade on second hand markets so that information on the prices of the various vintages of the durable at any point in time can be used to determine the pattern of depreciation. However, many durables (like housing) are custom produced (i.e., they are unique goods) and thus the methods for determining the form of depreciation explained in section 6 are not immediately applicable. The special problems caused by uniquely produced consumer durables are considered in section 11.

The remainder of this paper looks at the particular problems associated with measuring the services of housing. Sections 12-14 show how information on the sales of dwelling units can be used to decompose the sales price into land and structure components. This information is required for the country's national balance sheet accounts. The decomposition into land and structure components is also required for the construction of rental prices and user costs and for measures of multifactor productivity for the rental housing sector of the economy. ${ }^{6}$ Section 12 looks at land and structure decompositions for the sale of detached housing units while section 13 does the same for the sales of condominium units. Hedonic regression models are explained in sections 12 and 13 that are basically supply side models while section 14 looks at a demand side hedonic regression model for the sales of detached houses. Section 15 considers hedonic regression models for rents. Section 16 looks at the factors that influence rents. This section also explains why the amount that an owned dwelling unit could rent for is in general different from the user cost that could be used to price the services of the unit to an owner. This section brings up important issues that pertain to the measurement of the services of $\mathrm{OOH}$. Thus section 16 revisits issues surrounding the use of either the rental equivalence or user cost approaches to the valuation of Owner Occupied Housing.

As mentioned early, section 17 explains the payments approach while section 18 concludes.

\section{The Acquisitions Approach}

The net acquisitions approach to the treatment of owner occupied housing is described by Goodhart as follows:

"The first is the net acquisition approach, which is the change in the price of newly purchased owner occupied dwellings, weighted by the net purchases of the reference population. This is an asset based measure, and therefore comes close to my preferred measure of inflation as a change in the value of money, though the change in the price of the stock of existing houses rather than just of net purchases would in some respects be even better. It is, moreover, consistent with the treatment of other durables. A few countries, e.g., Australia and New Zealand, have used it, and it is, I understand, the main contender for use in the Euro-area Harmonized Index of Consumer Prices (HICP), which currently excludes any measure of the purchase price of (new) housing, though it does include minor repairs and maintenance by home owners, as well as all expenditures by tenants." Charles Goodhart (2001; F350).

\footnotetext{
${ }^{6}$ Depreciation applies to the structure part of property value but not to the land part.
} 
Thus the weights for the net acquisitions approach are the net purchases of the household sector of houses from other institutional sectors in the base period. Note that in principle, purchases of second-hand dwellings from other sectors are relevant here; e.g., a local government may sell rental dwellings to owner occupiers. However, typically, newly built houses form a major part of these types of transactions. Thus the long term price relative for this category of expenditure will be primarily the price of (new) houses (quality adjusted) in the current period relative to the price of new houses in the base period. ${ }^{7}$ If this approach is applied to other consumer durables, it is extremely easy to implement: the purchase of a durable is treated in the same way as a nondurable or service purchase is treated.

One additional implication of the net acquisition approach is that major renovations and additions to owner occupied dwelling units could also be considered as being in scope for this approach. In practice, major renovations to a house are treated as investment expenditures and not covered as part of a consumer price index. Normal maintenance expenditures on a dwelling unit are usually treated in a separate category in the CPI.

Traditionally, the net acquisitions approach also includes transfer costs relating to the buying and selling of second hand houses as expenditures that are in scope for an acquisitions type consumer price index. These costs are mainly the costs of using a real estate agent's services and asset transfer taxes. These costs can be measured but the question arises as to what is the appropriate deflator for these costs. An overall property price index is probably a satisfactory deflator. ${ }^{8}$

The major advantage of the acquisitions approach is that it treats durable and nondurable purchases in a completely symmetric manner and thus no special procedures have to be developed by a statistical agency to deal with durable goods. ${ }^{9}$ As will be seen in section 10 below, the major disadvantage of this approach is that the expenditures associated with this approach will tend to understate the corresponding expenditures on durables that are implied by the rental equivalence and user cost approaches.

Some differences between the acquisitions approach and the other approaches are:

\footnotetext{
${ }^{7}$ This price index may or may not include the price of the land that the new dwelling unit sits on; e.g., a new house price construction index would typically not include the land cost. The acquisitions approach concentrates on the purchases by households of goods and services that are provided by suppliers from outside the household sector. Thus if the land on which a new house sits was previously owned by the household sector, then presumably, the cost of this land would be excluded from an acquisitions type new house price index. In this case, the price index that corresponds to the acquisitions approach is basically a new house price index (excluding land) or a modification of a construction cost index where the modification takes into account builder's margins.

${ }^{8}$ See the discussion in section 16 below on transfer costs.

${ }^{9}$ The acquisitions approach is straightforward and simple for most durable goods but not for housing, if the land component of property value is regarded as out of scope. Properties are sold with a single price that includes both the land and structure components of housing and so if the land part of property value is regarded as out of scope for the index, then there is a problem in decomposing property value into land and structure components. This decomposition problem can be avoided if information on the construction costs for building a new housing unit are available. In this case, the construction cost index (including builder's markups) can serve as the price index for newly constructed dwelling units.
} 
- If rental or leasing markets for the durable exist and the durable has a long useful life, then as mentioned above, the expenditure weights implied by the rental equivalence or user cost approaches will typically be much larger than the corresponding expenditure weights implied by the acquisitions approach; see section 16 below.

- If the base year corresponds to a boom year (or a slump year) for the durable, then the base period expenditure weights may be too large or too small. Put another way, the aggregate expenditures that correspond to the acquisitions approach are likely to be more volatile than the expenditures for the aggregate that are implied by the rental equivalence or user cost approaches. ${ }^{10}$

- In making comparisons of consumption across countries where the proportion of owning versus renting or leasing the durable varies greatly, ${ }^{11}$ the use of the acquisitions approach may lead to misleading cross country comparisons. The reason for this is that opportunity costs of capital are excluded in the net acquisitions approach whereas they are explicitly or implicitly included in the other two approaches.

More fundamentally, whether the acquisitions approach is the right one or not depends on the overall purpose of the index number. If the purpose is to measure the price of current period consumption services, then the acquisitions approach can only be regarded as an approximation to a more appropriate approach (which would be either the rental equivalence or user cost approach). If the purpose of the index is to measure monetary (or nonimputed) expenditures by households during the period, then the acquisitions approach might be preferable (provided the land component of property value is in scope), since the rental equivalence and user cost approaches necessarily involve imputations. ${ }^{12}$

The details of the acquisitions approach (as applied to $\mathrm{OOH}$ ) are discussed in great detail in Eurostat (2017). ${ }^{13}$ Eurostat is considering the use of the acquisitions approach for the treatment of $\mathrm{OOH}$ in its Harmonized Index of Consumer Prices (HICP) but at this date, no decision has been finalized. At present, $\mathrm{OOH}$ is simply omitted in the HICP. Eurostat is considering the use of the acquisitions approach for $\mathrm{OOH}$ because at first sight, it seems that no imputations have to be made in order to implement it. The HICP was created as an index of consumer prices that used actual transactions prices without the

\footnotetext{
${ }^{10}$ Hill, Steurer and Waltl $(2017 ; 6)$ summarize the problem of variable weights as follows: "Hence the expenditure weights on $\mathrm{OOH}$ under the acquisitions approach can fluctuate very significantly over the housing cycle. If the weights are updated regularly this may have a destabilizing effect on the CPI. If the weights are not updated regularly, then the treatment of $\mathrm{OOH}$ may be highly sensitive to the choice of reference year."

${ }^{11}$ From Hoffmann and Kurz (2002; 3-4), about $60 \%$ of German households lived in rented dwellings whereas only about $11 \%$ of Spaniards rented their dwellings in 1999.

${ }^{12}$ Fenwick (2009) (2012) laid out the case for the use of the acquisitions approach as a useful measure of general inflation. He also argued for the construction of multiple consumer price indexes to suit different purposes.

${ }^{13}$ This very useful publication also discusses the main methods for the treatment of $\mathrm{OOH}$ and it also covers the methods used to construct residential property price indexes. The latter topic is also covered in Eurostat (2013).
} 
use of any imputations. ${ }^{14}$ As such, it was thought to be particularly useful for monitoring inflation by central banks. However, the sale of a newly constructed dwelling unit typically includes a land component which Eurostat wants to exclude but existing methods for excluding the land component involve imputations. ${ }^{15}$

\section{The Rental Equivalence Approach}

The rental equivalence approach simply values the services yielded by the use of a consumer durable good for a period by the corresponding market rental value for the same durable for the same period of time (if such a rental value exists). This is the approach taken in the System of National Accounts: 1993 for owner occupied housing:

"As well-organized markets for rented housing exist in most countries, the output of own-account housing services can be valued using the prices of the same kinds of services sold on the market with the general valuation rules adopted for goods and services produced on own account. In other words, the output of housing services produced by owner-occupiers is valued at the estimated rental that a tenant would pay for the same accommodation, taking into account factors such as location, neighbourhood amenities, etc. as well as the size and quality of the dwelling itself." Eurostat, IMF, OECD, UN and World Bank (1993; 134).

However, the System of National Accounts: 1993 follows Marshall (1898; 595) and does not extend the rental equivalence approach to consumer durables other than housing. This seemingly inconsistent treatment of durables is explained in the SNA 1993 as follows:

"The production of housing services for their own final consumption by owner-occupiers has always been included within the production boundary in national accounts, although it constitutes an exception to the general exclusion of own-account service production. The ratio of owner-occupied to rented dwellings can vary significantly between countries and even over short periods of time within a single country, so that both international and intertemporal comparisons of the production and consumption of housing services could be distorted if no imputation were made for the value of own-account services." Eurostat, IMF, OECD, UN and World Bank (1993; 126).

Eurostat's (2001) Handbook on Price and Volume Measures in National Accounts also recommends the rental equivalence approach for the treatment of the dwelling services for owner occupied housing:

"The output of dwelling services of owner occupiers at current prices is in many countries estimated by linking the actual rents paid by those renting similar properties in the rented sector to those of owner occupiers. This allows the imputation of a notional rent for the service owner occupiers receive from their property." Eurostat $(2001 ; 99)$.

To summarize the above material, it can be seen that the rental equivalence approach to the treatment of durables is conceptually simple: impute a current period rental or leasing

\footnotetext{
${ }^{14}$ However, with the passage of time, it became apparent that some imputations for changes in the quality of consumer goods and services had to be made. Thus the current HICP is not completely free from imputations. See Astin (1999) for the methodological foundations of the HICP.

${ }^{15}$ The use of a construction cost index also involves an imputation (but it is a reasonably straightforward one).
} 
price for a comparable dwelling unit as the price for the services of an owned dwelling unit. $^{16}$

But where will the statistical agency find the relevant rental data to price the services of $\mathrm{OOH}$ ? There are at least three possible methods:

- Ask home owners what they think the market rent for their dwelling unit is; ${ }^{17}$

- Undertake a survey of owners of rental properties or managers of rental properties and ask what rents they charge for their rental properties by type of property or

- Use one of the above two methods to get a rent to value ratio for various types of property for a benchmark period and then link these ratios to indexes of purchase prices for the various types of property. ${ }^{18}$

There are some disadvantages associated with the use of the rental equivalence approach to the valuation of $\mathrm{OOH}$ services:

- Homeowners may not be able to provide very accurate estimates for the rental value of their dwelling unit.

- On the other hand, if the statistical agency tries to match the characteristics of an owned dwelling unit with a comparable unit that is rented in order to obtain the imputed rent for the owned unit, there may be difficulties in finding such comparable units. Furthermore, even if a comparable unit is found, the rent for the comparable unit may not be an appropriate opportunity cost for valuing the services of the owned unit. ${ }^{19}$

- The statistical agency should make an adjustment to these estimated rents over time in order to take into account the effects of depreciation, which causes the quality of the unit to slowly decline over time (unless this effect is completely offset by renovation and repair expenditures). ${ }^{20}$

- Care must be taken to determine exactly what extra services are included in the homeowner's estimated rent; i.e., does the rent include insurance, electricity and fuel or the use of various consumer durables in addition to the structure? If so, these extra services should be stripped out of the rent, if they are covered elsewhere in the consumer price index. ${ }^{21}$

\footnotetext{
${ }^{16}$ As will be seen in section 16 below, the situation is not quite as simple as indicated above.

${ }^{17}$ This approach is used by the Bureau of Labor Statistics (1983) in order to determine expenditure weights for owner occupied housing; i.e., homeowners are asked to estimate what their house would rent for if it were rented to a third party.

${ }^{18}$ Lebow and Rudd $(2003 ; 169)$ note that the US Bureau of Economic Analysis applies a benchmark rent to value ratio for rented properties to the value of the owner occupied stock of housing. It can be seen that this approach is essentially a simplified user cost method where all of the key variables in the user cost formula (to be discussed later) are held constant except the asset price of the property.

${ }^{19} \mathrm{We}$ will return to this point after we have discussed the opportunity cost approach to the valuation of $\mathrm{OOH}$ services.

${ }^{20}$ This issue will be discussed in more detail in section 16 below.

${ }^{21}$ However, it could be argued that these extra services that might be included in the rent are mainly a weighting issue; i.e., it could be argued that the trend in the homeowner's estimated rent would be a reasonably accurate estimate of the trend in the rents after adjusting for the extra services included in the rent.
} 
In order to overcome the first difficulty listed above, statistical agencies, including the Japanese government, are currently collecting housing rent data from property management companies or owners who rent out their dwelling units; i.e., Japan uses the second method to value the services of $\mathrm{OOH}$. However, the characteristics of the owner occupied population of dwelling units are generally quite different from the characteristics of the rental population. ${ }^{22}$ Thus typically, it is difficult to find rental units that are comparable to owned dwelling units. The use of hedonic regression techniques can mitigate this lack of matching problem. Moreover the use of hedonic regressions can deal with the depreciation or quality decline problem mentioned above. We will discuss hedonic regression techniques later in this paper in sections 12-15.

In addition to the above possible biases in using the rental equivalence approach to the valuation of the services of $\mathrm{OOH}$, there are differences between contract rent and market rent. Contract rent refers to the rent paid by a renter who has a long term rental contract with the owner of the dwelling unit and market rent is the rent paid by the renter in the first period after a rental contract has been negotiated. In a normal economy which is experiencing moderate or low general inflation, typically market rent will be higher than contract rent. However, if there are rent controls or a temporary glut of rental units, then market rent could be lower than contract rent. In any case, it can be seen that if we value the services of an owner occupied dwelling at its current opportunity cost on the rental market, we should be using market rent rather than contract rent.

The rents used to estimate the cost of rented dwellings in the Japanese CPI is the aggregate of rents paid for rental accommodation. These rents include a combination of newly signed rental contracts and rollover contracts for existing tenants. It is appropriate to use both types of contract to measure the actual cost of rental housing (but of course, these rents should be quality adjusted for depreciation and other changes in quality). But it is not appropriate to use both types of contract to impute rents for owner occupied housing: only market rents should be used. It is known that price adjustments are basically not made for rollover contracts (i.e. renewed leases). As a result, it is to be expected that new contract rents determined freely by the market will diverge considerably from rollover contract rents. ${ }^{23}$

Genesove (2003), based on a study using individual data from the American Housing Survey and survey research, analyzed the stickiness of rents by dividing them into new contracts and rollover contracts.

\footnotetext{
${ }^{22}$ For example, according to the 2013 Japanese Housing and Land Survey, the average floor space (size) of owner occupied housing in Tokyo was 110.64 square meters for single family houses and 82.71 square meters for rental housing, a difference of over 30 square meters. For condominiums, an even greater discrepancy exists: the average floor space is 65.73 square meters for owner-occupied housing and 37.64 square meters for rental housing. Moreover, in addition to the difference in floor space between rented and owned units, the quality of the owned units tends to be higher than the rented units and these quality differences need to be taken into account.

${ }^{23}$ On this point, see also Lewis and Restieaux (2015).
} 
In Japan, Shimizu, Nishimura and Watanabe (2010b) and Shimizu and Watanabe (2011) used data from a housing listing magazine and a property management company to measure the extent of housing rent stickiness in the country and analyzed the micro structure of rental adjustments.

In the following section, we provide an introduction to user cost theory for a non-housing durable good. In subsequent sections, we will deal with the problems associated with measuring depreciation and the aggregation of user costs over different ages of the same good. And later yet, we will look at the additional difficulties that are associated with the formation of user costs for housing.

\section{The User Cost Approach for Pricing the Services of a Non-Housing Durable Good}

The user cost approach to the treatment of durable goods is in some ways very simple: it calculates the cost of purchasing the durable at the beginning of the period, using the services of the durable during the period and then netting off from these costs the benefit that could be obtained by selling the durable good at the end of the period. However, there are several details of this procedure that are somewhat controversial. These details involve the use of opportunity costs, which are usually imputed costs, the treatment of interest and the treatment of capital gains or holding gains.

Another complication with the user cost approach is that it involves making distinctions between current period (flow) purchases within the period under consideration and the holdings of physical stocks of the durable at the beginning and the end of the accounting period. Typically, when constructing a consumer price index, we think of all quantity purchases as taking place at a single point in time, say the middle of the period under consideration, at the (unit value) average prices for the period. In constructing user costs, prices at the beginning and end of an accounting period play an important role.

To determine the net cost of using a durable good during say period 0 , it is assumed that one unit of the durable good is purchased at the beginning of period 0 at the price $\mathrm{P}^{0}$. The "used" or "second-hand" durable good can be sold at the end of period 0 at the price $\mathrm{P}_{\mathrm{S}}{ }^{124}$ It might seem that a reasonable net cost for the use of one unit of the consumer durable during period 0 is its initial purchase price $\mathrm{P}^{0}$ less its end of period 0 "scrap value", $\mathrm{P}_{\mathrm{S}}{ }^{1}$. However, money received at the end of the period is not as valuable as money that is received at the beginning of the period. Thus in order to convert the end of period value into its beginning of the period equivalent value, it is necessary to discount the term $\mathrm{P}_{\mathrm{S}}{ }^{1}$ by the term $1+\mathrm{r}^{0}$ where $\mathrm{r}^{0}$ is the beginning of period 0 nominal interest rate that the consumer faces. Hence the period 0 user cost $\mathrm{u}^{0}$ for the consumer durable $\mathrm{e}^{25}$ is defined as

\footnotetext{
${ }^{24}$ Note that this approach to pricing the services of a durable good assumes the existence of second hand markets for units of the durable that have aged. This assumption may not be satisfied for many consumer durables including unique assets such as dwelling units and works of art, which are not bought and sold every period. We will deal with this situation later in section 12 .

${ }^{25}$ This approach to the derivation of a user cost formula was suggested by Diewert (1974) who in turn based it on an approach due to Hicks $(1946 ; 326)$.
} 
(1) $\mathrm{u}^{0} \equiv \mathrm{P}^{0}-\mathrm{P}_{\mathrm{S}}{ }^{1} /\left(1+\mathrm{r}^{0}\right)$.

There is another way to view the user cost formula (1): the consumer purchases the durable at the beginning of period 0 at the price $\mathrm{P}^{0}$ and charges himself or herself the rental price $u^{0}$. The remainder of the purchase price, $I^{0}$, defined as

(2) $\mathrm{I}^{0} \equiv \mathrm{P}^{0}-\mathrm{u}^{0}$

can be regarded as an investment, which is to yield the appropriate opportunity cost of capital $\mathrm{r}^{0}$ that the consumer faces. At the end of period 0 , this rate of return could be realized provided that $\mathrm{I}^{0}, \mathrm{r}^{0}$ and the selling price of the durable at the end of the period $\mathrm{P}_{\mathrm{S}}{ }^{1}$ satisfy the following equation:

(3) $\mathrm{I}^{0}\left(1+\mathrm{r}^{0}\right)=\mathrm{P}_{\mathrm{S}}{ }^{1}$.

Given $\mathrm{P}_{\mathrm{S}}{ }^{1}$ and $\mathrm{r}^{0},(3)$ determines $\mathrm{I}^{0}$, which in turn, given $\mathrm{P}^{0}$, determines the user cost $\mathrm{u}^{0}$ via $(2)^{26}$.

Thus user costs are not like the prices of nondurables or services because the user cost concept involves pricing the durable at two points in time rather than at a single point in time. Because the user cost concept involves prices at two points in time, money received or paid out at the first point in time is more valuable than money paid out or received at the second point in time and so interest rates creep into the user cost formula. Furthermore, because the user cost concept involves prices at two points in time, expected prices can be involved if the user cost is calculated at the beginning of the period under consideration instead of at the end. With all of these complications, it is no wonder that many price statisticians would like to avoid using user costs as a pricing concept. However, even for price statisticians who would prefer to use the rental equivalence approach to the treatment of durables over the user cost approach, there is some justification for considering the user cost approach in some detail, since this approach gives insights into the economic determinants of the rental or leasing price of a durable.

The user cost formula (1) can be put into a more familiar form if the period 0 economic depreciation rate $\delta$ and the period 0 ex post asset inflation rate $\mathrm{i}^{0}$ are defined. Define $\delta$ by:

(4) $(1-\delta) \equiv \mathrm{P}_{\mathrm{S}}{ }^{1} \mathrm{P}^{1}$

where $\mathrm{P}_{\mathrm{S}}{ }^{1}$ is the price of a one period old used asset at the end of period 0 and $\mathrm{P}^{1}$ is the price of a new asset at the end of period 0. Typically, if a new asset and a one period older asset are sold at the same time, then the new asset will be worth more than the used asset and hence $\delta$ will be a positive number between 0 and 1 . The period 0 inflation rate for the new asset, $i^{0}$, is defined by:

(5) $1+\mathrm{i}^{0} \equiv \mathrm{P}^{1} / \mathrm{P}^{0}$.

${ }^{26}$ This derivation for the user cost of a consumer durable was also made by Diewert (1974; 504). 
Eliminating $\mathrm{P}^{1}$ from equations (4) and (5) leads to the following formula for the end of period 0 used asset price:

(6) $\mathrm{P}_{\mathrm{S}}{ }^{1}=(1-\delta)\left(1+\mathrm{i}^{0}\right) \mathrm{P}^{0}$.

Substitution of (6) into (1) yields the following expression for the period 0 user cost $\mathrm{u}^{0}$ :

(7) $\mathrm{u}^{0}=\left[\left(1+\mathrm{r}^{0}\right)-(1-\delta)\left(1+\mathrm{i}^{0}\right)\right] \mathrm{P}^{0} /\left(1+\mathrm{r}^{0}\right)$.

Note that $\mathrm{r}^{0}-\mathrm{i}^{0}$ can be interpreted as a period 0 real interest rate and $\delta\left(1+\mathrm{i}^{0}\right)$ can be interpreted as an inflation adjusted depreciation rate.

The user cost $\mathrm{u}^{0}$ is expressed in terms of prices that are discounted to the beginning of period 0. However, it is also possible to express the user cost in terms of prices that are "anti-discounted" or appreciated to the end of period $0 .{ }^{27}$ Thus define the end of period 0 user cost $\mathrm{p}^{0}$ as: ${ }^{28}$

(8) $\mathrm{p}^{0} \equiv\left(1+\mathrm{r}^{0}\right) \mathrm{u}^{0}=\left[\left(1+\mathrm{r}^{0}\right)-(1-\delta)\left(1+\mathrm{i}^{0}\right)\right] \mathrm{P}^{0}$

where the last equation follows using (7). If the real interest rate $r^{0^{*}}$ is defined as the nominal interest rate $\mathrm{r}^{0}$ less the asset inflation rate $\mathrm{i}^{0}$ and the small term $\delta \mathrm{i}^{0}$ is neglected, then the end of the period user cost defined by (8) reduces to:

(9) $\mathrm{p}^{0}=\left(\mathrm{r}^{0^{*}}+\delta\right) \mathrm{P}^{0}$.

Abstracting from transactions costs and inflation, it can be seen that the end of the period user cost defined by (9) is an approximate rental cost; i.e., the rental cost for the use of a consumer (or producer) durable good should equal the (real) opportunity cost of the capital tied up, $\mathrm{r}^{0 *} \mathrm{P}^{0}$, plus the decline in value of the asset over the period, $\delta \mathrm{P}^{0}$. Formulae (8) and (9) thus cast some light on what are the economic determinants of rental or leasing prices for consumer durables.

\footnotetext{
${ }^{27}$ Thus the beginning of the period user cost $\mathrm{u}^{0}$ discounts all monetary costs and benefits into their dollar equivalent at the beginning of period 0 whereas $\mathrm{p}^{0}$ discounts (or appreciates) all monetary costs and benefits into their dollar equivalent at the end of period 0 . This leaves open how flow transactions that take place within the period should be treated. Following the conventions used in financial accounting suggests that flow transactions taking place within the accounting period be regarded as taking place at the end of the accounting period and hence following this convention, end of period user costs should be used by the price statistician; see Peasnell (1981).

${ }^{28}$ Christensen and Jorgenson (1969) derived a user cost formula similar to (7) in a different way using a continuous time optimization model. If the inflation rate i equals 0 , then the user cost formula (7) reduces to that derived by Walras $(1954 ; 269)$ (first edition 1874). This zero inflation rate user cost formula was also derived by the industrial engineer A. Hamilton Church (1901; 907-908), who perhaps drew on the work of Matheson: "In the case of a factory where the occupancy is assured for a term of years, and the rent is a first charge on profits, the rate of interest, to be an appropriate rate, should, so far as it applies to the buildings, be equal (including the depreciation rate) to the rental which a landlord who owned but did not occupy a factory would let it for." Ewing Matheson (1910; 169), first published in 1884. Additional derivations of user cost formulae in discrete time have been made by Katz $(1983 ; 408-409)$ and Diewert (2005a). Hall and Jorgenson (1967) introduced tax considerations into user cost formulae.
} 
If the simplified user cost formula defined by (9) above is used, then at first glance, forming a price index for the user cost of a durable good is not very much more difficult than forming a price index for the purchase price of the durable good, $\mathrm{P}^{0}$. The price statistician needs only to:

- Make a reasonable assumption as to what an appropriate monthly or quarterly real interest rate $\mathrm{r}^{0^{*}}$ should be;

- Make an assumption as to what a reasonable monthly or quarterly depreciation rate $\delta$ should be ${ }^{29}$

- Collect purchase prices $\mathrm{P}^{0}$ for the durable and use formula (9) to calculate the simplified user cost. ${ }^{30}$

If it is thought necessary to implement the more complicated user cost formula (8) in place of the simpler formula (9), then the situation is more complicated. As it stands, the end of the period user cost formula (8) is an ex post (or after the fact) user cost: the asset inflation rate $i^{0}$ cannot be calculated until the end of period 0 has been reached. Formula (8) can be converted into an ex ante (or before the fact) user cost formula if $\mathrm{i}^{0}$ is interpreted as an anticipated asset inflation rate. The resulting formula should approximate a market rental rate for the durable good. ${ }^{31}$

Note that in the user cost approach to the treatment of consumer durables, the entire user cost formula (8) or (9) is the period 0 price. Thus in the time series context, it is not necessary to deflate each component of the formula separately; the period 0 price $\mathrm{p}^{0} \equiv\left[\mathrm{r}^{0}\right.$ $\left.-\mathrm{i}^{0}+\delta\left(1+\mathrm{i}^{0}\right)\right] \mathrm{P}^{0}$ is compared to the corresponding period 1 price, $\mathrm{p}^{1} \equiv\left[\mathrm{r}^{1}-\mathrm{i}^{1}+\right.$ $\left.\delta\left(1+\mathrm{i}^{1}\right)\right] \mathrm{P}^{1}$ and so on.

\footnotetext{
${ }^{29}$ The geometric model for depreciation to be explained in more detail in section 6 below requires only a single monthly or quarterly depreciation rate. Other models of depreciation may require the estimation of a sequence of vintage depreciation rates. If the estimated annual geometric depreciation rate is $\delta_{\mathrm{a}}$, then the corresponding monthly geometric depreciation rate $\delta$ can be obtained by solving the equation $(1-\delta)^{12}=1$ $-\delta_{\mathrm{a}}$. Similarly, if the estimated annual real interest rate is $\mathrm{r}_{\mathrm{a}}{ }^{*}$, then the corresponding monthly real interest rate $r^{*}$ can be obtained by solving the equation $\left(1+r^{*}\right)^{12}=1+r_{a}^{*}$.

${ }^{30}$ Iceland uses a variant of the simplified user cost formula (9) to estimate the services of $\mathrm{OOH}$ with a real interest rate approximately equal to $4 \%$ and depreciation rate of $1.25 \%$. The depreciation rate is relatively low because it is applied to the entire property value and not to just the structure portion of property value; see Gudnason and Jonsdottir (2011). Eurostat (2005) also uses a simplified user cost formula. Additional simplified user cost formulae have been developed by Hill, Steurer and Waltl (2017) and many others.

${ }^{31}$ Since landlords must set their rent at the beginning of the period (and in fact, they usually set their rent for an extended period of time), if the user cost approach is used to model the economic determinants of market rental rates, then the asset inflation rate $\mathrm{i}^{0}$ should be interpreted as an expected inflation rate rather than an after the fact actual inflation rate. This use of ex ante prices in this price measurement context should be contrasted with the preference of national accountants to use actual or ex post prices in the system of national accounts.
} 
In principle, depreciation rates can be estimated using information on the selling prices of used units of the durable good. ${ }^{32}$ However, for housing, the situation is more complex, as will be explained later.

We conclude this introductory section by noting some practical problems that statistical agencies will face when calculating user costs for durable goods: ${ }^{33}$

- It is difficult to determine what the relevant nominal interest rate $r^{0}$ is for each household. If a consumer has to borrow to finance the cost of a durable good purchase, then this interest rate will typically be much higher than the safe rate of return that would be the appropriate opportunity cost rate of return for a consumer who had no need to borrow funds to finance the purchase. ${ }^{34}$ It may be necessary to simply use a benchmark interest rate that would be determined by either the government, a national statistical agency or an accounting standards board. ${ }^{35}$

- It will generally be difficult to determine what the relevant depreciation rate is for the consumer durable. ${ }^{36}$

- Ex post user costs based on formula (8) may be too volatile to be acceptable to users ${ }^{37}$ (due to the volatility of the ex post asset inflation rate $\mathrm{i}^{0}$ ) and hence an ex ante user

\footnotetext{
${ }^{32}$ For housing, the situation is more complex because typically, a dwelling unit is a unique good; its location is a price determining characteristic and each housing unit has a unique location and thus is a unique good. It also changes its character over time due to renovations and depreciation of the structure. Thus the treatment of housing is much more difficult than the treatment of other durable goods. Note that the definitions (4) and (5) of the depreciation rate $\delta$ and the asset inflation rate $\mathrm{i}^{0}$ implicitly assumed that prices for a new asset and a one period old asset were available in both periods 0 and 1 . This assumption is not satisfied for a unique asset.

${ }^{33}$ For additional material on difficulties with the user cost approach, see Diewert (1980; 475-479) and Katz $(1983 ; 415-422)$.

${ }^{34}$ Katz $(1983$; 415-416) comments on the difficulties involved in determining the appropriate rate of interest to use: "There are numerous alternatives: a rate on financial borrowings, on savings, and a weighted average of the two; a rate on nonfinancial investments. e.g., residential housing, perhaps adjusted for capital gains; and the consumer's subjective rate of time preference. Furthermore, there is some controversy about whether it should be the maximum observed rate, the average observed rate, or the rate of return earned on investments that have the same degree of risk and liquidity as the durables whose services are being valued."

${ }^{35}$ One way for choosing the nominal interest rate for period $t, r^{t}$, is to set it equal to $\left(1+r^{*}\right)\left(1+\rho^{t}\right)-1$ where $\rho^{t}$ is a consumer price inflation rate for period $t$ and $r^{*}$ is a reference real interest rate. The Australian Bureau of Statistics has used this method for determining $\mathrm{r}^{\mathrm{t}}$ with $\mathrm{r}^{*} \equiv 0.04$; i.e., a 4 percent real interest rate was chosen. Other methods for determining the appropriate interest rate that should be inserted into user cost formula are discussed by Harper, Berndt and Wood (1989), Schreyer (2001) and Hill, Steurer and Waltl (2017).

${ }^{36}$ We will discuss geometric or declining balance depreciation and one hoss shay depreciation below. For references to the depreciation literature and for empirical methods for estimating depreciation rates, see Hulten and Wykoff (1981a) (1981b) (1996), Beidelman (1973) (1976), Jorgenson (1996) and Diewert and Lawrence (2000).

${ }^{37}$ Goodhart (2001; F351) commented on the practical difficulties of using ex post user costs for housing as follows: "An even more theoretical user cost approach is to measure the cost foregone by living in an owner occupied property as compared with selling it at the beginning of the period and repurchasing it at the end ... But this gives the absurd result that as house prices rise, so the opportunity cost falls; indeed the more virulent the inflation of housing asset prices, the more negative would this measure become. Although it has some academic aficionados, this flies in the face of common sense; I am glad to say that no country has adopted this method." As noted above, Iceland and Eurostat have in fact adopted a simplified
} 
cost concept may have to be used. For most durable goods, the asset inflation rates are smaller than the reference nominal interest rate so that subtracting an ex post asset inflation rate from the sum of the nominal interest rate plus the asset depreciation rate will usually lead to reasonably stable positive user costs. However, for durable goods with very low depreciation rates, like a housing structure or like land (which has a zero depreciation rate), the resulting ex post user costs may turn out to be negative for some periods. This means that the resulting negative user costs are not useful approximations to rental prices for these long lived durable goods. This creates difficulties in that different national statistical agencies will generally make different assumptions and use different methods in order to construct forecast inflation rates for structures and land and hence the resulting ex ante user costs of the durable may not be comparable across countries. ${ }^{38}$

- The user cost formula (8) should be generalized to accommodate various taxes that may be associated with the purchase of a durable or with the continuing use of the durable. $^{39}$

Some of the problems associated with estimating depreciation rates will be discussed in section 6 below.

\section{The Opportunity Cost Approach}

The opportunity cost approach to the valuation of the services of a consumer durable during a time period is very easy to describe: the opportunity cost valuation is simply the maximum of the foregone rental or leasing price for the services of the durable during a period of time and the corresponding user cost for the durable. It is easy to see that when a household has a consumer durable in its possession, the household forgoes the money that one could earn by renting out the services of the durable good for the period of time under consideration. (Such rental markets may not exist, in which case, this opportunity cost is 0 ). Thus the rental equivalent (at current market rates) is one opportunity cost that the household incurs by continuing to own and use the services of the durable during the

user cost framework which seems to work well enough. Moreover, the user cost concept is used widely in production function and productivity studies and by national statisticians who construct multifactor productivity accounts for their countries.

${ }^{38}$ For additional material on the difficulties involved in constructing ex ante user costs, see Diewert (1980; 475-486) and Katz (1983; 419-420). For empirical comparisons of different user cost formulae, see Harper, Berndt and Wood (1989), Diewert and Lawrence (2000) and Diewert and Fox (2018). In the latter paper, the authors calculated Jorgensonian (ex post) user costs for US land used in residential housing and found that negative user costs occurred. Diewert and Fox then replaced the ex post capital gains term in the user cost for land with the long term inflation rate for land over the previous rolling window of 25 years and this substitution led to positive user costs for land that were relatively smooth. Hill, Steurer and Waltl (2017) also recommend the use of long run asset inflation rates to avoid chain drift in housing indexes based on user costs.

${ }^{39}$ For example, property taxes are associated with the use of housing services and hence should be included in the user cost formula; see section 16 below. As Katz $(1983 ; 418)$ noted, taxation issues also impact the choice of the interest rate: "Should the rate of return be a before or after tax rate?" From the viewpoint of a household that is not borrowing to finance the purchase of the durable, an after tax rate of return seems appropriate but from the point of a leasing firm, a before tax rate of return seems appropriate. This difference helps to explain why rental equivalence prices for the durable might be higher than user cost prices; see also section 16 below. 
period. However, there is another opportunity cost that is applicable to using the services of the durable good during the period under consideration. By using the services of the durable good, the household also forgoes a financial opportunity cost. Thus the durable good could be sold on the second hand market at the beginning of the period at the price $\mathrm{P}^{0}$. This amount of money could be invested in some financial instrument that earns the one period rate of return of $\mathrm{r}^{0}$. Thus at the end of the period, the household would have accumulated $\mathrm{P}^{0}\left(1+\mathrm{r}^{0}\right)$ dollars as a result of selling the consumer durable at the beginning of the period. Now suppose at the end of the period, the household buys back the consumer durable that it sold at the beginning of the period. The value of the durable good at the end of the period will be $\left(1+\mathrm{i}^{0}\right)\left(1-\delta^{0}\right) \mathrm{P}^{0}$ where $\mathrm{i}^{0}$ is the asset appreciation rate over period 0 and $\delta^{0}$ is the depreciation rate for the durable good. Thus the net opportunity cost of using the services of the durable for period 0 from the financial perspective is $\mathrm{P}^{0}\left(1+\mathrm{r}^{0}\right)-\left(1+\mathrm{i}^{0}\right)\left(1-\delta^{0}\right) \mathrm{P}^{0}$ which is exactly the end of period user cost for the durable good that was derived earlier; see equation (8) above. A true opportunity cost for using the services of a durable good should equal the maximum of the benefits that are foregone by not using these services. Thus the opportunity cost approach to pricing the services of a consumer durable is equivalent to taking the maximum of the rent and user cost that the durable could generate over the period under consideration. ${ }^{40}$

\section{A General Model of Depreciation for Consumer Durables}

In this section, a "general" model of depreciation for durable goods that appear on the market each period without undergoing quality change will be presented. In the following three sections, this general model will be specialized to the three most common models of depreciation that appear in the literature. In section 11 below, the additional problems that occur when the durable is a unique good (or when second hand markets do not exist) will be discussed.

The main tool that can be used to identify depreciation rates for a durable good is the cross sectional sequence of asset prices classified by their age that units of the good sell for on the second hand market at any point of time. ${ }^{41}$ Thus in order to apply this method of measurement, it is necessary that such second hand markets exist.

Some notation is required. Let $\mathrm{P}_{0}{ }^{\mathrm{t}}$ be the price of a newly produced unit of the durable good at the beginning of period $\mathrm{t}$. Let $\mathrm{P}_{\mathrm{v}}{ }^{\mathrm{t}}$ be the second hand market price at the

\footnotetext{
${ }^{40}$ The opportunity cost approach to pricing the services of Owner Occupied Housing was first proposed by Diewert (2008). It was further developed by Diewert and Nakamura (2011) and Diewert, Nakamura and Nakamura (2011). To our knowledge, there have been only two studies that implemented the opportunity cost approach to the valuation of the services of $\mathrm{OOH}$; see Shimizu, Diewert, Nishimura and Watanabe (2012) and Aten (2018).

${ }^{41}$ Another information source that could be used to identify depreciation rates for the durable good is the sequence of vintage rental or leasing prices that might exist for some consumer durables. In the closely related capital measurement literature, the general framework for an internally consistent treatment of capital services and capital stocks in a set of vintage accounts was set out by Jorgenson (1989) and Hulten (1990; 127-129) (1996; 152-160).
} 
beginning of period $\mathrm{t}$ of a unit of the durable good that is v periods old. ${ }^{42}$ The beginning of period $t$ cross sectional depreciation rate for a brand new unit of the durable good, $\delta_{0}{ }^{\mathrm{t}}$, is defined as follows:

(10) $1-\delta_{0}{ }^{\mathrm{t}} \equiv \mathrm{P}_{1}{ }^{\mathrm{t}} / \mathrm{P}_{0}{ }^{\mathrm{t}}$.

Once $\delta_{0}{ }^{t}$ has been defined by (10), the period t cross sectional depreciation rate for a unit of the durable good that is one period old at the beginning of period $\mathrm{t}, \delta_{1}{ }^{\mathrm{t}}$, can be defined using the following equation:

(11) $\left(1-\delta_{1}{ }^{\mathrm{t}}\right)\left(1-\delta_{0}{ }^{\mathrm{t}}\right) \equiv \mathrm{P}_{2}{ }^{\mathrm{t}} / \mathrm{P}_{0}{ }^{\mathrm{t}}$.

Note that $\mathrm{P}_{2}{ }^{\mathrm{t}}$ is the beginning of period $\mathrm{t}$ asset price of a unit of the durable good that is 2 periods old and it is compared to the price of a brand new unit of the durable, $\mathrm{P}_{0}{ }^{\mathrm{t}}$.

Given that the period t cross sectional depreciation rates for units of the durable that are 0 , $1,2, \ldots, \mathrm{v}-1$ periods old at the beginning of period 0 are defined (these are the depreciation rates $\left.\delta_{0}{ }^{\mathrm{t}}, \delta_{1}{ }^{\mathrm{t}}, \delta_{2}{ }^{\mathrm{t}}, \ldots, \delta_{\mathrm{v}-1}{ }^{\mathrm{t}}\right)$, then the period $t$ cross sectional depreciation rate for units of the durable that are $v$ periods old at the beginning of period $\mathrm{t}, \delta_{\mathrm{v}}{ }^{\mathrm{t}}$, can be defined using the following equation:

$$
\left(1-\delta_{\mathrm{v}}{ }^{\mathrm{t}}\right)\left(1-\delta_{\mathrm{v}-1}{ }^{\mathrm{t}}\right) \ldots\left(1-\delta_{1}^{\mathrm{t}}\right)\left(1-\delta_{0}{ }^{\mathrm{t}}\right) \equiv \mathrm{P}_{\mathrm{v}+1}{ }^{\mathrm{t}} / \mathrm{P}_{0}{ }^{\mathrm{t}}
$$

Thus it is clear how the sequence of period 0 vintage asset prices $\mathrm{P}_{\mathrm{v}}{ }^{\mathrm{t}}$ can be converted into a sequence of period $t$ vintage depreciation rates, $\delta_{\mathrm{v}}{ }^{\mathrm{t}}$. In the depreciation literature, it is usually assumed that the sequence of vintage depreciation rates, $\delta_{\mathrm{v}}{ }^{\mathrm{t}}$, is independent of the period t so that:

(13) $\delta_{\mathrm{v}}{ }^{\mathrm{t}}=\delta_{\mathrm{v}} \quad$ for all periods $\mathrm{t}$ and all ages $\mathrm{v}$.

The above material shows how the sequence of vintage or used durable goods prices at a point in time can be used in order to estimate depreciation rates. This method for estimating depreciation rates using data on second hand assets, with a few extra modifications to account for differing ages of retirement, was pioneered by Beidelman (1973) (1976) and Hulten and Wykoff (1981a) (1981b) (1996). ${ }^{43}$

Recall the user cost formula for a new unit of the durable good under consideration which was defined by (1) above. The same approach can be used in order to define a sequence of period 0 user costs for all vintages $\mathrm{V}$ of the durable. Thus suppose that $\mathrm{P}_{\mathrm{v}+1}{ }^{1 \mathrm{a}}$ is the anticipated end of period 0 price of a unit of the durable good that is $\mathrm{v}$ periods old at the

\footnotetext{
${ }^{42}$ If these second hand vintage prices depend on how intensively the durable good has been used in previous periods, then it will be necessary to further classify the durable good not only by its vintage $\mathrm{v}$ but also according to the intensity of its use. In this case, think of the sequence of vintage asset prices $\mathrm{P}_{\mathrm{v}}{ }^{\mathrm{t}}$ as corresponding to the prevailing market prices of the various vintages of the good at the beginning of period $t$ for assets that have been used at "average" intensities.

${ }^{43}$ See also Jorgenson (1996) for a review of the empirical literature on the estimation of depreciation rates.
} 
beginning of period 0 and let $r^{0}$ be the consumer's opportunity cost of capital for period 0 . Then the discounted to the beginning of period 0 user cost of a unit of the durable good that is $\mathrm{v}$ periods old at the beginning of period $0, \mathrm{u}_{\mathrm{v}}{ }^{0}$, is defined as follows:

(14) $\mathrm{u}_{\mathrm{v}}^{0} \equiv \mathrm{P}_{\mathrm{v}}^{0}-\mathrm{P}_{\mathrm{v}+1}{ }^{1 \mathrm{a}} /\left(1+\mathrm{r}^{0}\right)$;

$$
\mathrm{v}=0,1,2, \ldots
$$

It is now necessary to specify how the end of period 0 anticipated vintage asset prices $\mathrm{P}_{\mathrm{v}}{ }^{1 \mathrm{a}}$ are related to their counterpart beginning of period 0 vintage asset prices $\mathrm{P}_{\mathrm{v}}{ }^{0}$. The assumption that is made now is that the entire sequence of vintage asset prices at the end of period 0 is equal to the corresponding sequence of asset prices at the beginning of period 0 times a general anticipated period 0 inflation rate factor, $\left(1+\mathrm{i}^{0}\right)$, where $\mathrm{i}^{0}$ is the anticipated period 0 (general) asset inflation rate. Thus it is assumed that ${ }^{44}$

(15) $\mathrm{P}_{\mathrm{v}}{ }^{1 \mathrm{a}}=\left(1+\mathrm{i}^{0}\right) \mathrm{P}_{\mathrm{v}}^{0}$;

$\mathrm{v}=0,1,2, \ldots$

Substituting (15) and (10)-(13) into (14) leads to the following beginning of period 0 sequence of vintage user costs: ${ }^{45}$

$$
\begin{aligned}
\mathrm{u}_{\mathrm{v}}^{0} & =\left(1-\delta_{\mathrm{v}-1}\right)\left(1-\delta_{\mathrm{v}-2}\right) \ldots\left(1-\delta_{0}\right)\left[\left(1+\mathrm{r}^{0}\right)-\left(1-\delta_{\mathrm{v}}\right)\left(1+\mathrm{i}^{0}\right)\right] \mathrm{P}_{0}^{0} /\left(1+\mathrm{r}^{0}\right) \\
& =\left(1-\delta_{\mathrm{v}-1}\right)\left(1-\delta_{\mathrm{v}-2}\right) \ldots\left(1-\delta_{0}\right)\left[\mathrm{r}^{0}-\mathrm{i}^{0}+\delta_{\mathrm{v}}\left(1+\mathrm{i}^{0}\right)\right] \mathrm{P}_{0}^{0} /\left(1+\mathrm{r}^{0}\right) ; \quad \mathrm{v}=1,2, \ldots
\end{aligned}
$$

If $\mathrm{v}=0$, then $\mathrm{u}_{0}^{0} \equiv\left[\mathrm{r}^{0}-\mathrm{i}^{0}+\delta_{0}\left(1+\mathrm{i}^{0}\right)\right] \mathrm{P}_{0}^{0} /\left(1+\mathrm{r}^{0}\right)$ and this agrees with the user cost formula for a new purchase of the durable $\mathrm{u}^{0}$ that was derived earlier in (7) (with our changes in notation; i.e., $\mathrm{P}^{0}$ is now called $\mathrm{P}_{0}^{0}$ ).

The sequence of vintage user costs $\mathrm{u}_{\mathrm{v}}{ }^{0}$ defined by (16) are expressed in terms of prices that are discounted to the beginning of period 0. However, as was done in section 4 above, it is also possible to express the user costs in terms of prices that are "anti-discounted" to the end of period 0 . Thus define the sequence of vintage end of period 0 user cost $\mathrm{p}_{\mathrm{v}}{ }^{0}$ as follows:

$$
\mathrm{p}_{\mathrm{v}}{ }^{0} \equiv\left(1+\mathrm{r}^{0}\right) \mathrm{u}_{\mathrm{v}}^{0}=\left(1-\delta_{\mathrm{v}-1}\right)\left(1-\delta_{\mathrm{v}-2}\right) \ldots\left(1-\delta_{0}\right)\left[\mathrm{r}^{0}-\mathrm{i}^{0}+\delta_{\mathrm{v}}\left(1+\mathrm{i}^{0}\right)\right] \mathrm{P}_{0}^{0} ; \quad \mathrm{v}=1,2, \ldots
$$

with $\mathrm{p}_{0}{ }^{0}$ defined as follows:

(18) $\mathrm{p}_{0}{ }^{0} \equiv\left(1+\mathrm{r}^{0}\right) \mathrm{u}_{0}{ }^{0}=\left[\mathrm{r}^{0}-\mathrm{i}^{0}+\delta_{\mathrm{v}}\left(1+\mathrm{i}^{0}\right)\right] \mathrm{P}_{0}^{0}$

Thus if the price statistician has estimates for the vintage depreciation rates $\delta_{\mathrm{v}}$ and the real interest rate $\mathrm{r}^{0^{*}}$ and is able to collect a sample of prices for new units of the durable

\footnotetext{
${ }^{44}$ More generally, we assume that assumptions (15) hold for subsequent periods $t$ as well; i.e., it is assumed that $\mathrm{P}_{\mathrm{v}}{ }^{\mathrm{t}+1 \mathrm{a}}=\left(1+\mathrm{i}^{\mathrm{t}}\right) \mathrm{P}_{\mathrm{v}}{ }^{\mathrm{t}}$ for $\mathrm{v}=0,1,2, \ldots$ and $\mathrm{t}=0,1,2, \ldots$ where $\mathrm{P}_{\mathrm{v}}{ }^{\mathrm{t}+\mathrm{a}}$ is the anticipated price of a unit of the durable good that is $\mathrm{v}$ periods old at the end of period $\mathrm{t}, \mathrm{i}^{\mathrm{t}}$ is a period $\mathrm{t}$ expected asset inflation rate for all ages of the durable and $\mathrm{P}_{\mathrm{v}}{ }^{\mathrm{t}}$ is the second hand market price for a unit of the durable good that is v periods old at the beginning of period $t$.

${ }^{45}$ When $\mathrm{v}=0$, define $\delta_{-1} \equiv 1$; i.e., the terms in front of the square brackets on the right hand side of (16) are set equal to 1 .
} 
good $\mathrm{P}_{0}{ }^{0}$, then the sequence of vintage user costs defined by (17) can be calculated. To complete the model, the price statistician should gather information on the stocks held by the household sector of each vintage of the durable good and then normal index number theory can be applied to these p's and q's, with the p's being vintage user costs and the q's being the vintage stocks pertaining to each period. For some worked examples of this methodology under various assumptions about depreciation rates and the calculation of expected asset inflation rates, see Diewert and Lawrence (2000) and Diewert (2005a). ${ }^{46}$

In the following three sections, the general methodology described above is specialized by making additional assumptions about the form of the vintage depreciation rates $\delta_{\mathrm{v}}{ }^{47}$

\section{Geometric or Declining Balance Depreciation}

The declining balance method of depreciation dates back to Matheson $(1910 ; 55)$ at least. ${ }^{48}$ In terms of the algebra presented in the previous section, the method is very simple: all of the cross sectional vintage depreciation rates $\delta_{v}{ }^{t}$ defined by (10)-(12) are assumed to be equal to the same rate $\delta$, where $\delta$ is a positive number less than one; i.e., for all time periods $t$ and all vintages $v$, it is assumed that

(19) $\delta_{\mathrm{v}}{ }^{\mathrm{t}}=\delta$;

$\mathrm{v}=0,1,2, \ldots$

Substitution of (19) into (17) leads to the following formula for the sequence of end of period 0 vintage user costs:

$$
\text { (20) } \begin{aligned}
\mathrm{p}_{\mathrm{v}}{ }^{0} & =(1-\delta)^{\mathrm{v}}\left[\mathrm{r}^{0}-\mathrm{i}^{0}+\delta\left(1+\mathrm{i}^{0}\right)\right] \mathrm{P}^{0} ; \\
& =(1-\delta)^{\mathrm{v}} \mathrm{p}_{0}{ }^{0}
\end{aligned}
$$$$
\mathrm{v}=0,1,2, \ldots
$$

where the second equation follows using definition (18). The second set of equations in (20) says that all of the vintage user costs are proportional to the user cost for a new asset. This proportionality means that it is not necessary to use an index number formula to aggregate over vintages to form a durable services aggregate. To see this, it is useful to calculate the aggregate value of services yielded by all vintages of the consumer durable at the beginning of period 0 . Let $\mathrm{q}^{-\mathrm{v}}$ be the quantity of the new durable purchased by the household sector $\mathrm{v}$ periods ago for $\mathrm{v}=1,2, \ldots$ and let $\mathrm{q}^{0}$ be the new purchases of the durable during period 0 . The beginning of period 0 user cost for the holdings of the durable of age $\mathrm{v}$ will be $\mathrm{p}_{\mathrm{v}}{ }^{0}$ defined by (20) above. Thus the aggregate value of services over all vintages of the good, including those purchased in period 0 , will have the value $\mathrm{v}^{0}$ defined as follows:

\footnotetext{
${ }^{46}$ Additional examples and discussion can be found in two OECD Manuals on productivity measurement and the measurement of capital; see Schreyer (2001) (2009).

${ }^{47}$ In the case of one hoss shay depreciation, assumptions are made about the sequence of user costs, $\mathbf{u}_{\mathrm{v}}{ }_{\mathrm{v}}$, as the age $\mathrm{v}$ varies.

${ }^{48}$ A case for attributing the method to Walras $(1954 ; 268-269)$ could be made but he did not lay out all of the details. Matheson $(1910 ; 91)$ used the term "diminishing value" to describe the method. Hotelling $(1925 ; 350)$ used the term "the reducing balance method" while Canning $(1929 ; 276)$ used the term the "declining balance formula". For a modern exposition of the geometric model of depreciation, see Jorgenson (1989).
} 


$$
\text { (21) } \begin{aligned}
\mathrm{v}^{0} & =\mathrm{p}_{0}{ }^{0} \mathrm{q}^{0}+\mathrm{p}_{1}{ }^{0} \mathrm{q}^{-1}+\mathrm{p}_{2}{ }^{0} \mathrm{q}^{-2}+\ldots \\
& =\mathrm{p}_{0}{ }^{0} \mathrm{q}^{0}+(1-\delta) \mathrm{p}_{0}^{0} \mathrm{q}^{-1}+(1-\delta)^{2} \mathrm{p}_{0}{ }^{0} \mathrm{q}^{-2}+\ldots \\
& =\mathrm{p}_{0}^{0}\left[\mathrm{q}^{0}+(1-\delta) \mathrm{q}^{-1}+(1-\delta)^{2} \mathrm{q}^{-2}+\ldots\right] \\
& =\mathrm{p}_{0}{ }^{0} \mathrm{Q}^{0}
\end{aligned}
$$

using (20)

where the period 0 aggregate (quality adjusted) quantity of durable services consumed in period $0, Q^{0}$, is defined as

$$
\mathrm{Q}^{0} \equiv \mathrm{q}^{0}+(1-\delta) \mathrm{q}^{-1}+(1-\delta)^{2} \mathrm{q}^{-2}+\ldots
$$

Thus the period 0 services quantity aggregate $\mathrm{Q}^{0}$ is equal to new purchases of the durable in period $0, \mathrm{q}^{0}$, plus one minus the depreciation rate $\delta$ times the purchases of the durable in the previous period, $\mathrm{q}^{-1}$, plus the square of one minus the depreciation rate times the purchases of the durable two periods ago, $\mathrm{q}^{-2}$, and so on. The service price that can be applied to this quantity aggregate is $p_{0}^{0}$, the imputed rental price or user cost for a new unit of the durable purchased in period 0 .

The above result greatly simplifies the valuation of consumer durables. Normally, the price statistician would have to keep track of all new purchases of the durable good by the reference population by period, calculate the relevant user costs $\mathrm{p}_{\mathrm{v}}{ }^{0}$ and $\mathrm{p}_{\mathrm{v}}{ }^{\mathrm{t}}$ for periods 0 and $\mathrm{t}$, and apply the relevant index number formula (Laspeyres, Paasche, Fisher or whatever formula is being used in the CPI) to these age specific prices and quantities for periods 0 and t. But because under assumptions (13), (15) and (19), all vintage user costs vary in a proportional manner over time,${ }^{49}$ so any reasonable index number formula will find that the price index going from period 0 to $t$ is equal to $\mathrm{p}_{0}{ }^{\mathrm{t}} / \mathrm{p}_{0}{ }^{0}$, the ratio of user costs for a new unit of the durable good. Moreover the corresponding aggregate quantity index will be equal to $\mathrm{Q}^{\mathrm{t}} / \mathrm{Q}^{0}$, where $\mathrm{Q}^{0}$ is defined by (22) and $\mathrm{Q}^{\mathrm{t}}$ is defined by

$$
\begin{aligned}
Q^{t} & \equiv q^{t}+(1-\delta) q^{t-1}+(1-\delta)^{2} q^{t-2}+\ldots \\
& =q^{t}+(1-\delta) Q^{t-1}
\end{aligned}
$$

Note that the second equation simplifies the calculation of the period $t$ aggregate service flow (in real terms) over all vintages of the consumer durable: the period $t$ aggregate flow, $\mathrm{Q}^{\mathrm{t}}$, is equal to period $\mathrm{t}$ new purchases of the durable, $\mathrm{q}^{\mathrm{t}}$, plus (1- $\left.\delta\right)$ times the aggregate flow of services in the previous period, $\mathrm{Q}^{\mathrm{t}-1}$.

If the depreciation rate $\delta$ and the purchases of the durable in prior periods are known, then the aggregate service quantity $\mathrm{Q}^{0}$ can readily be calculated using (22). Then using

\footnotetext{
${ }^{49}$ Equations (20) for period $\mathrm{t}$ are the following ones: $\mathrm{p}_{\mathrm{v}}{ }^{\mathrm{t}}=(1-\delta)^{\mathrm{v}} \mathrm{p}_{0}{ }^{\mathrm{t}}$ for $\mathrm{v}=1,2, \ldots$ and so the entire sequence of user costs by age of asset vary in a proportional manner over time under our assumptions. Thus an aggregate period $t$ price for the entire group of assets of varying ages is $p_{0}{ }^{t}$ and the corresponding aggregate quantity will be $Q^{t}$ defined by (23). This is an application of Hicks' (1946; 312-313) Aggregation Theorem: "Thus we have demonstrated mathematically the very important principle, used extensively in the text, that if the prices of a group of goods change in the same proportion, that group of goods behaves just as if it were a single commodity."
} 
(21), it can be seen that the period 0 value of the services of the durable (over all vintages), $v^{0}$, decomposes into the price term $\mathrm{p}_{0}{ }^{0}$ times the quantity term $\mathrm{Q}^{0}$. Hence, it is not necessary to use an index number formula to aggregate over vintages using this depreciation model.

The stock of consumer durables held by the household sector of a country should appear in the balance sheets of the country. Using the geometric model of depreciation, it is very easy to calculate the nominal and real value of the stock of consumer durables held by households. At time $t$, the stocks held by the household sector for the particular type of consumer durable under consideration are $\mathrm{q}^{\mathrm{t}}, \mathrm{q}^{\mathrm{t}-1}, \mathrm{q}^{\mathrm{t}-2}, \ldots$ and the corresponding asset prices by age of asset are $\mathrm{P}_{0}{ }^{\mathrm{t}}, \mathrm{P}_{1}{ }^{\mathrm{t}}, \mathrm{P}_{2}{ }^{\mathrm{t}}, \ldots$. Assumptions (12), (13) and (19) imply that these period $t$ asset prices satisfy the following equations:

(24) $\mathrm{P}_{\mathrm{v}}{ }^{\mathrm{t}}=(1-\delta)^{\mathrm{v}} \mathrm{P}_{0}{ }^{\mathrm{t}}$;

$\mathrm{v}=1,2, \ldots$

Equations (24) can be used to define period t aggregate asset value for the stocks held by households for the durable good over all ages of the durable good, $\mathrm{V}^{\mathrm{t}}$ :

$$
\begin{aligned}
\mathrm{V}^{\mathrm{t}} & \equiv \mathrm{P}_{0}{ }_{0} \mathrm{q}^{\mathrm{t}}+\mathrm{P}_{1}{ }^{\mathrm{t}} \mathrm{q}^{\mathrm{t}-1}+\mathrm{P}_{2}{ }^{\mathrm{t}} \mathrm{q}^{\mathrm{t}-2}+\mathrm{P}_{3}{ }^{\mathrm{t}} \mathrm{q}^{\mathrm{t}-3}+\ldots \\
& =\mathrm{P}_{0}{ }^{\mathrm{t}}\left[\mathrm{q}^{\mathrm{t}}+(1-\delta)^{1} \mathrm{q}^{\mathrm{t}-1}+(1-\delta)^{2} \mathrm{q}^{\mathrm{t}-2}+\ldots\right] \quad \mathrm{using}(24) \\
& =\mathrm{P}_{0}{ }^{\mathrm{t}} \mathrm{Q}^{\mathrm{t}}
\end{aligned}
$$

where $\mathrm{Q}^{\mathrm{t}}$ is defined by (23). Thus $\mathrm{Q}^{\mathrm{t}}$ serves as a measure of the real capital stock of the consumer durable at the end of period $\mathrm{t}$ and it also serves as a measure of the real consumption services provided by this capital stock during period $t$.

The above algebra explains why the geometric model of depreciation is used so widely in production function studies and in the measurement of Total Factor Productivity or Multifactor Productivity in the production accounts of countries: it is very simple to work with! ${ }^{50}$

\section{Straight Line Depreciation}

Another very common model of depreciation is the straight line model. ${ }^{51}$ In this model, a most probable length of life for the durable is somehow determined, say L periods, so that after being used for $\mathrm{L}$ periods, the durable is scrapped. In the straight line depreciation model, it is assumed that the period 0 cross sectional vintage asset prices $\mathrm{P}_{\mathrm{v}}{ }^{0}$ decline in a linear fashion relative to the period 0 price of a new asset $\mathrm{P}_{0}{ }_{0}$ :

(26) $\mathrm{P}_{\mathrm{v}}{ }^{0} / \mathrm{P}_{0}{ }^{0}=[\mathrm{L}-\mathrm{v}] / \mathrm{L}$

for $\mathrm{v}=0,1,2, \ldots, \mathrm{L}-1$.

\footnotetext{
${ }^{50}$ See Jorgenson (1989) who popularized the use of the geometric model of depreciation in production function and Total Factor Productivity studies.

${ }^{51}$ This model of depreciation dates back to the late 1800's; see Matheson (1910; 55), Garcke and Fells $(1893 ; 98)$ or Canning $(1929 ; 265-266)$.
} 
For $\mathrm{v}=\mathrm{L}, \mathrm{L}+1, \ldots$, it is assumed that $\mathrm{P}_{\mathrm{v}}{ }^{0}=0$. Now use definitions (14) and (17) along with assumptions (15) in order to obtain the following sequence of end of period 0 vintage user costs for a unit of the durable good of age $\mathrm{v}$ at the beginning of period 0 :

$$
\text { (27) } \begin{aligned}
\mathrm{p}_{\mathrm{v}}{ }^{0} & =\mathrm{P}_{\mathrm{v}}^{0}\left(1+\mathrm{r}^{0}\right)-\left(1+\mathrm{i}^{0}\right) \mathrm{P}_{\mathrm{v}+1}{ }^{0} \\
& =[1 / \mathrm{L}]\left[(\mathrm{L}-\mathrm{v})\left(1+\mathrm{r}^{0}\right)-(\mathrm{L}-\mathrm{v}-1)\left(1+\mathrm{i}^{0}\right)\right] \mathrm{P}_{0}^{0} \\
& =\left[\left(\mathrm{r}^{0}-\mathrm{i}^{0}\right)(\mathrm{L}-\mathrm{v}) \mathrm{L}^{-1}+\left(1+\mathrm{i}^{0}\right) \mathrm{L}^{-1}\right] \mathrm{P}_{0}^{0} .
\end{aligned}
$$

for $\mathrm{v}=0,1,2, \ldots, \mathrm{L}-1$

using assumptions (26)

The user costs for units of the durable good that are older than L periods are zero; i.e., $\mathrm{p}_{\mathrm{v}}{ }^{0}$ $\equiv 0$ for $\mathrm{v} \geq \mathrm{L}$. Looking at the terms in square brackets on the right hand side of (27), it can be seen that the first term $\left(\mathrm{r}^{0}-\mathrm{i}^{0}\right)(\mathrm{L}-\mathrm{v}) \mathrm{P}_{0}{ }^{0} / \mathrm{L}$ is a real interest opportunity cost for holding and using the unit of the durable that is $\mathrm{v}$ periods old (and this imputed real interest cost declines as the durable good ages; i.e., as the age v increases) and the second term $\left(1+\mathrm{i}^{0}\right)(1 / \mathrm{L}) \mathrm{P}_{0}^{0}$ is an inflation adjusted depreciation term that is equal to the constant straight line depreciation rate $1 / \mathrm{L}$ times the adjustment factor for asset inflation over the period, $\left(1+\mathrm{i}^{0}\right)$, times the price of a new unit of the durable good $\mathrm{P}_{0}{ }^{0}$. Note that in period $\mathrm{t}$, the corresponding end of period user cost for a unit of the durable good that is $\mathrm{v}$ periods old is $\mathrm{p}_{\mathrm{v}}{ }^{\mathrm{t}} \equiv\left[\left(\mathrm{r}^{\mathrm{t}}-\mathrm{i}^{\mathrm{t}}\right)(\mathrm{L}-\mathrm{v}) \mathrm{L}^{-1}+\left(1+\mathrm{i}^{\mathrm{t}}\right) \mathrm{L}^{-1}\right] \mathrm{P}_{0}{ }^{\mathrm{t}}$ for $\mathrm{v}=0,1,2, \ldots, \mathrm{L}-1$. Thus in both periods 0 and $t$, the sequences of end of period user costs by age, $\left\{\mathrm{p}_{\mathrm{v}}{ }^{0}\right\}$ and $\left\{\mathrm{p}_{\mathrm{v}}{ }^{\mathrm{t}}\right\}$ for $\mathrm{v}=$ $0,1,2, \ldots, \mathrm{L}-1$, are proportional to the price of a new unit of the durable for periods 0 and $\mathrm{t}$, $\mathrm{P}_{0}{ }^{0}$ and $\mathrm{P}_{0}{ }^{\mathrm{t}}$ respectively ${ }^{52}$ but if $\mathrm{r}^{0}$ and/or $\mathrm{i}^{0}$ change to a different $\mathrm{r}^{\mathrm{t}}$ or $\mathrm{i}^{\mathrm{t}}$, then the factors of proportionality will change as we go from period 0 to $t$ and so we cannot apply Hicks' Aggregation Theorem in this case. Thus in the case of changing nominal interest rates $r$ and/or changing expected or actual asset price inflation rates, $\mathrm{i}^{\mathrm{t}}$, we cannot assume that the overall inflation rate between periods 0 and $t$ for all ages of the durable good is equal to $\mathrm{P}_{0}{ }^{\mathrm{t}} / \mathrm{P}_{0}{ }^{0}$ as was the case with the geometric model of depreciation. Thus for the straight line model of depreciation, it is necessary to keep track of household purchases of the durable for $\mathrm{L}$ periods and weight up each vintage quantity $\mathrm{q}^{-\mathrm{v}}$ of these purchases by the corresponding end of period user costs vintage user cost $\mathrm{p}_{\mathrm{v}}{ }^{0}$ defined by (27) for period 0 and a similar calculation of household holdings of the durable good by age for period $t$ along with the period $t$ counterparts to the period 0 user costs defined by (27) will be necessary. Once these vectors of prices and quantities have been calculated for both periods, then normal index number theory can be applied to get the overall price index for the household holdings of the durable good and this index can be used to deflate the user cost aggregate values to get an appropriate volume index. ${ }^{53}$ Thus the straight line model of depreciation is considerably more complicated to implement than the geometric model of depreciation explained in the previous section. ${ }^{54}$

\footnotetext{
${ }^{52}$ Thus as the price of a new unit of the durable good changes over time, the value of depreciation will also change in line with the change in the price of the new unit. Thus economic depreciation as we have defined it is different from historical cost accounting depreciation which does not adjust depreciation allowances for changes in the levels of asset prices over time.

${ }^{53}$ Diewert and Lawrence (2000) noted this problem with the straight line model of depreciation; i.e., that in general, an index number formula should be used to aggregate over the different ages of the asset in order to obtain an aggregate of the capital services of the different vintages of the asset.

${ }^{54}$ However, if one is willing to assume that the reference interest rate for period $\mathrm{t}, \mathrm{r}^{\mathrm{t}}$, and the expected asset inflation rate over all ages of the asset, $\mathrm{i}^{\mathrm{t}}$, both remain constant, then all reasonable index number formula will estimate the overall rate of user cost inflation between periods 0 and $t$ as the new good price ratio,
} 


\section{One Hoss Shay or Light Bulb Depreciation}

The final model of depreciation that is in common use is the "light bulb" or one hoss shay model of depreciation ${ }^{55}$ In this model, the durable delivers the same services for each vintage: a chair is a chair, no matter what its age is (until it falls to pieces and is scrapped). Thus this model also requires an estimate of the most probable life $L$ of the consumer durable. ${ }^{56}$ In this model, it is assumed that the sequence of vintage beginning of the period user costs $\mathrm{u}_{\mathrm{v}}{ }^{0}$ defined by (14) and (15) is constant for all vintages younger than the asset lifetime L; i.e., it is assumed that

(28) $\mathrm{u}_{\mathrm{v}}^{0} \equiv \mathrm{P}_{\mathrm{v}}^{0}-\left(1+\mathrm{i}^{0}\right) \mathrm{P}_{\mathrm{v}+1}{ }^{0} /\left(1+\mathrm{r}^{0}\right)=\mathrm{u}^{0}$;

$$
\mathrm{v}=0,1,2, \ldots, \mathrm{L}-1
$$

where $\mathrm{u}^{0}>0$ is a constant. Equations (28) can be rewritten in the following form:

(29) $\mathrm{u}^{0}=\mathrm{P}_{\mathrm{v}}{ }^{0}-\gamma \mathrm{P}_{\mathrm{v}+1}{ }^{0}$;

$$
\mathrm{v}=0,1,2, \ldots, \mathrm{L}-1
$$

where the discount factor $\gamma$ is defined as

(30) $\gamma \equiv\left(1+i^{0}\right) /\left(1+r^{0}\right)=1 /\left(1+r^{0^{*}}\right)$.

The interest rate $\mathrm{r}^{0^{*}}$ can be regarded as an asset specific real interest rate; i.e., $1+\mathrm{r}^{0^{*}} \equiv$ $\left(1+r^{0}\right) /\left(1+i^{0}\right)$ so that one plus the nominal interest rate $r^{0}$ is deflated by one plus the expected asset price inflation rate, $\mathrm{i}^{0}$. Note that equations (29) can be rewritten as follows:

(31) $\mathrm{P}_{\mathrm{v}}^{0}=\mathrm{u}^{0}+\gamma \mathrm{P}_{\mathrm{v}+1}^{0}$;

$$
\mathrm{v}=0,1,2, \ldots, \mathrm{L}-1 .
$$

$\mathrm{P}_{0}{ }^{\mathrm{t}} / \mathrm{P}_{0}{ }^{0}$. However, the assumption that $\mathrm{r}^{\mathrm{t}}$ and $\mathrm{i}^{\mathrm{t}}$ remain constant over time is only a rough approximation to reality. Note that in order to calculate real and nominal consumption of the durable (over all ages of the durable), it will be necessary to use the vintage user costs defined by (27) for a constant $r$ and $i$ to weight up past purchases of the durable good. Thus define the constants $\alpha_{\mathrm{v}} \equiv\left[(\mathrm{r}-\mathrm{i})(\mathrm{L}-\mathrm{v}) \mathrm{L}^{-1}+(1+\mathrm{i}) \mathrm{L}^{-1}\right]$ for $\mathrm{v}=$ $0,1,2, \ldots, \mathrm{L}-1$ and $\alpha_{\mathrm{v}} \equiv 0$ for $\mathrm{v} \geq \mathrm{L}$. Then the period $\mathrm{t}$ nominal value of durable services is defined as $\mathrm{v}^{\mathrm{t}} \equiv$ $p_{0}{ }^{t} q^{t}+p_{1}{ }^{t} q^{t-1}+p_{2}{ }^{t} q^{t-2}+\ldots+p_{L-1}{ }^{t} q^{t-L+1}=\alpha_{0} P_{0}{ }^{t} q^{t}+\alpha_{1} P_{0}{ }^{t} q^{t-1}+\alpha_{2} P_{0}{ }^{t} q^{t-2}+\ldots+\alpha_{L-1} P_{0}{ }^{t} q^{t-L+1}=P_{0}{ }^{t} Q^{t}$ where $Q^{t}$ is the real value or volume of durable services defined as $\mathrm{Q}^{\mathrm{t}} \equiv \alpha_{0} \mathrm{q}^{\mathrm{t}}+\alpha_{1} \mathrm{q}^{\mathrm{t}-1}+\alpha_{2} \mathrm{q}^{\mathrm{t}-2}+\ldots+\alpha_{\mathrm{L}-1} \mathrm{q}^{\mathrm{t}-\mathrm{L}+1}$. Define $\beta_{\mathrm{v}} \equiv(\mathrm{L}-\mathrm{v}) / \mathrm{L}$ for $\mathrm{v}=0,1,2, \ldots, \mathrm{L}-1$. The period $\mathrm{t}$ asset value of consumer holdings of the durable good is defined as $\mathrm{V}^{\mathrm{t}} \equiv \mathrm{P}_{0}{ }^{\mathrm{t}} \mathrm{q}^{\mathrm{t}}+\mathrm{P}_{1}{ }^{\mathrm{t}} \mathrm{q}^{\mathrm{t}-1}+\mathrm{P}_{2}{ }^{\mathrm{t}} \mathrm{q}^{\mathrm{t}-2}+\ldots+\mathrm{P}_{\mathrm{L}-1}{ }^{\mathrm{t}} \mathrm{q}^{\mathrm{t}-\mathrm{L}+1}=\mathrm{P}_{0}{ }^{\mathrm{t}}\left[\beta_{0} \mathrm{q}^{\mathrm{t}}+\beta_{1} \mathrm{q}^{\mathrm{t}-1}+\beta_{2} \mathrm{q}^{\mathrm{t}-2}+\ldots+\beta_{\mathrm{L}-1} \mathrm{q}^{\mathrm{t}-\mathrm{L}+1}\right]$ $=\mathrm{P}_{0}{ }^{\mathrm{t}} \mathrm{Q}^{\mathrm{t}^{*}}$ where we have used assumptions (26) applied to period $\mathrm{t}$ and the real value of durable stocks held by households at the end of period $t$ is defined as $Q^{t^{*}} \equiv \beta_{0} q^{t}+\beta_{1} q^{t-1}+\beta_{2} q^{t-2}+\ldots+\beta_{L-1} q^{t-L+1}$. The decomposition of $\mathrm{V}^{\mathrm{t}}$ into $\mathrm{P}_{0}{ }^{\mathrm{t}} \mathrm{Q}^{\mathrm{t}^{*}}$ does not require the assumption of constant $\mathrm{r}^{\mathrm{t}}$ and $\mathrm{i}^{\mathrm{t}}$.

${ }^{55}$ This model can be traced back to Böhm-Bawerk $(1891 ; 342)$. For a more comprehensive exposition, see Hulten $(1990 ; 124)$ or Diewert (2005a).

${ }^{56}$ The assumption of a single life L for a durable can be relaxed using a methodology due to Hulten: "We have thus far taken the date of retirement $\mathrm{T}$ to be the same for all assets in a given cohort (all assets put in place in a given year). However, there is no reason for this to be true, and the theory is readily extended to allow for different retirement dates. A given cohort can be broken into components, or subcohorts, according to date of retirement and a separate $\mathrm{T}$ assigned to each. Each subcohort can then be characterized by its own efficiency sequence, which depends among other things on the subcohort's useful life $T_{\mathrm{i}}$." Charles R. Hulten (1990; 125). 
Use equation (31) with $\mathrm{v}=0$ to express $\mathrm{P}_{0}{ }^{0}$ in terms of $\mathrm{u}^{0}$ and $\mathrm{P}_{1}{ }^{0}$. Now use (31) with $\mathrm{v}=$ 1 to express $\mathrm{P}_{2}{ }^{0}$ in terms of $\mathrm{u}^{0}$ and $\mathrm{P}_{1}{ }^{0}$ and then substitute out $\mathrm{P}_{1}{ }^{0}$ using the previous expression that expressed $\mathrm{P}_{1}^{0}$ in terms of $\mathrm{P}_{0}{ }^{0}$ and $\mathrm{u}^{0}$. Continue this substitution process until finally it ends after $\mathrm{L}$ such substitutions when $\mathrm{P}_{\mathrm{L}}{ }^{0}$ is reached and of course, $\mathrm{P}_{\mathrm{L}}{ }^{0}$ equals zero. The following equation is obtained:

$$
\begin{aligned}
P_{0}^{0} & =u^{0}+\gamma u^{0}+\gamma^{2} u^{0}+\ldots+\gamma^{L-1} u^{0} \\
& =u^{0}\left[1+\gamma+\gamma^{2}+\ldots+\gamma^{L-1}\right] \\
& =\left\{u^{0} /(1-\gamma)\right\}-\left\{u^{0} \gamma^{L} /(1-\gamma)\right\} \\
& =u^{0}\left(1-\gamma^{L}\right) /(1-\gamma)
\end{aligned}
$$

provided that $\gamma<1^{57}$

Now use the last equation in (32) in order to solve for the constant over vintages (beginning of the period) user cost for this model, $\mathrm{u}^{0}$, in terms of the period 0 price for a new unit of the durable, $\mathrm{P}_{0}{ }^{0}$, and the discount factor $\gamma$ defined by (31):

(33) $\mathrm{u}^{0}=(1-\gamma) \mathrm{P}_{0}{ }^{0} /\left(1-\gamma^{\mathrm{L}}\right)=\mathrm{u}_{\mathrm{v}}{ }^{0}$;

$$
\mathrm{v}=0,1,2, \ldots, \mathrm{L}-1 \text {. }
$$

The sequence of end of period 0 user cost, $\mathrm{p}_{\mathrm{v}}{ }_{\mathrm{v}}$, is as usual, equal to the corresponding beginning of the period 0 user cost, $\mathrm{u}_{\mathrm{v}}{ }^{0}$, times the period 0 nominal interest rate factor, $1+r^{0}$ :

$$
\mathrm{p}_{\mathrm{v}}{ }^{0} \equiv\left(1+\mathrm{r}^{0}\right) \mathrm{u}_{\mathrm{v}}{ }^{0}=\left[1+\mathrm{r}^{0}\right]\left[1-\gamma^{0}\right]\left[1-\left(\gamma^{0}\right)^{\mathrm{L}}\right]^{-1} \mathrm{P}_{0}{ }^{0}=\mathrm{p}_{0}{ }^{0} ; \quad \mathrm{v}=0,1,2, \ldots, \mathrm{L}-1
$$

and $\mathrm{p}_{\mathrm{v}}{ }^{0}=0$ for $\mathrm{v}=\mathrm{L}, \mathrm{L}+1, \ldots$ and $\gamma^{0} \equiv\left(1+\mathrm{i}^{0}\right) /\left(1+\mathrm{r}^{0}\right)$.

The aggregate services of all vintages of the good for period 0 , including those purchased in period 0 , will have the following value, $v^{0}$ :

$$
\text { (35) } \begin{aligned}
\mathrm{v}^{0} & \left.=\mathrm{p}_{0}{ }^{0} \mathrm{q}^{0}+\mathrm{p}_{1}{ }^{0} \mathrm{q}^{-1}+\mathrm{p}_{2}{ }^{0} \mathrm{q}^{-2}+\ldots+\mathrm{p}_{\mathrm{L}-1}{ }^{0} \mathrm{q}^{-(\mathrm{L}-1)}\right] \\
& =\mathrm{p}_{0}^{0}\left[\mathrm{q}^{0}+\mathrm{q}^{-1}+\mathrm{q}^{-2}+\ldots+\mathrm{q}^{-(\mathrm{L}-1)}\right] \\
& =\mathrm{p}_{0}{ }^{0} \mathrm{Q}^{0}
\end{aligned}
$$

where the period 0 aggregate (quality adjusted) quantity of durable services consumed in period $0, \mathrm{Q}^{0}$, is defined as follows for this depreciation model:

(36) $\mathrm{Q}^{0} \equiv \mathrm{q}^{0}+\mathrm{q}^{-1}+\mathrm{q}^{-2}+\ldots+\mathrm{q}^{-(\mathrm{L}-1)}$.

Thus in this model of depreciation, the service quantity aggregate is the simple sum of household purchases over the last L periods. ${ }^{58}$ As was the case with the geometric depreciation model, the one hoss shay model does not require index number aggregation over vintages when calculating aggregate services from all vintages of the durable: there is a constant service price $\mathrm{p}_{0}{ }^{0}$ for all assets that are less than $\mathrm{L}$ periods old and the

\footnotetext{
${ }^{57}$ If $\gamma \geq 1$, then use the second equation in (32) to express $\mathrm{u}^{0}$ in terms of $\mathrm{P}_{0}{ }^{0}$ and the various powers of $\gamma$.

${ }^{58}$ In the national income accounting literature, this measure is sometimes called the gross capital stock.
} 
associated period 0 quantity $\mathrm{Q}^{0}$ is the simple sum defined by (36) over the purchases of the last $\mathrm{L}$ periods for the one hoss shay model. ${ }^{59}$

The first two models of depreciation considered in sections 6 and 7 made assumptions about the pattern of depreciation rates for durables of different ages. The model in this section made assumptions about the pattern of user costs for durable goods of different ages. For a more general model of depreciation that allows for an arbitrary pattern of user costs by age of asset, see Diewert and Wei (2017).

How can the different models of depreciation be distinguished empirically? For durable goods that do not change in quality over time, there are three possible methods for determining the sequence of vintage depreciation rates: ${ }^{60}$

- By making a rough estimate of the average length of life L for the durable good and then by assuming a depreciation model that seems most appropriate. ${ }^{61}$

- By using cross sectional information on the sales of used durable prices at a single point in time and then using equations (10)-(12) above to determine the corresponding sequence of vintage depreciation rates. ${ }^{62}$

- By using cross sectional information on the rental or leasing prices of the durable as a function of the age of the durable and then equations (17) and (18), along with information on the appropriate nominal interest rate $\mathrm{r}^{0}$ and expected durables inflation rate $i^{0}$ along with information on the price of a new unit of the durable good $\mathrm{P}^{0}$, can be used to determine the corresponding sequence of vintage depreciation rates.

Which one of the three models of depreciation presented in sections 7-9 should be used in empirical applications? It is not possible to give a universally valid answer to this question but it is worth mentioning that the geometric model of depreciation is probably the most useful at the macro level. A problem with the models of depreciation considered in sections 8 and 9 is that they assume that all assets in the asset class under consideration are retired at the same age. In real life, this is not the case. Thus Hulten and Wykoff (1981a) and Schreyer (2009) generalized these models to allow for the assets to be retired at different ages and they showed under these conditions, aggregate depreciation followed the geometric model to a reasonably high degree of approximation. The resulting geometric depreciation rates reflect the sum of wear and tear depreciation of

\footnotetext{
${ }^{59}$ Using equations (31), it can be shown that $\mathrm{P}_{\mathrm{v}}{ }^{0}=\mathrm{u}^{0}\left[1+\left(\gamma^{0}\right)+\left(\gamma^{0}\right)^{2}+\ldots+\left(\gamma^{0}\right)^{\mathrm{L}-1-\mathrm{v}}\right]$ for $\mathrm{v}=0,1,2, \ldots, \mathrm{L}-1$ where $\gamma^{0} \equiv\left(1+i^{0}\right) /\left(1+r^{0}\right)$ and $P_{v}{ }^{0}=0$ for $v \geq L$. Thus the period 0 value of the stock of consumer durables is $\Sigma_{v=0}{ }^{\mathrm{L}-1} \mathrm{P}_{\mathrm{v}}{ }^{0} \mathrm{q}^{-\mathrm{v}}$. The corresponding asset prices for period $\mathrm{t}$ are equal to $\mathrm{P}_{\mathrm{v}}{ }^{\mathrm{t}}=\mathrm{u}^{\mathrm{t}}\left[1+\left(\gamma^{\mathrm{t}}\right)+\left(\gamma^{\mathrm{t}}\right)^{2}+\ldots+\left(\gamma^{\mathrm{t}}\right)^{\mathrm{L}-1-\mathrm{v}}\right]$ for $\mathrm{v}=0,1,2, \ldots, \mathrm{L}-1$ where $\mathrm{u}^{\mathrm{t}} \equiv\left[1-\left(\gamma^{\mathrm{t}}\right)\right] \mathrm{P}_{0}{ }^{\mathrm{t}} /\left[1-\left(\gamma^{t}\right)^{\mathrm{L}}\right], \gamma^{\mathrm{t}} \equiv\left(1+\mathrm{i}^{\mathrm{t}}\right) /\left(1+\mathrm{r}^{\mathrm{t}}\right)$ and $\mathrm{P}_{\mathrm{v}}{ }^{\mathrm{t}}=0$ for $\mathrm{v} \geq \mathrm{L}$. The period $\mathrm{t}$ value of the stock of consumer durables is $\Sigma_{v=0}{ }^{\mathrm{L}-1} \mathrm{P}_{\mathrm{v}} \mathrm{q}^{\mathrm{t}-\mathrm{v}}$. An index number formula will have to be used to form aggregate price and quantity indexes for the stocks of consumer durables using the one hoss shay model of depreciation.

${ }^{60}$ These three classes of methods were noted in Malpezzi, Ozanne and Thibodeau (1987; 373-375) in the housing context.

${ }^{61} \mathrm{~A}$ length of life $\mathrm{L}$ is can be converted into an equivalent geometric depreciation rate $\delta$ by setting $\delta$ equal to a number between $1 / \mathrm{L}$ and $2 / \mathrm{L}$.

${ }^{62}$ This method will be pursued in sections 12 and 13 for housing depreciation rates.
} 
unretired assets plus the average amount of additional depreciation that is due to premature retirement of the assets.

\section{The Relationship Between User Costs and Acquisition Costs}

In this section, the user cost approach to the treatment of consumer durables will be compared to the acquisitions approach. Obviously, in the short run, the value flows associated with each approach could be very different. For example, if real interest rates, $\mathrm{r}^{0}-\mathrm{i}^{0}$, are very high and the economy is in a severe recession or depression, then purchases of new consumer durables, $\mathrm{q}^{0}$ say, could be very low and even approach 0 for very long lived assets, like houses. On the other hand, using the user cost approach, existing stocks of consumer durables would be carried over from previous periods and priced out at the appropriate user costs and the resulting consumption value flow could be quite large. Thus in the short run, the monetary values of consumption under the two approaches could be vastly different. Hence, in what follows, a (hypothetical) longer run comparison is considered where real interest rates are held constant. ${ }^{63}$

Suppose that in period 0 , the reference population of households purchased $\mathrm{q}^{0}$ units of a consumer durable at the purchase price $\mathrm{P}^{0}$. Then the period 0 value of consumption from the viewpoint of the acquisitions approach is:

(37) $\mathrm{V}_{\mathrm{A}}^{0} \equiv \mathrm{P}^{0} \mathrm{q}^{0}$.

Recall that the end of period user cost for one new unit of the asset purchased at the beginning of period 0 was $\mathrm{p}^{0}$ defined by ( 8 ) above. In order to simplify the analysis, the geometric model of depreciation is assumed; i.e., at the beginning of period 0 , a one period old asset is worth $(1-\delta) \mathrm{P}^{0}$, a two period old asset is worth $(1-\delta)^{2} \mathrm{P}^{0}, \ldots$, a t period old asset is worth $(1-\delta)^{t} \mathrm{P}^{0}$, etc. Under these hypotheses, the corresponding end of period 0 user cost for a new asset purchased at the beginning of period 0 is $\mathrm{p}^{0}$; the end of period 0 user cost for a one period old asset at the beginning of period 0 is $(1-\delta) \mathrm{p}^{0}$; the corresponding user cost for a two period old asset at the beginning of period 0 is $(1-\delta)^{2} \mathrm{p}^{0} ; \ldots$; the corresponding user cost for a $\mathrm{t}$ period old asset at the beginning of period 0 is $(1-\delta)^{\mathrm{t}} \mathrm{p}^{0}$; etc. The final simplifying assumption is that household purchases of the consumer durable have been growing at the geometric rate $\mathrm{g}$ into the indefinite past. This means that if household purchases of the durable were $\mathrm{q}^{0}$ in period 0 , then in the previous period they purchased $\mathrm{q}^{0} /(1+\mathrm{g})$ new units, two periods ago, they purchased $\mathrm{q}^{0} /(1+\mathrm{g})^{2}$ new units, ..., t periods ago, they purchased $\mathrm{q}^{0} /(1+\mathrm{g})^{\mathrm{t}}$ new units, etc. Putting all of these assumptions together, it can be seen that the period 0 value of consumption services from the viewpoint of the user cost approach is:

$$
\begin{array}{rlrl}
\mathrm{V}_{\mathrm{U}}^{0} & \equiv \mathrm{p}^{0} \mathrm{q}^{0}+\left[(1-\delta) \mathrm{p}^{0} \mathrm{q}^{0} /(1+\mathrm{g})\right]+\left[(1-\delta)^{2} \mathrm{p}^{0} \mathrm{q}^{0} /(1+\mathrm{g})^{2}\right]+\ldots \\
& =(1+\mathrm{g}) \mathrm{p}^{0} \mathrm{q}^{0} /(\mathrm{g}+\delta) & \text { summing the infinite series } \\
& =(1+\mathrm{g})\left[\left(1+\mathrm{r}^{0}\right)-(1-\delta)\left(1+\mathrm{i}^{0}\right)\right] \mathrm{P}^{0} \mathrm{q}^{0} /(\mathrm{g}+\delta) & & \text { using }(8) .
\end{array}
$$

\footnotetext{
${ }^{63}$ The following material is based on Diewert (2002).
} 
Equation (38) can be simplified by letting the asset inflation rate $i^{0}$ be 0 ( or by replacing $\mathrm{r}^{0}-\mathrm{i}^{0}$ by the real interest rate $\mathrm{r}^{0^{*}}$ and by ignoring the small term $\delta \mathrm{i}^{0}$ ) and under these conditions, the ratio of the user cost flow of consumption (38) to the acquisitions measure of consumption in period $0,(37)$ is:

$$
\mathrm{V}_{\mathrm{U}}^{0} / \mathrm{V}_{\mathrm{A}}^{0}=(1+\mathrm{g})\left(\mathrm{r}^{0^{*}}+\delta\right) /(\mathrm{g}+\delta)
$$

Using formula (39), it can be seen that if $1+\mathrm{g}>0$ and $\delta+\mathrm{g}>0$, then $\mathrm{V}_{\mathrm{U}}{ }^{0} / \mathrm{V}_{\mathrm{A}}{ }^{0}$ will be greater than unity if $\mathrm{r}^{0^{*}}>\mathrm{g}(1-\delta) /(1+\mathrm{g})$, a condition that will usually be satisfied. Thus under normal conditions and over a longer time horizon, household expenditures on consumer durables using the user cost approach will tend to exceed the corresponding expenditures on new purchases of the consumer durable. Since the value of consumption services using the rental equivalence approach will tend to approximate the value of consumption services using the user cost approach, it can be seen that the acquisitions approach to household expenditures will tend to understate the value of consumption services estimated by the user cost and rental equivalence approaches. The difference between the user cost and acquisitions approach will tend to grow as the depreciation rate $\delta$ decreases.

To get a rough idea of the possible magnitude of the value ratio for the two approaches, $\mathrm{V}_{\mathrm{U}}^{0} / \mathrm{V}_{\mathrm{A}}{ }^{0}$, equation (39) is evaluated for a "housing" example using annual data where the depreciation rate is $2 \%$ (i.e., $\delta=.02$ ), the real interest rate is $3 \%$ (i.e., $\mathrm{r}^{0^{*}}=.03$ ) and the growth rate for the production of new houses is $1 \%$ (i.e., $\mathrm{g}=.01$ ). In this base case, the ratio of user cost expenditures on housing to the purchases of new housing in the same period, $\mathrm{V}_{\mathrm{U}}^{0} / \mathrm{V}_{\mathrm{A}}^{0}$, is 1.68. If the depreciation rate is decreased to $1 \%$, then $\mathrm{V}_{\mathrm{U}}^{0} / \mathrm{V}_{\mathrm{A}}{ }^{0}$ increases to 2.02. If the real interest rate is decreased to $2 \%$ (with $\delta=.02$ and $\mathrm{g}=.01$ ) then $\mathrm{V}_{\mathrm{U}}^{0} / \mathrm{V}_{\mathrm{A}}^{0}$ decreases to 1.35 while if the real interest rate is increased to $4 \%$, then $\mathrm{V}_{\mathrm{U}}{ }^{0} / \mathrm{V}_{\mathrm{A}}{ }^{0}$ increases to 2.02 . Thus an acquisitions approach to housing in the CPI is likely to give a substantially smaller weight to housing services than a user cost approach would give.

However, or shorter lived consumer durables like clothing, the difference between the acquisitions approach and the user cost approach will not be so large and hence, the acquisitions approach can be justified as being an approximately "correct" as a measure of consumption services for these high depreciation rate durable goods. ${ }^{64}$

For longer lived durables such as houses, automobiles and household furnishings, it would be useful for a national statistical agency to produce user costs for these goods and for the national accounts division to produce the corresponding consumption flows as "analytic series". This would extend the present national accounts treatment of housing to other long lived consumer durables. Note also that this revised treatment of consumption

\footnotetext{
${ }^{64}$ Let $\mathrm{r}^{0^{*}}=.03, \mathrm{~g}=.01$ and $\delta=.2$. Under these assumptions, using (39), we find that $\mathrm{V}_{\mathrm{U}}^{0} / \mathrm{V}_{\mathrm{A}}{ }^{0}=1.11$; i.e., using a geometric depreciation rate of $20 \%$, the user cost approach leads to an estimated value of consumption that is $11 \%$ higher than the acquisitions approach under the conditions specified. Thus the acquisitions approach for consumer durables with high depreciation rates is probably satisfactory.
} 
in the national accounts would tend to make rich countries richer, since poorer countries hold fewer long lived consumer durables on a per capita basis.

\section{Calculating User Costs for Unique Durable Goods}

Calculating rental prices or user costs for durable goods that are unique so that second hand markets for this type of good are either very thin or nonexistent will in general be impossible. Examples of such goods are paintings and unique jewels. ${ }^{65}$ It should be noted that dwelling units are also examples of unique goods in that the location of each dwelling unit is unique and a house at a certain location does not remain the same over time due to renovations and depreciation of the structure. However, as we shall see in subsequent sections, the measurement situation is not so dire with respect to measuring housing service as it is for measuring valuable services.

As was mentioned above, it is impossible to measure the services of a unique good that never trades. If the good trades sporadically, it is possible to make estimates of the service flows generated by the good between sales of the good in an ex post fashion. We will indicate how this can be done below. The resulting estimates will not be very accurate but some kind of estimate is probably better than no estimate at all.

Suppose that a valuable is purchased at the beginning of period 0 at the price $\mathrm{P}^{0}$ and it is sold at the beginning of period $\mathrm{T}$ at the price $\mathrm{P}^{\mathrm{T}}$. It is assumed that both asset prices are observed and there is an average one period nominal interest rate $\mathrm{r}$ that provides an opportunity cost of borrowing or lending for the owner of the asset over the $\mathrm{T}$ periods. An average geometric asset inflation rate $\mathrm{i}$ for the asset over the $\mathrm{T}$ periods is defined as follows:

(40) $1+\mathrm{i} \equiv\left[\mathrm{P}^{\mathrm{T}} / \mathrm{P}^{0}\right]^{1 / \mathrm{T}}$.

We assume that the purchase price of the asset, $\mathrm{P}^{0}$, is set equal to the discounted imputed flow of services that the asset generates for its owner plus the discounted selling price of the asset at the beginning of period T; i.e., we assume that the following equation holds:

(41) $\mathrm{P}^{0}=\mathrm{u}^{0}+\gamma \mathrm{u}^{1}+\gamma^{2} \mathrm{u}^{2}+\ldots+\gamma^{\mathrm{T}-1} \mathrm{u}^{\mathrm{T}-1}+(1+\mathrm{r})^{-\mathrm{T}} \mathrm{P}^{\mathrm{T}}$

where $\mathrm{u}^{\mathrm{t}}$ is the constant quality consumption value for the durable's services in period $\mathrm{t}^{66}$ for $\mathrm{t}=0,1, \ldots, \mathrm{T}-1$ and the discount factor $\gamma$ is defined as follows:

(42) $\gamma \equiv(1+\mathrm{i}) /(1+\mathrm{r})$.

Make the further assumption that the quality of the service rendered by the unique durable good is constant over the $\mathrm{T}$ periods so that:

\footnotetext{
${ }^{65}$ In the international System of National Accounts, these unique goods are listed as valuables.

${ }^{66}$ The nominal imputed user cost for period $t$ is $(1+i)^{t} u^{t}$.
} 

(43) $\mathrm{u}^{\mathrm{t}}=\mathrm{u}^{0}$;
$\mathrm{t}=1,2, \ldots, \mathrm{T}-1$.

Substitution of assumptions (43) into (41) enables one to solve for $\mathrm{u}^{0}$ :

(44) $\mathrm{u}^{0}=\left[\mathrm{P}^{0}-\mathrm{P}^{\mathrm{T}}(1+\mathrm{r})^{-\mathrm{T}}\right] /\left[1+\gamma+\gamma^{2}+\ldots+\gamma^{\mathrm{T}-1}\right]$.

Once $\mathrm{u}^{0}$ has been calculated, the sequence of imputed rental prices for the unique asset for periods $0,1, \ldots, T-1$ is $u^{0},(1+i) u^{0},(1+i)^{2} u^{0}, \ldots,(1+i)^{T-1} u^{0}$. The corresponding quantities are all equal to 1 . Note that these computations can only be done once $\mathrm{P}^{\mathrm{T}}$ is known; i.e., these user cost valuations cannot be made until period T occurs.

The above analysis assumes that $\mathrm{P}^{0}>\mathrm{P}^{\mathrm{T}} /(1+\mathrm{r})^{\mathrm{T}}$ which ensures that $\mathrm{u}^{0}>0$. If $\mathrm{P}^{0}=$ $\mathrm{P}^{\mathrm{T}} /(1+\mathrm{r})^{\mathrm{T}}$, then $\mathrm{u}^{0}=0$ and the services of the valuable for the $\mathrm{T}$ periods are provided to the owner at no (imputed) charge! If $\mathrm{P}^{0}<\mathrm{P}^{\mathrm{T}} /(1+\mathrm{r})^{\mathrm{T}}$, then $\mathrm{u}^{0}<0$ and the services of the valuable for the $\mathrm{T}$ periods are provided to the owner for no charge and in addition, the valuable provides a source of income to the owner. The total benefit to the owner in terms of dollars at the beginning of period 0 is $\mathrm{P}^{\mathrm{T}} /(1+\mathrm{r})^{\mathrm{T}}-\mathrm{P}^{0}$. The income benefit to the owner in terms of dollars at the end of period $\mathrm{T}-1$ is $\mathrm{P}^{\mathrm{T}}-(1+\mathrm{r})^{\mathrm{T}} \mathrm{P}^{0}$.

For some unique assets, the quality of the service flow from using the services of the durable may decline over time. For example, the service flow from a custom built automobile or custom built horse trailer may decline over time due to the aging of the asset. The above model can be modified to take into account this complication but it is necessary to assume an exogenous service flow quality diminution rate $\delta$ where $0<\delta<1$. Thus in place of the constant relative quality assumption (43), the following assumption is made:

$(45) \mathrm{u}^{\mathrm{t}}=(1-\delta)^{\mathrm{t}} \mathrm{u}^{0} ; \quad \mathrm{t}=1,2, \ldots, \mathrm{T}-1$.

Assumptions (41) and (42) still hold. Now substitute assumptions (45) into (41) in order to obtain the following equation:

(46) $\mathrm{P}^{0}=\mathrm{u}^{0}+\gamma(1-\delta) \mathrm{u}^{0}+\gamma^{2}(1-\delta)^{2} \mathrm{u}^{0}+\ldots+\gamma^{\mathrm{T}-1}(1-\delta)^{\mathrm{T}-1} \mathrm{u}^{0}+(1+r)^{-\mathrm{T}} \mathrm{P}^{\mathrm{T}}$.

Define the constant $\phi$ as follows:

(47) $\phi \equiv \gamma(1-\delta)=(1+\mathrm{i})(1-\delta) /(1+\mathrm{r})$.

There is a new definition for $\mathrm{i}$ as a constant quality asset inflation rate over the $\mathrm{T}$ periods between period 0 and period $\mathrm{T}$ :

(48) $1+\mathrm{i}=\left[\mathrm{P}^{\mathrm{T}} / \mathrm{P}^{0}\right]^{1 / \mathrm{T}} /(1-\delta)$.

Thus the quality adjusted asset inflation rate is now adjusted upwards by dividing the old asset inflation rate by $1-\delta$. Using definition (47), equation (46) can be rewritten as follows: 
(49) $\mathrm{P}^{0}=u^{0}\left[1+\phi+\phi^{2}+\ldots+\phi^{\mathrm{T}-1}\right]+(1+\mathrm{r})^{-\mathrm{T}} \mathrm{P}^{\mathrm{T}}$.

Thus $u^{0}$ can be determined from equation (49) as follows: ${ }^{67}$

$(50) \mathrm{u}^{0}=\left[\mathrm{P}^{0}-\mathrm{P}^{\mathrm{T}}(1+\mathrm{r})^{-\mathrm{T}}\right] /\left[1+\phi+\phi^{2}+\ldots+\phi^{\mathrm{T}-1}\right]$.

Once $u^{0}$ has been calculated, the sequence of imputed rental prices for the unique asset for periods $0,1, \ldots, \mathrm{T}-1$ is $\mathrm{u}^{0},(1+\mathrm{i})(1-\delta) \mathrm{u}^{0},(1+\mathrm{i})^{2}(1-\delta)^{-2} \mathrm{u}^{0}, \ldots,(1+\mathrm{i})^{\mathrm{T}-1}(1-\delta)^{-\mathrm{T}+1} \mathrm{u}^{0}$. The corresponding sequence of constant quality quantities is $1,(1-\delta)^{-1},(1-\delta)^{-2}, \ldots,(1-\delta)^{-\mathrm{T}+1}$. Again, note that these computations can only be done once $\mathrm{P}^{\mathrm{T}}$ is known; i.e., these user cost valuations cannot be made in real time.

The above models for measuring the services of a unique durable good are subject to many criticisms but perhaps these models can serve as starting points for more realistic models. In any case, having an imperfect model for measuring the services of a unique durable good is better than having no model at all.

In the remaining sections of this paper, the focus will be on the special problems that are associated with both measuring the value of the housing stock as well as on valuing the services of Owner Occupied Housing $(\mathrm{OOH})$.

\section{Decomposing Residential Property Prices into Land and Structure Components}

In this section, the problems associated with the construction of constant quality residential property price indexes will be studied. In this section, we will look at the construction of constant quality indexes for the stock of residential housing units; in subsequent sections, we will look at the problems associated with pricing the services of a residential dwelling unit.

There are two difficult measurement problems associated with the construction of a constant quality house price index:

- A dwelling unit is a unique consumer durable good; i.e., the location of a housing unit is a price determining characteristic of the unit and each house or apartment has a unique location.

- There are two main components of a dwelling unit: (i) the size of the structure (measured in square meters of floor space) and (ii) the size of the land plot that the structure sits on (also measured in square meters). However, the purchase price of a dwelling unit is for the entire property and thus the decomposition of property price into its two main components will involve imputations.

\footnotetext{
${ }^{67}$ If $\mathrm{P}^{0}-\mathrm{P}^{\mathrm{T}}(1+\mathrm{r})^{-\mathrm{T}}<0$, then as before, $\mathrm{u}^{0}$ becomes negative (and $\mathrm{u}^{1}, \ldots \mathrm{u}^{\mathrm{T}-1}$ become negative as well) and again, the services of the unique durable are free of charge and $-(1+i)^{t-1}(1-\delta)^{t-1} u^{t}=-(1+i)^{t-1} u^{0}>0$ becomes an addition to household income for period $t$.
} 
The first problem area listed above might not be a problem if the same dwelling unit sold at market prices at a frequent rate so that the location would be held constant and it would seem that the usual matched model methodology that is used in constructing price indexes could be applied. But houses do not transact all that frequently; typically, a house is held for 10-20 years by the same owner before it is resold. Moreover, the structure is not constant over time; depreciation of the structure occurs over time and owners renovate and replace aging components of the structure. For example, the roofing materials for many dwellings are replaced every 20 or 30 years. Thus depreciation and renovation constantly change the quality of the structure.

The second problem area is associated with the difficulty of decomposing the transaction price for a housing unit into separate components representing the structure value and the land value; i.e., the single property price is for both components of the housing unit but for many purposes, we require separate valuations for the two components. The international System of National Accounts, requires separate valuations for the land and structure components of residential housing in the National Balance Sheets of the country. Many countries construct estimates for the Total Factor Productivity or Multifactor Productivity of the various sectors in the economy and the methodology used to construct these estimates requires separate price and quantity information on both structures and the land that the structures sit on. In this section, we will indicate a possible method that can be used to accomplish this decomposition of property value into constant quality land and structure components.

The builder's model for valuing a detached dwelling unit postulates that the value of the property is the sum of two components: the value of the land which the structure sits on plus the value of the structure. This model can be justified in two situations:

- A household purchases a residential land plot with no structure on it (or if there are structures on the land plot, they are immediately demolished). ${ }^{68}$

- A household purchases a land plot and immediately builds a new dwelling unit on the property.

In the first case, it is clear that the property value is equal to the land value. In the second case, The total cost of the property after the structure is completed will be equal to the floor space area of the structure, say S square meters, times the building cost per square meter $\beta_{t}$ during period $t$, plus the cost of the land, which will be equal to the cost per square meter $\alpha_{t}$ times the area of the land site, say L square meters. Now think of a sample of properties of the same general type in the same general location, which have prices or values $\mathrm{V}_{\mathrm{tn}}$ in period $\mathrm{t}$ (where $\mathrm{t}=1, \ldots, \mathrm{T}$ ) and structure floor space areas $\mathrm{S}_{\mathrm{tn}}$ and land areas $\mathrm{L}_{\mathrm{tn}}$ for $\mathrm{n}=1, \ldots, \mathrm{N}(\mathrm{t})$ where $\mathrm{N}(\mathrm{t})$ is the number of observations in period $\mathrm{t}$. Assume that these prices are equal to the sum of the land and structure costs plus error terms $\varepsilon_{\mathrm{tn}}$ which we assume are independently normally distributed with zero means and

\footnotetext{
${ }^{68}$ The cost of the demolition should be added to the purchase price for the land to get the overall land price for the land plot.
} 
constant variances. This leads to the following hedonic regression model for period $\mathrm{t}$ where the $\alpha_{\mathrm{t}}$ and $\beta_{\mathrm{t}}$ are the parameters to be estimated in the regression: ${ }^{69}$

(51) $\mathrm{V}_{\mathrm{tn}}=\alpha_{\mathrm{t}} \mathrm{L}_{\mathrm{tn}}+\beta_{\mathrm{t}} \mathrm{S}_{\mathrm{tn}}+\varepsilon_{\mathrm{tn}}$

$\mathrm{t}=1, \ldots, \mathrm{T} ; \mathrm{n}=1, \ldots, \mathrm{N}(\mathrm{t})$.

The hedonic regression model defined by (51) applies to new structures and to purchases of vacant residential lots in the neighbourhood under consideration where $S_{\mathrm{tn}}=0$. Note that there are some strong simplifying assumptions built into the model defined by (51): (i) the period t land price $\alpha_{t}\left(\right.$ per $\left.\mathrm{m}^{2}\right)$ is assumed to be constant across all properties in the neighbourhood under consideration and (ii) the construction cost $\left(\mathrm{per}^{2}\right)$ is also assumed to be constant across all housing units built in the neighbourhood during period t. The above model applies to raw land purchases and the purchases of new dwelling units during period $t$ in the neighbourhood under consideration. It is likely that a model that is similar to (51) applies to sales of older structures as well. Older structures will be worth less than newer structures due to the depreciation of the structure. Assuming that we have information on the age of the structure $\mathrm{n}$ at time $\mathrm{t}$, say $\mathrm{A}(\mathrm{t}, \mathrm{n})$, and assuming a geometric (or declining balance) depreciation model, a more realistic hedonic regression model than that defined by (51) above is the following basic builder's model:

$$
\mathrm{V}_{\mathrm{tn}}=\alpha_{\mathrm{t}} \mathrm{L}_{\mathrm{tn}}+\beta_{\mathrm{t}}(1-\delta)^{\mathrm{A}(\mathrm{t}, \mathrm{n})} S_{\mathrm{tn}}+\varepsilon_{\mathrm{tn}}
$$$$
\mathrm{t}=1, \ldots, \mathrm{T} ; \mathrm{n}=1, \ldots, \mathrm{N}(\mathrm{t})
$$

where the parameter $\delta$ reflects the net geometric depreciation rate as the structure ages one additional period. Thus if the age of the structure is measured in years, we would expect an annual net depreciation rate to be around 1 to 3 percent per year. ${ }^{70}$ Note that (52) is now a nonlinear regression model whereas (51) was a simple linear regression model. The period $t$ constant quality price of land will be the estimated coefficient for the parameter $\alpha_{t}$ and the price of a unit of a newly built structure for period t will be the estimate for $\beta_{t}$. The period $t$ quantity of land for property $n$ is $L_{t n}$ and the period $t$ quantity of structure for property $\mathrm{n}$, expressed in equivalent units of a new structure, is (1 $\delta)^{\mathrm{A}(\mathrm{t}, \mathrm{n})} \mathrm{S}_{\mathrm{tn}}$ where $\mathrm{S}_{\mathrm{tn}}$ is the floor space area of the structure for property $\mathrm{n}$ in period $\mathrm{t}$.

Note that the above model can be viewed as a supply side model as opposed to a demand side model. ${ }^{71}$ Basically, we are assuming a valuation of a housing structures that is equal to the cost per unit floor space area of a new unit times the floor space area times an adjustment for structure depreciation. The corresponding land value of the property is determined residually as total property value minus the imputed value of structures

\footnotetext{
${ }^{69}$ Other papers that have suggested hedonic regression models that lead to additive decompositions of property values into land and structure components include Clapp (1980; 257-258), Bostic, Longhofer and Redfearn (2007; 184), Francke and Vos (2004), Diewert (2008; 19-22) (2010), Francke (2008; 167), Koev and Santos Silva (2008), Rambaldi, McAllister, Collins and Fletcher (2010), Diewert, Haan and Hendriks (2011) (2015), Eurostat (2013), Diewert and Shimizu (2015) (2016) (2017a), Burnett-Issacs, Huang and Diewert (2016) and Diewert, Huang and Burnett-Issacs (2017).

${ }^{70}$ This estimate of depreciation is regarded as a net depreciation rate because it is equal to a "true" gross structure depreciation rate less an average renovations appreciation rate. Since typically information on renovations and major repairs to a structure is not available, the age variable will only pick up average gross depreciation less average real renovation expenditures.

${ }^{71}$ We will pursue a demand side model in Section 14 below.
} 
quality adjusted for the age of the structure. This assumption is justified for the case of newly built houses and sales of vacant lots but it is less well justified for sales of properties with older structures where a demand side model may be more relevant.

There is a major practical problem with the hedonic regression model defined by (52): The multicollinearity problem. Experience has shown that it is usually not possible to estimate sensible land and structure prices in a hedonic regression like that defined by (52) due to the multicollinearity between lot size and structure size. ${ }^{72}$ Thus in order to deal with the multicollinearity problem, the parameter $\beta_{\mathrm{t}}$ in (52) is replaced by $\mathrm{p}_{\mathrm{st}}$, an exogenous period $t$ construction cost price for houses in the area under consideration. ${ }^{73}$ The exogenous construction price index may be an official construction price index estimated by the national statistical agency or a relevant commercially available residential construction price index. Thus the new model that replaces (52) is the following nonlinear hedonic regression model:

$$
\mathrm{V}_{\mathrm{tn}}=\alpha_{\mathrm{t}} \mathrm{L}_{\mathrm{tn}}+\mathrm{p}_{\mathrm{St}}(1-\delta)^{\mathrm{A}(\mathrm{t}, \mathrm{n})} \mathrm{S}_{\mathrm{tn}}+\varepsilon_{\mathrm{tn}} ; \quad \mathrm{t}=1, \ldots, \mathrm{T} ; \mathrm{n}=1, \ldots, \mathrm{N}(\mathrm{t})
$$

This model has $\mathrm{T}$ land price parameters (the $\alpha_{t}$ ) and one (net) geometric depreciation rate $\delta$. Note that the replacement of the $\beta_{\mathrm{t}}$ by the exogenous construction price level, $\mathrm{p}_{\mathrm{St}}$, means that we have saved $\mathrm{T}$ degrees of freedom as well as eliminated the multicollinearity problem.

In order to allow for a finer structure of local land prices, the sales data may be further classified into a finer classification of locations. For example, the initial regression (53) may be applied to say city wide sales of residential properties. Suppose that the postal code of each sale is also available and there are J postal codes. Then one can introduce the following postal code dummy variables, $\mathrm{D}_{\mathrm{PC}, \mathrm{tn}, \mathrm{j}}$, into the hedonic regression (53). These $\mathrm{J}$ dummy variables are defined as follows: for $\mathrm{t}=1, \ldots, \mathrm{T} ; \mathrm{n}=1, \ldots, \mathrm{N}(\mathrm{t}) ; \mathrm{j}=1, \ldots, \mathrm{J}$ :

(54) $\mathrm{D}_{\mathrm{PC}, \mathrm{tn}, \mathrm{j}} \equiv 1$ if observation $\mathrm{n}$ in period $\mathrm{t}$ is in Postal Code $\mathrm{j}$; $\equiv 0$ if observation $\mathrm{n}$ in period $\mathrm{t}$ is not in Postal Code $\mathrm{j}$.

We now modify the model defined by (53) to allow the level of land prices to differ across the $\mathbf{J}$ postal codes. The new nonlinear regression model is the following one:

$$
\mathrm{V}_{\mathrm{tn}}=\alpha_{\mathrm{t}}\left(\sum_{\mathrm{j}=1}^{\mathrm{J}} \omega_{\mathrm{j}} \mathrm{D}_{\mathrm{PC}, \mathrm{tn}, \mathrm{j}}\right) \mathrm{L}_{\mathrm{tn}}+\mathrm{p}_{\mathrm{St}}(1-\delta)^{\mathrm{A}(\mathrm{t}, \mathrm{n})} \mathrm{S}_{\mathrm{tn}}+\varepsilon_{\mathrm{tn}} ; \quad \mathrm{t}=1, \ldots, \mathrm{T} ; \mathrm{n}=1, \ldots, \mathrm{N}(\mathrm{t})
$$

Comparing the models defined by equations (53) and (55), it can be seen that we have added an additional $\mathbf{J}$ neighbourhood relative land value parameters, $\omega_{1}, \ldots, \omega_{\mathrm{J}}$, to the

\footnotetext{
${ }^{72}$ See Schwann (1998) and Diewert, de Haan and Hendriks (2011) (2015) on the multicollinearity problem.

${ }^{73}$ This formulation follows that of Diewert (2010), Diewert, Haan and Hendriks (2011) (2015), Eurostat (2013), Diewert and Shimizu (2015) (2016) (2017a), Burnett-Issacs, Huang and Diewert (2016) and Diewert, Huang and Burnett-Issacs (2017). These authors assume that property value is the sum of land and structure components but movements in the price of structures are proportional to an exogenous structure price index. Note that the index $\mathrm{p}_{\mathrm{St}}$ should be a levels price that gives the period $t$ cost of building one square meter of structure.
} 
model defined by (53). However, looking at (55), it can be seen that the $\mathrm{T}$ land time parameters $\left(\right.$ the $\alpha_{\mathrm{t}}$ ) and the $\mathrm{J}$ location parameters (the $\omega_{\mathrm{j}}$ ) cannot all be identified. Thus it is necessary to impose at least one identifying normalization on these parameters. The following normalization is a convenient one: ${ }^{74}$

(56) $\omega_{1} \equiv 1$.

Thus Model 2 is defined by equations (55) and (56) has $\mathrm{J}-1$ additional parameters compared to Model 1 defined by (53). Note that if we initially set all of the $\omega_{\mathrm{j}}$ equal to unity, Model 2 collapses down to Model 1. It is useful to make use of this fact in running a sequence of nonlinear hedonic regressions. The models that are proposed in this section are nested so that the final parameter estimates from a previous model can be used as starting parameter values in the next model's nonlinear regression. ${ }^{75}$

In the next model, some nonlinearities in the pricing of the land area for each property are introduced. The land plot areas in a typical sample of properties can vary 5 or 10 fold. $^{76}$ Up to this point, we have assumed that land plots in the same neighbourhood sell at a constant price per square meter of lot area. However, it is likely that there is some nonlinearity in this pricing schedule; for example, it is likely that large lots sell at a per $\mathrm{m}^{2}$ price that is well below the per $\mathrm{m}^{2}$ price of medium sized lots. In order to capture this nonlinearity, divide up the total number of observations into $\mathrm{K}$ groups of observations based on their lot size. The Group 1 properties have lot size less than $\mathrm{L}_{1} \mathrm{~m}^{2}$, the Group 2 properties $\mathrm{L}_{\mathrm{tn}}$ have lot sizes which satisfy the inequalities $\mathrm{L}_{1} \leq \mathrm{L}_{\mathrm{tn}}<\mathrm{L}_{2}$; the Group 3 properties $\mathrm{L}_{\mathrm{tn}}$ have lot sizes which satisfy the inequalities $\mathrm{L}_{2} \leq \mathrm{L}_{\mathrm{tn}}<\mathrm{L}_{3} ; \ldots$; the Group $\mathrm{K}$ properties $\mathrm{L}_{\mathrm{tn}}$ have lot sizes which satisfy the inequalities $\mathrm{L}_{\mathrm{K}-1} \leq \mathrm{L}_{\mathrm{tn}}$. The break points $\mathrm{L}_{1}$ $<\mathrm{L}_{2}<\ldots<\mathrm{L}_{\mathrm{K}-1}$ should be chosen so that the sample probability that any property in the sample will fall into any one of the groups is approximately equal. For each observation $\mathrm{n}$ in period $\mathrm{t}$, the $\mathrm{K}$ land dummy variables, $\mathrm{D}_{\mathrm{L}, \mathrm{tn}, \mathrm{k}}$, for $\mathrm{k}=1, \ldots, \mathrm{K}$ are defined as follows:

$$
\begin{aligned}
\mathrm{D}_{\mathrm{L}, \mathrm{tn}, \mathrm{k}} & \equiv 1 \text { if observation tn has land area that belongs to group } \mathrm{k} ; \\
& \equiv 0 \text { if observation th has land area that does not belong to group } \mathrm{k} .
\end{aligned}
$$

\footnotetext{
${ }^{74}$ Equivalently, one could make the normalization $\alpha_{1}=1$ and not normalize the $\omega_{\mathrm{j}}$. The resulting estimated $\alpha_{t}$ for $t=2,3, \ldots, T$ can then be interpreted as a constant quality land price index for the entire region relative to period 1 where $\alpha_{1} \equiv 1$. In this section, we are drawing heavily on Diewert, Huang and Burnett-Isaacs (2017) and using the normalization used in that paper.

${ }^{75}$ In order to obtain sensible parameter estimates in our final (quite complex) nonlinear regression model, it is absolutely necessary to follow our procedure of sequentially estimating gradually more complex models, using the final coefficients from the previous model as starting values for the next model. The models that are being described in this section were implemented in Diewert, Huang and Burnett-Issacs (2017) where the econometric software Shazam was used to perform the nonlinear regressions; see White (2004).

${ }^{76}$ This brings up an important point that has not been mentioned up to now. Panel data on the selling prices of properties and on the characteristics of the properties are subject to tremendous variations in the ratio of the say highest price property to the lowest price property, to the largest lot size to the smallest lot size, to the largest floor space area to the smallest floor space area and so on. The observations that appear in the tales of the distribution of prices and in the distributions of property characteristics are inevitably sparse and subject to measurement error. Thus in order to obtain sensible estimates in running these hedonic regressions, it is typically necessary to delete the observations that are in the tales of these distributions.
} 
These dummy variables are used in the definition of the following piecewise linear function of $\mathrm{L}_{\mathrm{tn}}, \mathrm{f}_{\mathrm{L}}\left(\mathrm{L}_{\mathrm{tn}}\right)$, defined as follows:

$$
\begin{aligned}
\mathrm{f}_{\mathrm{L}}\left(\mathrm{L}_{\mathrm{tn}}\right) \equiv & \mathrm{D}_{\mathrm{L}, \mathrm{tn}, 1} \lambda_{1} \mathrm{~L}_{\mathrm{tn}}+\mathrm{D}_{\mathrm{L}, \mathrm{tn}, 2}\left[\lambda_{1} \mathrm{~L}_{1}+\lambda_{2}\left(\mathrm{~L}_{\mathrm{tn}}-\mathrm{L}_{1}\right)\right]+\mathrm{D}_{\mathrm{L}, \mathrm{tn}, 3}\left[\lambda_{1} \mathrm{~L}_{1}+\lambda_{2}\left(\mathrm{~L}_{2}-\mathrm{L}_{1}\right)+\lambda_{3}\left(\mathrm{~L}_{\mathrm{tn}}-\mathrm{L}_{2}\right)\right] \\
& +\ldots+\mathrm{D}_{\mathrm{L}, \mathrm{tn}, \mathrm{K}}\left[\lambda_{1} \mathrm{~L}_{1}+\lambda_{2}\left(\mathrm{~L}_{2}-\mathrm{L}_{1}\right)+\ldots+\lambda_{\mathrm{K}}\left(\mathrm{L}_{\mathrm{tn}}-\mathrm{L}_{\mathrm{K}-1}\right)\right]
\end{aligned}
$$

where the $\lambda_{\mathrm{k}}$ are unknown parameters. The function $\mathrm{f}_{\mathrm{L}}\left(\mathrm{L}_{\mathrm{tn}}\right)$ defines a relative valuation function for the land area of a house as a function of the plot area, $\mathrm{L}_{\mathrm{tn}}$. The new nonlinear regression model is the following one:

$$
\mathrm{V}_{\mathrm{tn}}=\alpha_{\mathrm{t}}\left(\sum_{\mathrm{j}=1}^{\mathrm{J}} \omega_{\mathrm{j}} \mathrm{D}_{\mathrm{PC}, \mathrm{tn}, \mathrm{j}}\right) \mathrm{f}_{\mathrm{L}}\left(\mathrm{L}_{\mathrm{tn}}\right)+\mathrm{p}_{\mathrm{St}}(1-\delta)^{\mathrm{A}(\mathrm{t}, \mathrm{n})} \mathrm{S}_{\mathrm{tn}}+\varepsilon_{\mathrm{tn}} ; \quad \mathrm{t}=1, \ldots, \mathrm{T} ; \mathrm{n}=1, \ldots, \mathrm{N}(\mathrm{t}) .
$$

Comparing the models defined by equations (55) and (59), it can be seen that we have added an additional $\mathrm{K}$ land plot size parameters, $\lambda_{1}, \ldots, \lambda_{\mathrm{K}}$, to the model defined by (55). However, looking at (59), it can be seen that the T land time parameters (the $\alpha_{t}$ ), the $J$ postal code parameters (the $\omega_{\mathrm{j}}$ ) and the $\mathrm{K}$ land plot size parameters (the $\lambda_{\mathrm{k}}$ ) cannot all be identified. Thus the following identification normalizations on the parameters for Model 3 defined by (59) and (60) are imposed:

(60) $\omega_{1} \equiv 1 ; \lambda_{1} \equiv 1$.

Note that if all of the $\lambda_{\mathrm{k}}$ are set equal to unity, Model 3 collapses down to Model 2. Typically, the log likelihood for Model 3 will be considerably higher than for Model $2 .{ }^{77}$ Land prices as functions of lot size do not always decline monotonically but for very large land plots, the marginal price of an extra square foot of land is typically quite low.

The next model is similar to Model 3 except that now the marginal price of adding an extra amount of structure is allowed to vary as the size of the structure increases. It is likely that the quality of the structure increases as the size of the structure increases. In order to capture this nonlinearity, divide up the sample observations into M groups of observations based on their structure size. The Group 1 properties have structures with floor space area $S_{\mathrm{tn}}$ less than $\mathrm{S}_{1} \mathrm{~m}^{2}$, the Group 2 properties have structure areas $\mathrm{S}_{\mathrm{tn}}$ satisfying the inequalities $S_{1} \leq S_{\mathrm{tn}}<S_{2}, \ldots$, the Group M-1 properties have structure areas $\mathrm{S}_{\mathrm{tn}}$ satisfying the inequalities $\mathrm{S}_{\mathrm{M}-2} \leq \mathrm{S}_{\mathrm{tn}}<\mathrm{S}_{\mathrm{M}-1}$, and the Group M properties have structure areas $S_{\mathrm{tn}}$ satisfying the inequalities $\mathrm{S}_{\mathrm{M}-1} \leq \mathrm{S}_{\mathrm{tn}}$ where the M-1 break points satisfy the inequalities $S_{1}<S_{2}<\ldots<S_{M-1}$. Again, the break points should be chosen so that the sample probability that any property in the sample will fall into any one of the groups is approximately equal. For each observation $n$ in period $t$, we define the $M$ structure dummy variables, $\mathrm{D}_{\mathrm{S}, \mathrm{tn}, \mathrm{m}}$, for $\mathrm{m}=1, \ldots, \mathrm{M}$ as follows:

(61) $\mathrm{D}_{\mathrm{S}, \mathrm{tn}, \mathrm{m}} \equiv 1$ if observation tn has structure area that belongs to structure group $\mathrm{m}$;

\footnotetext{
${ }^{77}$ For the example in Diewert, Huang and Burnett-Isaacs (2017) where the models described in this section were estimated, the log likelihood increased by $1762 \log$ likelihood points and the $\mathrm{R}^{2}$ jumped from 0.7662 for Model 2 to 0.8283 for Model 3 for the addition of 6 new $\lambda_{k}$ parameters.
} 
$\equiv 0$ if observation tn has structure area that does not belong to group $\mathrm{m}$.

These dummy variables are used in the definition of the following piecewise linear function of $S_{\mathrm{tn}}, \mathrm{g}_{\mathrm{S}}\left(\mathrm{S}_{\mathrm{tn}}\right)$, defined as follows:

$$
\begin{aligned}
\mathrm{g}_{\mathrm{S}}\left(\mathrm{S}_{\mathrm{tn}}\right) \equiv & \mathrm{D}_{\mathrm{S}, \mathrm{tn}, 1} \mu_{1} \mathrm{~S}_{\mathrm{tn}}+\mathrm{D}_{\mathrm{S}, \mathrm{tn}, 2}\left[\mu_{1} \mathrm{~S}_{1}+\mu_{2}\left(\mathrm{~S}_{\mathrm{tn}}-\mathrm{S}_{1}\right)\right]+\mathrm{D}_{\mathrm{S}, \mathrm{tn}, 3}\left[\mu_{1} \mathrm{~S}_{1}+\mu_{2}\left(\mathrm{~S}_{2}-\mathrm{S}_{1}\right)+\mu_{3}\left(\mathrm{~S}_{\mathrm{tn}}-\mathrm{S}_{2}\right)\right] \\
& +\mathrm{D}_{\mathrm{S}, \mathrm{n}, 4}\left[\mu_{1} \mathrm{~S}_{1}+\mu_{2}\left(\mathrm{~S}_{2}-\mathrm{S}_{1}\right)+\mu_{3}\left(\mathrm{~S}_{3}-\mathrm{S}_{2}\right)+\mu_{4}\left(\mathrm{~S}_{\mathrm{tn}}-\mathrm{S}_{3}\right)\right]+\ldots \\
& +\mathrm{D}_{\mathrm{S}, \mathrm{tn}, \mathrm{M}}\left[\mu_{1} \mathrm{~S}_{1}+\mu_{2}\left(\mathrm{~S}_{2}-\mathrm{S}_{1}\right)+\mu_{3}\left(\mathrm{~S}_{3}-\mathrm{S}_{2}\right)+\ldots+\mu_{\mathrm{M}}\left(\mathrm{S}_{\mathrm{tn}}-\mathrm{S}_{\mathrm{M}-1}\right)\right]
\end{aligned}
$$

where the $\mu_{\mathrm{m}}$ are unknown parameters. The function $\mathrm{g}_{\mathrm{s}}\left(\mathrm{S}_{\mathrm{tn}}\right)$ defines a relative valuation function for the structure area of a house as a function of the structure area.

The new nonlinear regression model is the following Model 4:

$$
\mathrm{V}_{\mathrm{tn}}=\alpha_{\mathrm{t}}\left(\sum_{\mathrm{j}=1}{ }^{\mathrm{J}} \omega_{\mathrm{j}} \mathrm{D}_{\mathrm{PC}, \mathrm{tn}, \mathrm{j}}\right) \mathrm{f}_{\mathrm{L}}\left(\mathrm{L}_{\mathrm{tn}}\right)+\mathrm{p}_{\mathrm{St}}(1-\delta)^{\mathrm{A}(\mathrm{t}, \mathrm{n})} \mathrm{g}_{\mathrm{S}}\left(\mathrm{S}_{\mathrm{tn}}\right)+\varepsilon_{\mathrm{tn}} ; \mathrm{t}=1, \ldots, \mathrm{T} ; \mathrm{n}=1, \ldots, \mathrm{N}(\mathrm{t})
$$

Comparing the models defined by equations (59) and (63), it can be seen that an additional M structure floor space parameters, $\mu_{1}, \ldots, \mu_{\mathrm{M}}$, have been added to the model defined by (59) ${ }^{78}$ Again, we add the normalizations (60) in order to identify all of the parameters in the model. Note that if all of the $\mu_{\mathrm{m}}$ are set equal to unity, Model 4 collapses down to Model 3. Typically, the log likelihood for Model 4 will be considerably higher than for Model 3. ${ }^{79}$

At this stage, it is often the case that an acceptable model has been estimated. How can the estimated parameters from the final model be used in order to form price and quantity indexes?

The sequence of price levels for the land component of residential property sales is defined to be $\alpha_{1}, \alpha_{2}, \ldots, \alpha_{\mathrm{T}}$ and the corresponding sequence of price levels for the structure component of residential property sales in the T periods is defined to be the exogenous sequence of indexes, $\mathrm{p}_{\mathrm{S} 1}, \mathrm{p}_{\mathrm{S} 2}, \ldots, \mathrm{p}_{\mathrm{ST}}$. The land and structure values of properties transacted in period $t, V_{L t}$ and $V_{S t}$, are defined by using the estimated land and structure additive components of transacted properties in period $t, \alpha_{t}\left(\sum_{j=1}{ }^{J} \omega_{j} D_{P C, t n, j}\right) f_{L}\left(L_{t n}\right)$ and $p_{S t}(1-$ $\delta)^{A(t, n)} g_{S}\left(S_{t n}\right)$ respectively, and summing over properties that were sold in period $t$ :

(64) $\mathrm{V}_{\mathrm{Lt}} \equiv \Sigma_{\mathrm{n} \in \mathrm{N}(\mathrm{t})} \alpha_{\mathrm{t}}\left(\sum_{\mathrm{j}=1}{ }^{\mathrm{J}} \omega_{\mathrm{j}} \mathrm{D}_{\mathrm{PC}, \mathrm{tn}, \mathrm{j}}\right) \mathrm{f}_{\mathrm{L}}\left(\mathrm{L}_{\mathrm{tn}}\right)$; (65) $\mathrm{V}_{\mathrm{St}} \equiv \Sigma_{\mathrm{n} \in \mathrm{N}(\mathrm{t})} \mathrm{p}_{\mathrm{St}}(1-\delta)^{\mathrm{A}(\mathrm{t}, \mathrm{n})} \mathrm{g}_{\mathrm{S}}\left(\mathrm{S}_{\mathrm{tn}}\right)$;

$$
\begin{aligned}
& \mathrm{t}=1, \ldots, \mathrm{T} \\
& \mathrm{t}=1, \ldots, \mathrm{T}
\end{aligned}
$$

\footnotetext{
${ }^{78}$ At this stage of the sequential estimation procedure, it is usually not necessary to impose a normalization on the parameters $\mu_{1}-\mu_{\mathrm{M}}$. This lack of a normalization means that the scale of the exogenous structure price levels $\mathrm{p}_{\mathrm{St}}$ is allowed to change; i.e., essentially, allowance is now made to quality adjust the exogenous index to a certain extent. However, if the resulting estimated structure values turn out to be unreasonably large or small, then it will be necessary to set one of the $\mu_{\mathrm{m}}$ to equal 1 .

${ }^{79}$ For the example in Diewert, Huang and Burnett-Isaacs (2017), the log likelihood increased by $935 \log$ likelihood points and the $\mathrm{R}^{2}$ jumped from 0.8283 for Model 3 to 0.8520 for Model 4 for the addition of 5 new $\mu_{\mathrm{M}}$ parameters.
} 
Using the prices $\alpha_{1}, \alpha_{2}, \ldots, \alpha_{\mathrm{T}}$ and the corresponding estimated land values, $\mathrm{V}_{\mathrm{L} 1}, \ldots, \mathrm{V}_{\mathrm{LT}}$ and the prices $\mathrm{p}_{\mathrm{S} 1}, \mathrm{p}_{\mathrm{S} 2}, \ldots, \mathrm{p}_{\mathrm{ST}}$ and the corresponding estimated structure values, $\mathrm{V}_{\mathrm{S} 1}, \ldots, \mathrm{V}_{\mathrm{ST}}$, one can just apply normal index number theory using these data to construct Laspeyres, Paasche, Fisher or whatever index formula is being used by the statistical agency in order to construct constant quality price and quantity overall property indexes for the sales of residential properties in the area under consideration for the $\mathrm{T}$ periods.

However, constant quality land and structure price indexes for sales of Owner Occupied Residential houses is not what is needed for most purposes; what is required are constant quality price and quantity indexes for the stock of residential houses. In order to accomplish this task, it is necessary to have a census of the housing stock in the country which would include information on the characteristics that are used in the hedonic regression model that is defined by (63). The information that is required in order to estimate (63) is information on the following variables:

- The selling price of the residential properties $\left(\mathrm{P}_{\mathrm{tn}}\right)$;

- The age of the structure on the property $\left(\mathrm{A}_{\mathrm{tn}}\right)$;

- The area of the land plot $\left(\mathrm{L}_{\mathrm{tn}}\right)$;

- The floor space area of the structure $\left(\mathrm{S}_{\mathrm{tn}}\right)$;

- The neighbourhood of the property (or the postal code) and

- An exogenous structure price index which provides the construction cost of a new structure per meter squared or per square foot $\left(\mathrm{p}_{\mathrm{St}}\right)$.

If a national housing Census has information on the above property characteristics (excluding the information on selling prices $\mathrm{P}_{\mathrm{tn}}$ and on the exogenous structure price index $\left.\mathrm{p}_{\mathrm{St}}\right)^{80}$, then it will be possible to insert the characteristics of each residential dwelling unit into the right hand side of (63) and then using appropriate modifications of definitions (64) and (65), it will be possible to obtain estimates for the land and structure value for each dwelling unit in the area covered by the regression. If there is no national housing census information or the required characteristics are not included in the census, then it will be very difficult to form estimates for the value of residential land.

Additional information on house and property characteristics will lead to more accurate land and structure decompositions of property value. Examples of useful additional structure price determining characteristics are: (i) the number of bathrooms; (ii) the number of bedrooms; (iii) the type of construction material; (iv) the number of stories; etc. Examples of useful additional land price determining characteristics are: (i) the distance to the nearest subway station; (ii) the distance to the city core; (iii) the quality of neighbourhood schools; (iv) the existence of various neighbourhood amenities; etc. For examples of how these characteristics can be integrated into the builder's model, see

\footnotetext{
${ }^{80}$ Every country will have a national residential construction deflator because this deflator is required in order to form estimates of real investment in residential structures. However, this national deflator may not be entirely appropriate for the type of buildings in a particular neighbourhood.
} 
Diewert, de Haan and Hendriks (2011) (2015), Eurostat (2013) (2017), Diewert and Shimizu (2015) and Diewert, Huang and Burnett-Isaacs (2017). ${ }^{81}$

The estimates for the geometric depreciation rate generated by the application of the builder's model are useful for national income accountants because they facilitate the accurate estimation of structure depreciation, which is required for the national accounts. However, the depreciation estimates that are generated by the builder's model are wear and tear depreciation estimates that apply to structures that continue in existence over the sample period. The estimated depreciation rate measures (net) depreciation ${ }^{82}$ of a structure that has survived from its birth to the period of its sale. However, there is another form of structure depreciation that the estimated depreciation rate misses; namely the loss of residual structure value that results from the early demolition of the structure. This problem was noticed and addressed by Hulten and Wykoff (1981a; 377-379) (1981b) (1996). Wear and tear depreciation is often called deterioration depreciation and demolition or early retirement depreciation is sometimes called obsolescence depreciation. ${ }^{83}$ Methods for estimating this form of depreciation have been proposed by Hulten and Wykoff as mentioned above and by Diewert and Shimizu (2017a; 512-516). Both methods require information on the distribution of the ages of retirement for the asset class. The Hulten and Wykoff method absorbs demolition depreciation into the wear and tear depreciation rate whereas the Diewert and Shimizu method uses the wear and tear depreciation rate that is generated by sales of surviving buildings but adds a separate depreciation rate that is due to early demolition of the structures in the asset class. Both methods require information on the age of structures when they are demolished. ${ }^{84}$

The above paragraph simply warns the reader that wear and tear depreciation ${ }^{85}$ for surviving buildings is not the entire depreciation story: there is also a loss of asset value that results from the early retirement of a building that needs to be taken into account when constructing national income accounting estimates of depreciation.

\footnotetext{
${ }^{81}$ It is also possible to estimate more general models of depreciation using the builder's model; see Diewert and Shimizu (2017a) and Diewert, Huang and Burnett-Isaacs (2017).

${ }^{82}$ It is a net estimate since renovation and replacement investments in the building tend to extend the life of the building or augment its value. Thus the gross wear and tear depreciation rate for the structure will tend to be larger than the estimated net depreciation rate.

${ }^{83}$ Crosby, Devaney and Law $(2012 ; 230)$ distinguish the two types of depreciation and in addition, they provide a comprehensive survey of the depreciation literature as it applies to commercial properties.

${ }^{84}$ The Hulten and Wykoff method estimates the age of retirement in a somewhat arbitrary fashion whereas the Diewert and Shimizu method relies on mortality distributions on the age of buildings at the time they are demolished. Over long periods of time and using country wide data, the two methods should be equivalent. However, the Diewert and Shimizu method should give more accurate results at the firm and regional levels since their method is consistent with the hedonic estimation of structure depreciation rates as explained in this section.

${ }^{85}$ What has been labeled as wear and tear depreciation could be better described as anticipated amortization of the structure rather than wear and tear depreciation. Once a structure is built, it becomes a fixed asset which cannot be transferred to alternative uses (like a truck or machine). Thus amortization of the cost of the structure should be proportional to the cash flows or to the service flows of utility that the building generates over its expected lifetime. However, technical progress, obsolescence or unanticipated market developments can cause the building to be demolished before it is fully amortized. See Diewert and Fox (2016) for a more complete discussion of the fixity problem.
} 
There is one additional complication that needs to be taken into account when running a hedonic regression on the sales of houses; i.e., what happens when the sales information for an additional period becomes available? The simplest way of dealing with this problem dates back to Court (1939). His method works as follows: set $\mathrm{T}=2$ and run a hedonic regression that has a time dummy variable in it. In the context of the hedonic regression model defined by (63), estimates for the price of land for periods 1 and 2 would be obtained, say $\alpha_{1}{ }^{1}$ and $\alpha_{2}{ }^{1}$. The price index for land for periods 1 and 2 is defined as $\mathrm{P}_{\mathrm{L}}{ }^{1}=1$ and $\mathrm{P}_{\mathrm{L}}{ }^{2}=\alpha_{2}{ }^{1} / \alpha_{1}{ }^{1}$. Now run a new hedonic regression using (63) for $\mathrm{t}=$ 2,3 and obtain new estimates for the price of land in periods 2 and 3 , say $\alpha_{2}{ }^{2}$ and $\alpha_{3}{ }^{2}$. The price index for land in period 3 is defined as $\mathrm{P}_{\mathrm{L}}{ }^{3}=\mathrm{P}_{\mathrm{L}}{ }^{2}\left(\alpha_{3}{ }^{2} / \alpha_{2}{ }^{2}\right)$; i.e., we update the price index value for period $2, \mathrm{P}_{\mathrm{L}}^{2}$, by the rate of change in land prices going from period 2 to 3 , $\left(\alpha_{3}{ }^{2} / \alpha_{2}{ }^{2}\right)$. Thus the previously estimated index is updated each period as new information becomes available. This adjacent period time dummy model has the advantage that it does not revise the previously estimated indexes as the new information becomes available. ${ }^{86}$

The above method does not always work well in the context of estimating property price indexes due to the sparseness of sales in a neighbourhood and the multiplicity of parameters that are required to adequately control for differences in housing characteristics. Thus Shimizu, Nishimura and Watanabe (2010a; 797) suggested extending the number of periods from 2 to a longer window of $\mathrm{T}$ consecutive periods, leading to the rolling window time dummy hedonic regression model. Thus for the model defined by (63), the land price parameters that are estimated by the first regression using the data for periods 1 to $\mathrm{T}$ are $\alpha_{1}{ }^{1}, \alpha_{2}{ }^{1}, \ldots, \alpha_{\mathrm{T}}{ }^{1}$ and the corresponding land price indexes for periods 1 to $\mathrm{t}$ are $\mathrm{P}_{\mathrm{L}}{ }^{\mathrm{t}} \equiv \alpha_{\mathrm{t}}{ }^{1} / \alpha_{1}{ }^{1}$ for $\mathrm{t}=1, \ldots, \mathrm{T}$. The second hedonic regression uses the data for periods $2,3, \ldots, \mathrm{T}, \mathrm{T}+1$ and the estimated land price parameters are $\alpha_{2}{ }^{2}, \alpha_{3}{ }^{2}, \ldots$, $\alpha_{\mathrm{T}}^{2}, \alpha_{\mathrm{T}+1}{ }^{2}$. The price index for land in period $\mathrm{T}+1$ is defined as $\mathrm{P}_{\mathrm{L}}^{\mathrm{T}+1}=\mathrm{P}_{\mathrm{L}}^{\mathrm{T}}\left(\alpha_{\mathrm{T}+1}{ }^{2} / \alpha_{\mathrm{T}}{ }^{2}\right)$; i.e., the price index for period $\mathrm{T}, \mathrm{P}_{\mathrm{L}}{ }^{\mathrm{t}}$, is updated by the rate of change in land prices going from period $\mathrm{T}$ to $\mathrm{T}+1, \alpha_{\mathrm{T}+1}{ }^{2} / \alpha_{\mathrm{T}}^{2}$.

There are two additional issues that need to be addressed when using a rolling window time dummy hedonic regression model:

- How long should the window length be? A longer window length will usually lead to more stable estimates for the unknown parameters in the hedonic regression. A shorter window length will allow for taste changes to take place more quickly. A window length of one year plus one period will allow for

\footnotetext{
${ }^{86}$ The two period time dummy variable hedonic regression (and its extension to many periods) was first considered explicitly by Court $(1939 ; 109-111)$ as his hedonic suggestion number two. Court used adjacent period time dummy hedonic regressions as links in a longer chain of comparisons extending from 1920 to 1939 for US automobiles: "The net regressions on time shown above are in effect price link relatives for cars of constant specifications. By joining these together, a continuous index is secured." If the two periods being compared are consecutive years, Griliches $(1971 ; 7)$ coined the term "adjacent year regression" to describe this method for updating the index as new information becomes available. Diewert (2005b) looked at the axiomatic properties of adjacent year time dummy hedonic regressions.
} 
seasonal effects. At this stage of our knowledge, it is difficult to give definitive advice on the length of the window.

- When a new window is computed, how should the index results from the new window be linked to the previous index values? The same issue applies when a multilateral method is used in the time series context. Ivancic, Diewert and Fox (2011) along with Shimizu, Nishimura and Watanabe (2010a) and Shimizu, Takatsuji, Ono and Nishimura (2010) suggested that the movement of the indexes for the last two periods in the new window be linked to the last index value generated by the previous window. However Krsinich (2016) suggested that the movement of the indexes generated by the new window over the entire new window period be linked to the previous window index value for the second period in the previous window. Krsinich called this a window splice as opposed to the movement splice explained above. De Haan $(2015 ; 27)$ suggested that perhaps the linking period should be in the middle of the old window which the Australian Bureau of Statistics $(2016 ; 12)$ termed a half splice. Ivancic, Diewert and Fox $(2011 ; 33)$ suggested that the average of all possible links of the new window to the old window be used and they called this a mean splice method for linking the results of the new window to the previous window. ${ }^{87}$ Again, there is no consensus at this time on which linking method is "best". However, it is likely that all of these linking methods will generate much the same results.

It can be seen that estimating price indexes for houses (or detached dwelling units) is not a straightforward task, particularly if one wants separate constant quality indexes for the land and structure components of property value. ${ }^{88}$ In the following section, it will be seen that it is even more complicated to obtain separate indexes for the land and structure components for condominium sales.

\section{Decomposing Condominium Sales Prices into Land and Structure Components}

A starting point for applying the builder's model to condominium sales is the hedonic regression model defined by equations (53) in the previous section. ${ }^{89}$ For convenience, equations (53) are repeated below as equations (66):

(66) $\mathrm{V}_{\mathrm{tn}}=\alpha_{\mathrm{t}} \mathrm{L}_{\mathrm{tn}}+\mathrm{p}_{\mathrm{St}}(1-\delta)^{\mathrm{A}(\mathrm{t}, \mathrm{n})} \mathrm{S}_{\mathrm{tn}}+\varepsilon_{\mathrm{tn}}$

$$
\mathrm{t}=1, \ldots, \mathrm{T} ; \mathrm{n}=1, \ldots, \mathrm{N}(\mathrm{t})
$$

where $\mathrm{V}_{\mathrm{tn}}$ is the selling price of a condominium property in a neighbourhood in period $\mathrm{t}$, $\alpha_{t}$ is the price of the land that the structure sits on $\left(\right.$ per $\left.\mathrm{m}^{2}\right), \mathrm{L}_{\mathrm{tn}}$ is the land area that can be attributed to the condo unit, $\mathrm{p}_{\mathrm{St}}$ is an exogenous period $\mathrm{t}$ construction cost for the type of condo under consideration (per $\mathrm{m}^{2}$ ), $\delta$ is the one period wear and tear geometric depreciation rate for the structure, $A_{t n}=A(t, n)$ is the age of the structure in periods, $S_{t n}$ is the floor space of unit $\mathrm{n}$ that is sold in period $\mathrm{t}\left(\mathrm{in} \mathrm{m}^{2}\right.$ ) and $\varepsilon_{\mathrm{tn}}$ is an error term.

\footnotetext{
${ }^{87}$ For the details on how the mean splice method works, see Diewert and Fox (2017).

${ }^{88}$ For additional hedonic regression models for detached houses, see Verbrugge (2008), Garner and Verbrugge (2011), Eurostat (2013) (2017), Hill (2013), Hill, Scholz, Shimizu and Steurer (2018), Rambaldi and Fletcher (2014) and Silver (2018).

${ }^{89}$ The analysis in this section follows that of Diewert and Shimizu (2016).
} 
A problem with the above model is that it is not appropriate to allocate the entire land value of the condominium property to any particular unit that is sold in period $t$. Thus each condo unit in the building should be allocated a share of the total land value of the property. The problem is: how exactly should this imputed land share be calculated? There are two simple methods for constructing an appropriate land share: (i) Use the unit's share of floor space to total structure floor space or (ii) simply use $1 / \mathrm{N}$ as the share where $\mathrm{N}$ is the total number of units in the building. Thus define the following two land share imputations for unit $\mathrm{n}$ in period $\mathrm{t}$ :

$$
\mathrm{L}_{\mathrm{Stn}} \equiv\left(\mathrm{S}_{\mathrm{tn}} / \mathrm{TS}_{\mathrm{tn}}\right) \mathrm{TL}_{\mathrm{tn}} ; \mathrm{L}_{\mathrm{Ntn}} \equiv\left(1 / \mathrm{N}_{\mathrm{tn}}\right) \mathrm{TL}_{\mathrm{tn}}
$$$$
\mathrm{t}=1, \ldots, \mathrm{T} ; \mathrm{n}=1, \ldots, \mathrm{N}(\mathrm{t})
$$

where $S_{t n}$ is the floor space area of unit $n$ which is sold in period $t, \mathrm{TS}_{\mathrm{tn}}$ is the total building floor space area, $\mathrm{TL}_{\mathrm{tn}}$ is the total land area of the building and $\mathrm{N}_{\mathrm{tn}}$ is the total number of units in the building for unit $\mathrm{n}$ sold in period $\mathrm{t}$. The first method of land share imputation is used by the Japanese land tax authorities. The second method of imputation implicitly assumes that each unit can enjoy the use of the entire land area and so an equal share of land for each unit seems "fair".

There is a problem with the definition of $\mathrm{L}_{\mathrm{Stn}}$ in (67): the floor space "share" of unit $\mathrm{n}$, $\mathrm{S}_{\mathrm{tn}} / \mathrm{TS}_{\mathrm{tn}}$ if summed over all units in the building would be less than 1 because the privately held floor space of each unit in the building does not account for shared building floor spaces such as halls, elevators, storage spaces, furnace rooms and other "public" floor spaces, which are included in total building floor space, $\mathrm{TS}_{\mathrm{tn}}$. Thus the "share" $\mathrm{S}_{\mathrm{tn}} / \mathrm{TS}_{\mathrm{tn}}$ must be adjusted upward by some percentage to account for these shared building facilities. ${ }^{90}$ In what follows, it is assumed that this adjustment has been made to $\mathrm{S}_{\mathrm{tn}}$ (so that $\mathrm{S}_{\mathrm{tn}}$ is now interpreted as adjusted condo floor space area).

In order to obtain sensible decompositions of the condominium selling price into land and structure components, it may be necessary to assume a structure value and focus on the determinants of land value at the initial stages of the sequential estimation procedure. Thus following Diewert and Shimizu (2016), assume that the imputed structure value for unit $\mathrm{n}$ in period $\mathrm{t}, \mathrm{V}_{\mathrm{Stn}}$, is defined as follows:

$$
\mathrm{V}_{\mathrm{Stn}} \equiv \mathrm{p}_{\mathrm{St}}(1-\delta)^{\mathrm{A}(\mathrm{t}, \mathrm{n})} \mathrm{S}_{\mathrm{tn}}
$$$$
\mathrm{t}=1, \ldots, \mathrm{T} ; \mathrm{n}=1, \ldots, \mathrm{N}(\mathrm{t})
$$

\footnotetext{
${ }^{90}$ Diewert and Shimizu $(2016$; 303) constructed estimates of Tokyo total building private floor space to total building floor space for each observation nt as $\mathrm{N}_{\mathrm{tn}} \mathrm{S}_{\mathrm{tn}} / \mathrm{TS}_{\mathrm{tn}}$, where $\mathrm{N}_{\mathrm{tn}}$ is the number of units in the building which contained condo sale $n$ in period $t, S_{t n}$ is the private floor space of the sold unit and $\mathrm{TS}_{\mathrm{tn}}$ is the total floor space of the building. The sample wide average of these ratios was 0.899. Thus the first imputation method in definitions (67) was changed from $\mathrm{L}_{\mathrm{Stn}} \equiv\left(\mathrm{S}_{\mathrm{tn}} / \mathrm{TS}_{\mathrm{tn}}\right) \mathrm{TL}_{\mathrm{tn}}$ to $\mathrm{L}_{\mathrm{Stn}} \equiv$ $(1 / 0.899)\left(\mathrm{S}_{\mathrm{tn}} / \mathrm{TS}_{\mathrm{tn}}\right) \mathrm{TL}_{\mathrm{tn}}=(1.1)\left(\mathrm{S}_{\mathrm{tn}} / \mathrm{TS}_{\mathrm{tn}}\right) \mathrm{TL}_{\mathrm{tn}}$. Burnett-Issacs, Huang and Diewert (2016) estimated a similar condo model and consulted with construction experts and determined that on average, the ratio of total space to private space for Ottawa condominium apartments was approximately 1.33 . Thus they changed $\mathrm{L}_{\mathrm{Stn}} \equiv\left(\mathrm{S}_{\mathrm{tn}} / \mathrm{TS}_{\mathrm{tn}}\right) \mathrm{TL}_{\mathrm{tn}}$ to $\mathrm{L}_{\mathrm{Stn}} \equiv(1.33)\left(\mathrm{S}_{\mathrm{tn}} / \mathrm{TS}_{\mathrm{tn}}\right) \mathrm{TL}_{\mathrm{tn}}$.
} 
where $\delta$ is an assumed geometric depreciation rate. ${ }^{91}$ Once the imputed value of the structure has been defined by (68), the imputed land value for condo $\mathrm{n}$ in period $\mathrm{t}, \mathrm{V}_{\mathrm{Ltn}}$, is defined by subtracting the imputed structure value from the total value of the condo unit, which is $\mathrm{V}_{\mathrm{tn}}$ :

$$
\mathrm{V}_{\mathrm{Ltn}} \equiv \mathrm{V}_{\mathrm{tn}}-\mathrm{V}_{\mathrm{Stn}}
$$$$
\mathrm{t}=1, \ldots, \mathrm{T} ; \mathrm{n}=1, \ldots, \mathrm{N}(\mathrm{t}) .
$$

In the hedonic regressions which follow immediately, the imputed value of land for the condominium unit, $\mathrm{V}_{\mathrm{Ltn}}$, is used as the dependent variable in a hedonic regression. The following regressions explain variations in these imputed land values in terms of the property characteristics.

Suppose that the postal code of each sale is also available and there are $\mathbf{J}$ postal codes. Then one can introduce the following postal code dummy variables, $\mathrm{D}_{\mathrm{PC}, \mathrm{tn}, \mathrm{j}}$, as explanatory variables into a hedonic regression. Define these J dummy variables using definitions (54) in the previous section and estimate the following hedonic regression which is a land counterpart to the hedonic regression defined by (55) in the previous section: are defined as follows:

$$
\mathrm{V}_{\mathrm{Ltn}}=\alpha_{\mathrm{t}}\left(\sum_{\mathrm{j}=1}^{\mathrm{J}} \omega_{\mathrm{j}} \mathrm{D}_{\mathrm{PC}, \mathrm{tn}, \mathrm{j}}\right) \mathrm{L}_{\mathrm{Stn}}+\varepsilon_{\mathrm{tn}}
$$$$
\mathrm{t}=1, \ldots, \mathrm{T} ; \mathrm{n}=1, \ldots, \mathrm{N}(\mathrm{t}) \text {. }
$$

Note that the imputed value of land, $\mathrm{V}_{\mathrm{Ltn}}$ defined by (69), replaces total property value $\mathrm{V}_{\mathrm{tn}}$ which was the dependent variable in (55). ${ }^{92}$

It is likely that the height of the building (number of stories) increases the value of the land plot supporting the building, all else equal. Thus define the number of stories dummy variables, $\mathrm{D}_{\mathrm{NS}, \mathrm{tn}, \mathrm{s}}$, as follows: $\mathrm{t}=1, \ldots, \mathrm{T} ; \mathrm{n}=1, \ldots, \mathrm{N}(\mathrm{t}) ; \mathrm{s}=1, \ldots, \mathrm{NS}$ :

(71) $\mathrm{D}_{\mathrm{NS}, \mathrm{tn}, \mathrm{s}} \equiv 1$ if observation $\mathrm{n}$ in period $\mathrm{t}$ is in a building with s stories ; $\equiv 0$ if observation $\mathrm{n}$ in period $\mathrm{t}$ is not in building with s stories.

The new nonlinear regression model is the following one:

$$
\mathrm{V}_{\mathrm{Ltn}}=\alpha_{\mathrm{t}}\left(\sum_{\mathrm{j}=1}^{\mathrm{J}} \omega_{\mathrm{j}} \mathrm{D}_{\mathrm{PC}, \mathrm{tn}, \mathrm{j}}\right)\left(\sum_{\mathrm{s}=1}{ }^{\mathrm{NS}} \chi_{\mathrm{s}} \mathrm{D}_{\mathrm{NS}, \mathrm{tn}, \mathrm{S}}\right) \mathrm{L}_{\mathrm{Stn}}+\varepsilon_{\mathrm{tn}} ; \quad \mathrm{t}=1, \ldots, \mathrm{T} ; \mathrm{n}=1, \ldots, \mathrm{N}(\mathrm{t}) \text {. }
$$

Comparing the models defined by equations (70) and (72), it can be seen that an additional NS building height parameters, $\chi_{1}, \ldots, \chi_{\mathrm{NS}}$, have been added to the model defined by (70). ${ }^{93}$ As usual, the models defined by (70) and (72) are nested so that the

\footnotetext{
${ }^{91}$ Diewert and Shimizu (2016) assumed $\delta=0.03$ and Burnett-Isaacs, Huang and Diewert (2016) assumed $\delta$ $=0.02$ where the age variable $\mathrm{A}_{\mathrm{tn}}$ is measured in years. Later, $\delta$ will be estimated.

${ }^{92}$ As usual, we need a normalization on the parameters such as $\alpha_{1}=1$ in order to identify all of the remaining parameters, $\alpha_{2}, \ldots, \alpha_{\mathrm{T}}, \omega_{1}, \ldots, \omega_{\mathrm{J}}$. Note that this regression uses the first method of land imputation defined by (67). Later, the second method will also be considered.

93 Again normalizations like $\alpha_{1} \equiv 1 ; \chi_{1} \equiv 1$ are required in order to identify the remaining parameters. If all $\chi_{\mathrm{s}}=1$, then the model defined by (72) collapses down to the model defined by (70).
} 
finishing parameter values from the nonlinear regression (70) can be used as starting values for (72) along with the starting values $\chi_{1}=\chi_{2}=\ldots=\chi_{\mathrm{NS}}=1$.

The higher up a unit is, the better is the view on average and so it could be expected that the price of the unit increases as its height increases. The quality of the structure probably does not increase as the height of the unit increases so it seems reasonable to impute the height premium as an adjustment to the land price component of the unit.

It is possible to introduce the height of the unit (the $\mathrm{H}$ variable) as a categorical variable (like the number of stories NS in the last hedonic regression model). However, both Diewert and Shimizu (2016) (hereafter DS) and Burnett-Isaacs, Huang and Diewert (2016) (hereafter BHD) found that this dummy variable approach could be replaced by using $\mathrm{H}$ as a continuous variable with little change in the fit of the model. Thus the new nonlinear regression model is the following one where $t=1, \ldots, T ; n=1, \ldots, N(t)$ :

$$
\mathrm{V}_{\mathrm{Ltn}}=\alpha_{\mathrm{t}}\left(\sum_{\mathrm{j}=1}^{\mathrm{J}} \omega_{\mathrm{j}} \mathrm{D}_{\mathrm{PC}, \mathrm{tn}, \mathrm{j}}\right)\left(\sum_{\mathrm{s}=1}{ }^{\mathrm{NS}} \chi_{\mathrm{s}} \mathrm{D}_{\mathrm{NS}, \mathrm{tn}, \mathrm{s}}\right)\left(1+\gamma\left(\mathrm{H}_{\mathrm{tn}}-3\right)\right) \mathrm{L}_{\mathrm{Stn}}+\varepsilon_{\mathrm{tn}}
$$

where $\mathrm{H}_{\mathrm{tn}}$ is the height of the sold unit $\mathrm{n}$ in period $\mathrm{t}$ (measured in number of stories from ground level) and $\gamma$ is a height of the unit parameter to be estimated. ${ }^{94}$ The above model assumes that the lowest height for the units sold in the sample was $\mathrm{H}_{\mathrm{tn}}=3$. Thus for all the observations that correspond to the sold unit being located on the third floor of the building, the new parameter $\gamma$ in (73) will not affect the predicted value in the regression. However, for heights of the sold units that were greater than 3 , the regression implies that the land value will increase by $\gamma$ for each story that is above $3 .^{95}$

As was mentioned earlier, there are two simple methods for imputing the share of the building's total land area to the sold unit. Up until now, we have used the first method of imputation defined by (67) which set the share of total land imputed to unit $\mathrm{n}$ in period $\mathrm{t}$, $\mathrm{L}_{\mathrm{Stn}}$, equal to $\left(\mathrm{S}_{\mathrm{tn}} / \mathrm{TS}_{\mathrm{tn}}\right) \mathrm{TL}_{\mathrm{tn}}$ whereas the second method set $\mathrm{L}_{\mathrm{Ntn}}$ equal to $\left(1 / \mathrm{N}_{\mathrm{tn}}\right) \mathrm{TL}_{\mathrm{tn}}$. In the next model, the land imputation for unit $\mathrm{n}$ in period $\mathrm{t}$ is set equal to a weighted average of the two imputation methods and the best fitting weight, $\lambda$, is estimated. Thus define:

$$
\mathrm{L}_{\mathrm{tn}}(\lambda)=\left[\lambda\left(\mathrm{S}_{\mathrm{tn}} / \mathrm{TS}_{\mathrm{tn}}\right)+(1-\lambda)\left(1 / \mathrm{N}_{\mathrm{tn}}\right)\right] \mathrm{TL}_{\mathrm{tn}} ; \quad \mathrm{t}=1, \ldots, \mathrm{T} ; \mathrm{n}=1, \ldots, \mathrm{N}(\mathrm{t})
$$

The new nonlinear regression model is the following one where $t=1, \ldots, T ; n=1, \ldots, N(t)$ and $\mathrm{L}_{\mathrm{tn}}(\lambda)$ is defined by (74)..$^{96}$ :

(75) $\mathrm{V}_{\mathrm{Ltn}}=\alpha_{\mathrm{t}}\left(\sum_{\mathrm{j}=1}^{\mathrm{J}} \omega_{\mathrm{j}} \mathrm{D}_{\mathrm{PC}, \mathrm{tn}, \mathrm{j}}\right)\left(\sum_{\mathrm{s}=1}^{\mathrm{NS}} \chi_{\mathrm{s}} \mathrm{D}_{\mathrm{NS}, \mathrm{tn}, \mathrm{s}}\right)\left(1+\gamma\left(\mathrm{H}_{\mathrm{tn}}-3\right)\right) \mathrm{L}_{\mathrm{tn}}(\lambda)+\varepsilon_{\mathrm{tn}}$.

\footnotetext{
${ }^{94}$ Normalizations like $\alpha_{1} \equiv 1 ; \chi_{1} \equiv 1$ need to be imposed in order to identify the remaining parameters.

${ }^{95}$ The studies that have implemented this model found that the estimated $\gamma$ was in the $2-4 \%$ range. Thus the imputed land value of a unit increases by 2 to $4 \%$ for each story above the threshold level of 3 .

${ }^{96}$ For the DS Tokyo condo data, the estimated $\lambda$ turned out to be $\lambda^{*}=0.3636(t=9.84)$ so that the very simple land imputation method that just divided the total land plot size by the number of units in the building got a higher weight $(0.6364)$ than the weight for the floor space allocation method (0.3636). For the Ottawa condo data, the estimated $\lambda$ turned out to be $\lambda^{*}=0.2525(t=12.10)$.
} 
Conditional on the land area of the building, one would expect the sold unit's land imputation value to increase as the number of units in the building increases. Thus one could use the total number of units in the building, $\mathrm{N}_{\mathrm{tn}}$, as a quality adjustment variable for the imputed land value of a condo unit. DS introduced this variable as a continuous variable. The smallest number of units in the buildings in their sample was 11 . Thus they introduced the term $1+\kappa\left(\mathrm{N}_{\mathrm{tn}}-11\right)$ as an explanatory term in the nonlinear regression. The new parameter $\kappa$ is the percentage increase in the unit's imputed value of land as the number of units in the building grows by one unit. The new nonlinear regression model is the following one where $\mathrm{t}=1, \ldots, \mathrm{T} ; \mathrm{n}=1, \ldots, \mathrm{N}(\mathrm{t})$ and $\mathrm{L}_{\mathrm{tn}}(\lambda)$ is defined by $(74)$ :

$$
\mathrm{V}_{\mathrm{Ltn}}=\alpha_{\mathrm{t}}\left(\sum_{\mathrm{j}=1}^{\mathrm{J}} \omega_{\mathrm{j}} \mathrm{D}_{\mathrm{PC}, \mathrm{tn}, \mathrm{j}}\right)\left(\sum_{\mathrm{s}=1}{ }^{\mathrm{NS}} \chi_{\mathrm{s}} \mathrm{D}_{\mathrm{NS}, \mathrm{tn}, \mathrm{s}}\right)\left(1+\gamma\left(\mathrm{H}_{\mathrm{tn}}-3\right)\right)\left(1+\kappa\left(\mathrm{N}_{\mathrm{tn}}-11\right)\right) \mathrm{L}_{\mathrm{tn}}(\lambda)+\varepsilon_{\mathrm{tn}}
$$

where $\mathrm{L}_{\mathrm{tn}}(\lambda)$ is defined by (74).

The next explanatory variable to be introduced into the hedonic regression model is one which is not obvious but turned out to be very significant in the regressions run by DS and BHD. The footprint of a building is the area of the land that directly supports the structure. An approximation to the footprint land for unit $\mathrm{n}$ in period $\mathrm{t}$ is the total structure area $\mathrm{TS}_{\mathrm{tn}}$ divided by the total number of stories in the structure $\mathrm{TH}_{\mathrm{tn}}$. If footprint land is subtracted from the total land area, $\mathrm{TL}_{\mathrm{tn}}$, the resulting variable is excess land, ${ }^{97}$ $\mathrm{EL}_{\mathrm{tn}}$, defined as follows:

(77) $\mathrm{EL}_{\mathrm{tn}} \equiv \mathrm{TL}_{\mathrm{tn}}-\left(\mathrm{TS}_{\mathrm{tn}} / \mathrm{TH}_{\mathrm{tn}}\right)$

$$
\mathrm{t}=1, \ldots, \mathrm{T} ; \mathrm{n}=1, \ldots, \mathrm{N}(\mathrm{t}) \text {. }
$$

In the Tokyo data used by DS, excess land ranged from $47 \mathrm{~m}^{2}$ to $2912 \mathrm{~m}^{2}$. Now group the sample observations into $M$ categories, depending on the amount of excess land that pertained to each observation. Group 1 consists of observations tn where $\mathrm{EL}_{\mathrm{tn}}$ is less than some number $\mathrm{EL}_{1}$; Group 2: observations such that $\mathrm{EL}_{1} \leq \mathrm{EL}_{\mathrm{tn}}<\mathrm{EL}_{2} ; \ldots$; Group $\mathrm{M}$ : $\mathrm{EL}_{\mathrm{M}-1} \leq \mathrm{EL}_{\mathrm{tn}}$. The break points, $\mathrm{EL}_{1}, \mathrm{EL}_{2}, \ldots, \mathrm{EL}_{\mathrm{M}-1}$ should be chosen so that the number of observations in each group is approximately equal. Define the excess land dummy variables, $\mathrm{D}_{\mathrm{EL}, \mathrm{tn}, \mathrm{m}}$, as follows for $\mathrm{t}=1, \ldots, \mathrm{T} ; \mathrm{n}=1, \ldots, \mathrm{N}(\mathrm{t}) ; \mathrm{m}=1, \ldots, \mathrm{M}$ :

(78) $\mathrm{D}_{\mathrm{EL}, \mathrm{tn}, \mathrm{m}} \equiv 1$ if observation $\mathrm{n}$ in period $\mathrm{t}$ is in excess land group $\mathrm{m}$; $\equiv 0$ if observation $\mathrm{n}$ in period $\mathrm{t}$ is not in excess land group $\mathrm{m}$.

The new regression model is the following one:

$$
\begin{aligned}
\mathrm{V}_{\mathrm{Ltn}}= & \alpha_{\mathrm{t}}\left(\sum_{\mathrm{j}=1}^{\mathrm{J}} \omega_{\mathrm{j}} \mathrm{D}_{\mathrm{PC}, \mathrm{tn}, \mathrm{j}}\right)\left(\sum_{\mathrm{s}=1}^{\mathrm{NS}} \chi_{\mathrm{s}} \mathrm{D}_{\mathrm{NS}, \mathrm{tn}, \mathrm{s}}\right)\left(\sum_{\mathrm{m}=1}^{\mathrm{M}} \mu_{\mathrm{m}} \mathrm{D}_{\mathrm{EL}, \mathrm{tn}, \mathrm{m}}\right) \times \\
& \left(1+\gamma\left(\mathrm{H}_{\mathrm{tn}}-3\right)\right)\left(1+\kappa\left(\mathrm{N}_{\mathrm{tn}}-11\right)\right) \mathrm{L}_{\mathrm{tn}}(\lambda)+\varepsilon_{\mathrm{tn}} ; \quad \mathrm{t}=1, \ldots, \mathrm{T} ; \mathrm{n}=1, \ldots, \mathrm{N}(\mathrm{t}) .
\end{aligned}
$$

Not all of the parameters in (79) can be identified so the following normalizations on the parameters in (79) are imposed:

\footnotetext{
${ }^{97}$ This is land that is usable for purposes other than the direct support of the structure on the land plot.
} 
(80)

$$
\alpha_{1} \equiv 1 ; \chi_{1} \equiv 1 ; \mu_{1} \equiv 1
$$

Introducing the excess land dummy variables led to huge jumps in the log likelihoods for the hedonic regressions run by DS and BHS: 1020 for DS and 2652 for BHS. ${ }^{98}$ Both studies found that the estimated $\mu_{\mathrm{m}}$ were positive but their magnitudes decreased monotonically as the excess land variable increased.

There are three additional explanatory variables that were used by DS that may affect the price of land. Define TW as the walking time in minutes to the nearest subway station; TT as the subway running time in minutes to the Central Tokyo station from the nearest station and the SOUTH dummy variable is set equal to 1 if the sold condo unit faces south and 0 otherwise. Let $\mathrm{D}_{\mathrm{S}, \mathrm{n}, 2}$ equal the SOUTH dummy variable for sale $\mathrm{n}$ in period $\mathrm{t}$. Define $D_{S, t n, 2}=1-D_{S, t n, 1}$. In the Tokyo data set used by DS, TW ranged from 1 to 19 minutes while TT ranged from 12 to 48 minutes. These new variables are inserted into the previous nonlinear regression model (79) in the following manner for $\mathrm{t}=1, \ldots, \mathrm{T} ; \mathrm{n}=$ $1, \ldots, N(t)$ :

$$
\begin{aligned}
\mathrm{V}_{\mathrm{Ltn}}= & \alpha_{\mathrm{t}}\left(\sum_{\mathrm{j}=1}^{\mathrm{J}} \omega_{\mathrm{j}} \mathrm{D}_{\mathrm{PC}, \mathrm{tn}, \mathrm{j}}\right)\left(\sum_{\mathrm{s}=1}^{\mathrm{NS}} \chi_{\mathrm{s}} \mathrm{D}_{\mathrm{NS}, \mathrm{tn}, \mathrm{s}}\right)\left(\sum_{\mathrm{m}=1}^{\mathrm{M}} \mu_{\mathrm{m}} \mathrm{D}_{\mathrm{EL}, \mathrm{tn}, \mathrm{m}}\right)\left(\phi_{1} \mathrm{D}_{\mathrm{S}, \mathrm{tn}, 1}+\phi_{2} \mathrm{D}_{\mathrm{S}, \mathrm{tn}, 2}\right) \\
& \times\left(1+\gamma\left(\mathrm{H}_{\mathrm{tn}}-3\right)\right)\left(1+\kappa\left(\mathrm{N}_{\mathrm{tn}}-11\right)\right)\left(1+\eta\left(\mathrm{TW}_{\mathrm{tn}}-1\right)\right)\left(1+\theta\left(\mathrm{TT}_{\mathrm{tn}}-12\right)\right) \mathrm{L}_{\mathrm{tn}}(\lambda)+\varepsilon_{\mathrm{tn}}
\end{aligned}
$$

where $\mathrm{L}_{\mathrm{tn}}(\lambda)$ is defined by (74). Not all of the parameters in (81) can be identified so the following normalizations (82) are imposed on the parameters in (81):

$$
\alpha_{1} \equiv 1 ; \chi_{1} \equiv 1 ; \mu_{1} \equiv 1 ; \phi_{1} \equiv 1
$$

Using the DS Tokyo data, the $\mathrm{R}^{2}$ for this model turned out to be 0.6308 and the $\log$ likelihood increased by 406 points over the log likelihood of the previous model defined by (79) for the addition of 3 new parameters. The estimated parameters had the expected signs and had reasonable magnitudes.

At this point, DS concluded that the imputed land value for each condominium in their sample was predicted reasonably well by the hedonic regression defined by (81) and (82). Thus in the following regression, they switched from using the imputed land value $V_{\text {Ltn }}$ defined by (69) as the dependent variable in the regressions to using the actual selling price of the property, $\mathrm{V}_{\mathrm{tn}}$. They used the specification for the land component of the property that that is defined by (81) and (82) but they also added the structure term $\mathrm{p}_{\mathrm{St}}(1$ $-\delta)^{\mathrm{A}(\mathrm{t}, \mathrm{n})} \mathrm{S}_{\mathrm{tn}}$ to account for the structure component of the value of the condo unit. Note that the annual depreciation rate $\delta$ is now estimated by the new hedonic regression model, rather than assuming that it was equal to $3 \%$. Thus the number of unknown parameters in

\footnotetext{
${ }^{98}$ Recall the hedonic regression model defined by (59) in the previous section which introduced linear splines on the valuation of the land area of a stand alone housing unit. This introduction also greatly increased the log likelihood of the regression. In the present context, the excess land dummy variables take the place of the linear spline functions in (59).
} 
the new model increased by 1 . They used the estimated values for the coefficients in (81) as starting values in this new nonlinear regression. ${ }^{99}$

Using their Tokyo data, DS found that the $\mathrm{R}^{2}$ for this new model was 0.8190 and the estimated depreciation rate was $\delta^{*}=0.0367(\mathrm{t}=27.1)$. Note that the $\mathrm{R}^{2}$ is satisfactory; i.e., the new model explains a substantial fraction of the variation in condo prices.

DS and BHD introduced some additional explanatory variables as quality adjusting variables for the imputed value of structures. DS introduced the number of bedrooms and the type of building as quality adjusters for the value of the structure. BHD introduced the number of bedrooms, the number of bathrooms, the presence of balconies, the use of natural gas as the heating fuel and whether there was commercial space in the building as additional variables that could determine the value of the structure. These variables were significant explanatory variables but the overall $\mathrm{R}^{2}$ for the final hedonic regression did not increase by a large amount with the addition of these variables to the regression. The details may be found in Diewert and Shimizu (2016) and Burnett-Isaacs, Huang and Diewert (2016).

Once the final hedonic regression has been run, the sequence of land prices is given by $\alpha_{1}$, $\alpha_{2}, \ldots, \alpha_{\mathrm{T}}$ and the sequence of condo structure prices is given by the exogenous structure price indexes, $\mathrm{p}_{\mathrm{S} 1}, \mathrm{p}_{\mathrm{S} 2}, \ldots, \mathrm{p}_{\mathrm{ST}}$. To obtain overall property price indexes for sales of condos, form the following counterparts to equations (64) and (65) in the previous section to obtain an estimate of period $t$ condo land value, $\mathrm{V}_{\mathrm{Lt}}$, and estimated period $\mathrm{t}$ structure value, $\mathrm{V}_{\mathrm{St}}$, for $\mathrm{t}=1, \ldots, \mathrm{T}$ :

$$
\begin{aligned}
& \text { (83) } \mathrm{V}_{\mathrm{Lt}} \equiv \sum_{\mathrm{n} \in \mathrm{N}(\mathrm{t})} \quad \alpha_{\mathrm{t}}\left(\sum_{\mathrm{j}=1}^{\mathrm{J}} \omega_{\mathrm{j}} \mathrm{D}_{\mathrm{PC}, \mathrm{tn}, \mathrm{j}}\right)\left(\sum_{\mathrm{s}=1}^{\mathrm{NS}} \chi_{\mathrm{s}} \mathrm{D}_{\mathrm{NS}, \mathrm{tn}, \mathrm{s}}\right)\left(\sum_{\mathrm{m}=1}^{\mathrm{M}} \mu_{\mathrm{m}} \mathrm{D}_{\mathrm{EL}, \mathrm{tn}, \mathrm{m}}\right) \\
& \times\left(\phi_{1} \mathrm{D}_{\mathrm{S}, \mathrm{tn}, 1}+\phi_{2} \mathrm{D}_{\mathrm{S}, \mathrm{tn}, 2}\right)\left(1+\gamma\left(\mathrm{H}_{\mathrm{tn}}-3\right)\right)\left(1+\kappa\left(\mathrm{N}_{\mathrm{tn}}-11\right)\right)\left(1+\eta\left(\mathrm{TW}_{\mathrm{tn}}-1\right)\right)\left(1+\theta\left(\mathrm{TT}_{\mathrm{tn}}-12\right)\right) \mathrm{L}_{\mathrm{tn}}(\lambda) ; \\
& \text { (84) } \mathrm{V}_{\mathrm{St}} \equiv \sum_{\mathrm{n} \in \mathrm{N}(\mathrm{t})} \mathrm{p}_{\mathrm{St}}(1-\delta)^{\mathrm{A}(\mathrm{t}, \mathrm{n})} \mathrm{S}_{\mathrm{tn}} .
\end{aligned}
$$

Using the prices $\alpha_{1}, \alpha_{2}, \ldots, \alpha_{\mathrm{T}}$ and the corresponding estimated land values, $\mathrm{V}_{\mathrm{L} 1}, \ldots, \mathrm{V}_{\mathrm{LT}}$ and the prices $\mathrm{p}_{\mathrm{S} 1}, \mathrm{p}_{\mathrm{S} 2}, \ldots, \mathrm{p}_{\mathrm{ST}}$ and the corresponding estimated structure values, $\mathrm{V}_{\mathrm{S} 1}, \ldots, \mathrm{V}_{\mathrm{ST}}$, one can again apply normal index number theory using these data to construct Laspeyres, Paasche, Fisher or whatever index formula is being used by the statistical agency in order to construct constant quality price and quantity overall property indexes for the sales of condominium units in the area under consideration for the T periods.

In summary: the builder's model can be modified to apply to the sales of condominium units and reasonable decompositions of property value into land and structure components can be obtained. However, the nonlinear regressions that are required in order to implement the model end up being rather complex. In addition, information on

\footnotetext{
${ }^{99}$ Attempting to estimate the parameters in (83) without good starting values for the nonlinear regression will not lead to sensible parameter estimates. Thus it is necessary to obtain good starting values for (83) by estimating the rather long sequence of regressions explained above, starting with a very simple model and gradually introducing additional explanatory variables. Each regression in the sequence contains the previous one as a special case so that the final estimates of one regression can be used as starting values for the subsequent one.
} 
more characteristics of the condominium properties needs to be collected in order to implement the models. The information that is required in order to estimate the final model and calculate (83) and (84) is as follows:

- The selling prices of the condominium properties in the sample $\left(\mathrm{P}_{\mathrm{tn}}\right)$;

- The age of the structure on the property $\left(\mathrm{A}_{\mathrm{tn}}\right)$;

- The total area of the land plot $\left(\mathrm{TL}_{\mathrm{tn}}\right)$;

- The floor space area of the condo unit $\left(\mathrm{S}_{\mathrm{tn}}\right)$;

- The total floor space area of the entire building $\left(\mathrm{TS}_{\mathrm{tn}}\right)$;

- The neighbourhood of the property (or the postal code);

- An exogenous structure price index which provides the construction cost of a new structure per meter squared or per square foot $\left(\mathrm{p}_{\mathrm{St}}\right)$;

- The number of stories of the building $\left(\mathrm{NS}_{\mathrm{tn}}\right)$;

- The height of the sold unit (the number of stories from ground level) $\left(\mathrm{H}_{\mathrm{tn}}\right)$;

- The number of units in the building $\left(\mathrm{N}_{\mathrm{tn}}\right)$;

- The walking time in minutes to the nearest subway station $\left(\mathrm{TW}_{\mathrm{tn}}\right)$ and

- The subway running time in minutes to the city center from the nearest station $\left(\mathrm{TT}_{\mathrm{tn}}\right)$.

The last two variables are not essential (and are not relevant in small towns and cities). Other non-essential variables which could be useful are the number of bedrooms, the number of bathrooms, the existence of balconies, the type of construction, the number of parking spaces and so on.

The hedonic regression models that were considered in the last two sections are essentially modified supply side models. In the following section, demand side hedonic regressions are considered.

\section{Demand Side Property Price Hedonic Regressions}

A way of rationalizing the traditional log price time dummy hedonic regression model for properties with varying amounts of land area $L$ and constant quality structure area $S^{*}$ is that the utility that these properties yield to consumers is proportional to the CobbDouglas utility function $\mathrm{L}^{\alpha} \mathrm{S}^{* \beta}$ where $\alpha$ and $\beta$ are positive parameters (which do not necessarily sum to one). ${ }^{100}$ Initially, assume that the constant quality structure area $S^{*}$ is equal to the floor space area of the structure, $\mathrm{S}$, times an age adjustment, $(1-\delta)^{\mathrm{A}}$, where $\mathrm{A}$ is the age of the structure in years and $\delta$ is a positive depreciation rate that is less than 1 . Thus $\mathrm{S}^{*}$ is related to $\mathrm{S}$ as follows:

$(85) S^{*} \equiv S(1-\delta)^{A}$

\footnotetext{
${ }^{100}$ The early analysis in this section follows that of McMillen (2003; 289-290), Shimizu, Nishimura and Watanabe (2010a; 795) and Diewert, Huang and Burnett-Isaacs (2017). McMillen assumed that $\alpha+\beta=1$. We follow Shimizu, Nishimura and Watanabe in allowing $\alpha$ and $\beta$ to be unrestricted.
} 
In any given time period $t$, assume that the sale price of transacted property $n, V_{t n}$, with the amount of land $\mathrm{L}_{\mathrm{tn}}$ and the amount of quality adjusted structure $\mathrm{S}_{\mathrm{tn}}{ }^{*}$ is equal to the following expression:

$$
\begin{aligned}
\mathrm{V}_{\mathrm{tn}} & =\mathrm{p}_{\mathrm{t}} \mathrm{L}_{\mathrm{t}}{ }^{\alpha} \mathrm{S}_{\mathrm{t}}{ }^{* \beta} \\
& =\mathrm{p}_{\mathrm{t}} \mathrm{L}_{\mathrm{tn}}{ }^{\alpha}\left[\mathrm{S}_{\mathrm{tn}}(1-\delta)^{\mathrm{A}(\mathrm{t}, \mathrm{n})}\right]^{\beta} \\
& =\mathrm{p}_{\mathrm{t}} \mathrm{L}_{\mathrm{tn}}{ }^{\alpha}{ }^{\beta} \mathrm{S}_{\mathrm{tn}}{ }^{\beta}(1-\delta)^{\beta A(\mathrm{t}, \mathrm{n})} \\
& =\mathrm{p}_{\mathrm{t}} \mathrm{L}_{\mathrm{tn}}{ }^{\alpha}{ }^{\beta} \mathrm{S}_{\mathrm{tn}}{ }^{\beta} \phi^{\mathrm{A}(\mathrm{t}, \mathrm{n})}
\end{aligned}
$$

where $\mathrm{A}(\mathrm{t}, \mathrm{n})=\mathrm{A}_{\mathrm{tn}}$ is the age of house $\mathrm{n}$ sold in period $\mathrm{t}, \mathrm{p}_{\mathrm{t}}$ can be interpreted as a period $t$ property price index and the constant $\phi$ is defined as follows:

(87) $\phi \equiv(1-\delta)^{\beta}$.

Thus if $\mathrm{V}_{\mathrm{tn}}$ is deflated by the period t property price index $\mathrm{p}_{\mathrm{t}}$, the real value or utility $\mathrm{u}_{\mathrm{tn}}$ of the property with characteristics $\mathrm{L}_{\mathrm{tn}}$ and $\mathrm{S}_{\mathrm{tn}}{ }^{*}$ is obtained:

(88) $\mathrm{V}_{\mathrm{tn}} / \mathrm{p}_{\mathrm{t}}=\mathrm{L}_{\mathrm{tn}}{ }^{\alpha} \mathrm{S}_{\mathrm{tn}}{ }^{*} \equiv \mathrm{u}_{\mathrm{tn}}$.

Thus $\mathrm{u}_{\mathrm{tn}} \equiv \mathrm{q}_{\mathrm{t}}$ is the aggregate real value of the property with characteristics $\mathrm{L}_{\mathrm{tn}}$ and $\mathrm{S}_{\mathrm{tn}}{ }^{*}$.

Define $\rho_{\mathrm{t}}$ as the logarithm of $\mathrm{p}_{\mathrm{t}}$ and $\gamma$ as the logarithm of $\phi$; i.e.,

(89) $\rho_{\mathrm{t}} \equiv \ln p_{\mathrm{t}} ; \gamma \equiv \ln \phi$.

After taking logarithms of both sides of the first equation in (88), using definitions (85) and (89) and adding error terms, the following system of estimating equations is obtained: ${ }^{101}$

(90) $\ln \mathrm{V}_{\mathrm{tn}}=\rho_{\mathrm{t}}+\alpha \operatorname{lnL} \mathrm{L}_{\mathrm{tn}}+\beta \ln \mathrm{S}_{\mathrm{tn}}+\gamma \mathrm{A}_{\mathrm{tn}}+\varepsilon_{\mathrm{tn}} ;$

$\mathrm{t}=1, \ldots, \mathrm{T} ; \mathrm{n}=1, \ldots, \mathrm{N}(\mathrm{t})$

where the $\varepsilon_{\text {tn }}$ are independently distributed error terms with 0 means and constant variances. It can be seen that (90) is a traditional log price time dummy hedonic regression model with a minimal number of characteristics. The unknown parameters in (90) are the constant quality log property prices, $\rho_{1}, \ldots, \rho_{\mathrm{T}}$, and the taste parameters $\alpha, \beta$ and the transformed depreciation rate $\gamma$. Once these parameters have been determined, the geometric depreciation rate $\delta$ which appears in equations (86) can be recovered from the regression parameter estimates as follows:

(91) $\delta \equiv 1-\mathrm{e}^{\gamma / \beta}$.

We now explain how the hedonic pricing model defined by (86) can be manipulated to provide a decomposition of property value in period $t$ into land and quality adjusted structure components.

${ }^{101} \log$ price hedonic regressions for property prices date back to Bailey, Muth and Nourse (1963). 
Once estimates for $\alpha, \beta$ and $\delta$ have been obtained, define period t value of a property with characteristics $\mathrm{L}_{\mathrm{tn}}$ and $\mathrm{S}_{\mathrm{tn}}{ }^{*}$ is given by the following period t property valuation function by the right hand side of (86); i.e., define $\mathrm{V}\left(\mathrm{p}_{\mathrm{t}}, \mathrm{L}_{\mathrm{tn}}, \mathrm{S}_{\mathrm{tn}}{ }^{*}\right) \equiv \mathrm{p}_{\mathrm{t}} \mathrm{L}_{\mathrm{tn}}{ }^{\alpha} \mathrm{S}_{\mathrm{tn}}{ }^{* \beta}$. In empirical applications of the hedonic regression model defined by (90), it will often happen that estimates for $\alpha$ and $\beta$ are such that $\alpha+\beta$ is less than $1 .^{102}$ This means that a property in a given period that has double the land and quality adjusted structure than another property will sell for less than double the price of the smaller property. This follows from the fact that the Cobb-Douglas hedonic utility function, $u\left(L, S^{*}\right) \equiv L^{\alpha} S^{* \beta}$, exhibits diminishing returns to scale when $\alpha+\beta<1$; i.e., we have:

(92) $\mathrm{u}\left(\lambda \mathrm{L}, \lambda \mathrm{S}^{*}\right)=\lambda^{\alpha+\beta} \mathrm{u}\left(\mathrm{L}, \mathrm{S}^{*}\right)$

for all $\lambda>0$. This behavior is roughly consistent with our builder's Models 5-7 where there was a tendency for property prices to increase less than proportionally as $\mathrm{L}$ and $\mathrm{S} *$ increased.

The marginal prices of land and constant quality structure in period t for a property with characteristics $\mathrm{L}$ and $\mathrm{S}^{*}, \pi_{\mathrm{L}}\left(\mathrm{p}_{\mathrm{t}}, \mathrm{L}, \mathrm{S}^{*}\right)$ and $\pi_{\mathrm{S}^{*}}\left(\mathrm{p}_{\mathrm{t}}, \mathrm{L}, \mathrm{S}^{*}\right)$, are defined by partially differentiating the property valuation function with respect to $L$ and $S^{*}$ respectively:

$$
\begin{aligned}
& \pi_{\mathrm{L}}\left(\mathrm{p}_{\mathrm{t}}, \mathrm{L}_{\mathrm{tn}}, \mathrm{S}_{\mathrm{tn}}{ }^{*}\right) \equiv \partial \mathrm{V}\left(\mathrm{p}_{\mathrm{t}}, \mathrm{L}_{\mathrm{tn}}, \mathrm{S}_{\mathrm{tn}}{ }^{*}\right) / \partial \mathrm{L} \equiv \mathrm{p}_{\mathrm{t}} \alpha \mathrm{L}_{\mathrm{tn}}{ }^{\alpha} \mathrm{S}_{\mathrm{tn}}{ }^{*} \beta / \mathrm{L}_{\mathrm{tn}}=\alpha \mathrm{V}\left(\mathrm{p}_{\mathrm{t}}, \mathrm{L}_{\mathrm{tn}}, \mathrm{S}_{\mathrm{tn}}{ }^{*}\right) / \mathrm{L}_{\mathrm{tn}} ; \\
& \pi_{\mathrm{S}}^{*}\left(\mathrm{p}_{\mathrm{t}}, \mathrm{L}_{\mathrm{tn}}, \mathrm{S}_{\mathrm{tn}}{ }^{*}\right) \equiv \partial \mathrm{V}\left(\mathrm{p}_{\mathrm{t}}, \mathrm{L}_{\mathrm{tn}}, \mathrm{S}_{\mathrm{tn}}{ }^{*}\right) / \partial \mathrm{S}^{*} \equiv \mathrm{p}_{\mathrm{t}} \beta \mathrm{L}_{\mathrm{tn}}{ }^{\alpha} \mathrm{S}_{\mathrm{tn}}{ }^{*} / \mathrm{S}_{\mathrm{tn}}{ }^{*}=\beta \mathrm{V}\left(\mathrm{p}_{\mathrm{t}}, \mathrm{L}_{\mathrm{tn}}, \mathrm{S}_{\mathrm{tn}}{ }^{*}\right) / \mathrm{S}_{\mathrm{tn}}{ }^{*} \text {. }
\end{aligned}
$$

Multiply the marginal price of land by the amount of land in the property and add to this value of land the product of the marginal price of constant quality structure by the amount of constant quality structure on the property in order to obtain the following identity:

$$
(\alpha+\beta) \mathrm{V}\left(\mathrm{p}_{\mathrm{t}}, \mathrm{L}_{\mathrm{tn}}, \mathrm{S}_{\mathrm{tn}}{ }^{*}\right)=\pi_{\mathrm{L}}\left(\mathrm{p}_{\mathrm{t}}, \mathrm{L}_{\mathrm{tn}}, \mathrm{S}_{\mathrm{tn}}{ }^{*}\right) \mathrm{L}_{\mathrm{tn}}+\pi_{\mathrm{S}}{ }^{*}\left(\mathrm{p}_{\mathrm{t}}, \mathrm{L}_{\mathrm{tn}}, \mathrm{S}_{\mathrm{tn}}{ }^{*}\right) \mathrm{S}_{\mathrm{tn}}{ }^{*}
$$

If $\alpha+\beta$ is less than one, then using marginal prices to value the land and constant quality structure in a property will lead to a property valuation that is less than its selling price. Thus to make the land and structure components of property value add up to property value, divide the marginal prices defined by (93) and (94) by $\alpha+\beta$ in order to obtain the following adjusted prices of land and structures for property $n$ sold in period $t$, $\mathrm{p}_{\mathrm{tL}}\left(\mathrm{p}_{\mathrm{t}}, \mathrm{L}_{\mathrm{tn}}, \mathrm{S}_{\mathrm{tn}}{ }^{*}\right)$ and $\mathrm{p}_{\mathrm{t} \mathrm{s} *}\left(\mathrm{p}_{\mathrm{t}}, \mathrm{L}_{\mathrm{tn}}, \mathrm{S}_{\mathrm{tn}}{ }^{*}\right)$ :

(96) $\mathrm{p}_{\mathrm{tL}}\left(\mathrm{p}_{\mathrm{t}}, \mathrm{L}_{\mathrm{tn}}, \mathrm{S}_{\mathrm{tn}}{ }^{*}\right) \equiv \pi_{\mathrm{L}}\left(\mathrm{p}_{\mathrm{t}}, \mathrm{L}_{\mathrm{tn}}, \mathrm{S}_{\mathrm{tn}}{ }^{*}\right) /(\alpha+\beta)=\alpha(\alpha+\beta)^{-1} \mathrm{~V}\left(\mathrm{p}_{\mathrm{t}}, \mathrm{L}_{\mathrm{tn}}, \mathrm{S}_{\mathrm{tn}}{ }^{*}\right) / \mathrm{L}_{\mathrm{tn}}$;

(97) $\mathrm{p}_{\mathrm{t} \mathrm{S}^{*}}\left(\mathrm{p}_{\mathrm{t}}, \mathrm{L}_{\mathrm{tn}}, \mathrm{S}_{\mathrm{tn}}{ }^{*}\right) \equiv \pi_{\mathrm{S}^{*}}\left(\mathrm{p}_{\mathrm{t}}, \mathrm{L}_{\mathrm{tn}}, \mathrm{S}_{\mathrm{tn}}{ }^{*}\right) /(\alpha+\beta)=\beta(\alpha+\beta)^{-1} \mathrm{~V}\left(\mathrm{p}_{\mathrm{t}}, \mathrm{L}_{\mathrm{tn}}, \mathrm{S}_{\mathrm{tn}}{ }^{*}\right) / \mathrm{S}_{\mathrm{tn}}{ }^{*}$.

The above material outlines a theoretical framework that can generate a decomposition of property value into land and structure components using the results of a traditional log price time dummy hedonic regression model. To complete the analysis, it is necessary to

\footnotetext{
${ }^{102}$ See for example the estimated model in Diewert, Huang and Burnett-Isaacs (2017).
} 
fill in the details of how the individual property land and structure prices that are generated by the model can be aggregated into period t overall land and structure price indexes.

Run the hedonic regression model defined by (90). Define the constant quality property price index $\mathrm{p}_{\mathrm{t}}$ for period $\mathrm{t}$ as follows:

(98) $\mathrm{p}_{\mathrm{t}} \equiv \exp \left(\rho_{\mathrm{t}}\right)$;

$\mathrm{t}=1, \ldots, \mathrm{T}$.

Define the geometric depreciation rate $\delta$ by (91). Once $\delta$ has been defined, the amount of quality adjusted structure for property $\mathrm{n}$ in period $\mathrm{t}, \mathrm{S}_{\mathrm{tn}}{ }^{*}$ is defined as follows:

(99) $\ln \left(\mathrm{S}_{\mathrm{tn}}{ }^{*}\right) \equiv \ln \left(\mathrm{S}_{\mathrm{tn}}\right)+\mathrm{A}_{\mathrm{tn}} \ln (1-\delta)$; $\mathrm{t}=1, \ldots, \mathrm{T} ; \mathrm{n}=1, \ldots, \mathrm{N}(\mathrm{t})$.

Now that $\mathrm{p}_{\mathrm{t}}, \mathrm{L}_{\mathrm{tn}}, \mathrm{S}_{\mathrm{tn}}{ }^{*}, \alpha$ and $\beta$ have all been defined, we use these data in order to define the predicted prices for property $\mathrm{n}$ sold in period $\mathrm{t}, \mathrm{V}_{\mathrm{tn}}{ }^{*}$ :

(100) $\mathrm{V}_{\mathrm{tn}}^{*} \equiv \mathrm{p}_{\mathrm{t}}\left(\mathrm{L}_{\mathrm{tn}}\right)^{\alpha}\left(\mathrm{S}_{\mathrm{tn}}^{*}\right)^{\beta}$ $\mathrm{t}=1, \ldots, \mathrm{T} ; \mathrm{n}=1, \ldots, \mathrm{N}(\mathrm{t})$.

Use equations (96) and (97) in order to define constant quality land and structure prices for sold property $\mathrm{n}$ in period $\mathrm{t}, \mathrm{p}_{\mathrm{tnL}}$ and $\mathrm{p}_{\mathrm{tnS}}$, as follows:

(101) $\mathrm{p}_{\mathrm{tnL}} \equiv \alpha(\alpha+\beta)^{-1} \mathrm{~V}_{\mathrm{tn}}{ }^{*} / \mathrm{L}_{\mathrm{tn}}$;

(102) $\mathrm{p}_{\mathrm{tn} \mathrm{S}^{*}} \equiv \beta(\alpha+\beta)^{-1} \mathrm{~V}_{\mathrm{tn}}{ }^{*} / \mathrm{S}_{\mathrm{tn}}{ }^{*}$;

$$
\begin{aligned}
& \mathrm{t}=1, \ldots, \mathrm{T} ; \mathrm{n}=1, \ldots, \mathrm{N}(\mathrm{t}) \\
& \mathrm{t}=1, \ldots, \mathrm{T} ; \mathrm{n}=1, \ldots, \mathrm{N}(\mathrm{t}) .
\end{aligned}
$$

Finally, unit value constant quality land and structure prices for all properties sold in period $\mathrm{t}, \mathrm{p}_{\mathrm{tL}}$ and $\mathrm{p}_{\mathrm{t}} *$, are defined as follows:

(103) $\mathrm{p}_{\mathrm{tL}} \equiv \sum_{\mathrm{n}=1}{ }^{\mathrm{N}(\mathrm{t})} \mathrm{p}_{\mathrm{tnL}} \mathrm{L}_{\mathrm{tn}} / \Sigma_{\mathrm{n}=1}{ }^{\mathrm{N}(\mathrm{t})} \mathrm{L}_{\mathrm{tn}}$

(104) $\mathrm{p}_{\mathrm{t} \mathrm{S}^{*}} \equiv \sum_{\mathrm{n}=1}{ }^{\mathrm{N}(\mathrm{t})} \mathrm{p}_{\mathrm{tn} \mathrm{S}^{*}} \mathrm{~S}_{\mathrm{tn}}{ }^{*} / \sum_{\mathrm{n}=1}{ }^{\mathrm{N}(\mathrm{t})} \mathrm{S}_{\mathrm{tn}}{ }^{*}$;

$\mathrm{t}=1, \ldots, \mathrm{T}$

$\mathrm{t}=1, \ldots, \mathrm{T}$.

The period t land and structure prices that are defined by (103) and (104) are reasonable summary statistic prices for land and structures sold in period that are generated by the log price time dummy hedonic regression model defined by (90).

The time dummy log price hedonic regression model defined by (90) will generate very different constant quality land and structure subindexes when compared to the corresponding indexes estimated by the builder's model. To see this, suppose the same house $\mathrm{n}$ sold in period $\mathrm{t}$ and sold again in the following period $\mathrm{t}+1$. The period $\mathrm{t}$ data for this house are $\mathrm{V}_{\mathrm{tn}}{ }^{*}, \mathrm{~L}_{\mathrm{tn}}$ and $\mathrm{S}_{\mathrm{tn}}{ }^{*}$ while the period $\mathrm{t}+1$ data are $\mathrm{V}_{\mathrm{t}+1 \mathrm{n}}{ }^{*}, \mathrm{~L}_{\mathrm{t}+1 \mathrm{n}}=\mathrm{L}_{\mathrm{tn}}$ and $\mathrm{S}_{\mathrm{t}+1 \mathrm{n}}{ }^{*}=$ $(1-\delta) \mathrm{S}_{\mathrm{tn}}{ }^{*}$. Use definitions $(101)$ and (102) for this house for periods $t$ and $t+1$ and calculate the following land and structure inflation rates for this house going from period $\mathrm{t}$ to period $\mathrm{t}+1$ :

(105) $\mathrm{p}_{\mathrm{t}+1 \mathrm{~nL}} / \mathrm{p}_{\mathrm{tnL}}=\left[\alpha(\alpha+\beta)^{-1} \mathrm{~V}_{\mathrm{t}+1 \mathrm{n}}{ }^{*} / \mathrm{L}_{\mathrm{tn}}\right] /\left[\alpha(\alpha+\beta)^{-1} \mathrm{~V}_{\mathrm{tn}}{ }^{*} / \mathrm{L}_{\mathrm{tn}}\right] \quad=\mathrm{V}_{\mathrm{t}+1 \mathrm{n}}{ }^{*} / \mathrm{V}_{\mathrm{tn}}^{*}$; (106) $\mathrm{p}_{\mathrm{t}+1 \mathrm{nS}} * / \mathrm{p}_{\mathrm{tn} S^{*}}=\left[\beta(\alpha+\beta)^{-1} \mathrm{~V}_{\mathrm{t}+1 \mathrm{n}}{ }^{*} /(1-\delta) \mathrm{S}_{\mathrm{tn}}{ }^{*}\right] /\left[\beta(\alpha+\beta)^{-1} \mathrm{~V}_{\mathrm{tn}}{ }^{*} / \mathrm{S}_{\mathrm{tn}}{ }^{*}\right]=(1-\delta)^{-1}\left(\mathrm{~V}_{\mathrm{t}+1 \mathrm{n}}{ }^{*} / \mathrm{V}_{\mathrm{tn}}{ }^{*}\right)$. 
Thus (one plus) the imputed land inflation rate, $\mathrm{p}_{\mathrm{t}+\mathrm{ln} /} / \mathrm{p}_{\mathrm{tnL}}$, will equal (one plus) the growth in property value, $\mathrm{V}_{\mathrm{t}+1 \mathrm{n}}{ }^{*} / \mathrm{V}_{\mathrm{tn}}{ }^{*}$, and (one plus) the imputed constant quality structure inflation rate, $\mathrm{p}_{\mathrm{t}+\operatorname{lnS} S^{*}} / \mathrm{p}_{\mathrm{tnS}} S^{*}$, will equal $(1-\delta)^{-1}\left(\mathrm{~V}_{\mathrm{t}+\ln }{ }^{*} / \mathrm{V}_{\mathrm{tn}}{ }^{*}\right)$. Hence if $\delta$ is small, then the land and structure inflation rates will be almost identical and approximately equal to (one plus) the growth rate for overall property value. Thus the constant quality price indexes for land and structures will move in an almost proportional manner. In most countries, the price of land will grow much more rapidly than the price of structures so the hedonic regression model defined by (90) is not suitable for finding usable land price indexes for residential housing.

However, the hedonic regression model defined by (90) (and its generalizations) can generate very reasonable overall constant quality property price indexes, provided that the model generates a plausible estimate for the structure depreciation rate. To see why this result might occur, a highly simplified comparison of a builder's model and the log price traditional hedonic regression model studied in this section will be undertaken below.

Consider the valuation of a representative property in periods 1 and 2 using both the builders model and the traditional hedonic regression model explained in this section. In period 1 , the quantity of land and constant quality structure is $\mathrm{L}_{1}$ and $\mathrm{S}_{1}{ }^{*}$ with total property value equal to $V_{1}$. In period 2 , the quantity of land and constant quality structure is $\mathrm{L}_{2}=\left(1+\mathrm{g}_{\mathrm{L}}\right) \mathrm{L}_{1}$ and $\mathrm{S}_{2}{ }^{*}=\left(1+\mathrm{g}_{\mathrm{S}}\right) \mathrm{S}_{1}{ }^{*}$ with total property value equal to $\mathrm{V}_{2}$. The $\mathrm{L}_{\mathrm{t}}$ and $\mathrm{S}_{\mathrm{t}}{ }^{*}$ are known and hence the growth rates $\mathrm{g}_{\mathrm{L}}$ and $\mathrm{g}_{\mathrm{S}}$ are also known. Using the property valuation function defined by (100), the two properties have the following value decompositions where $\mathrm{p}_{1}$ and $\mathrm{p}_{2}$ are the constant quality property price levels for periods 1 and 2 :

$$
\begin{aligned}
(107) \mathrm{V}_{1} & =\mathrm{p}_{1} \mathrm{~L}_{1}{ }^{\alpha} \mathrm{S}_{1}{ }^{* \beta} ; \\
(108) \mathrm{V}_{2} & =\mathrm{p}_{2} \mathrm{~L}_{2}{ }^{\alpha} \mathrm{S}_{2}{ }^{* \beta} \\
& =\mathrm{p}_{1}(1+\rho)\left[\mathrm{L}_{1}\left(1+\mathrm{g}_{\mathrm{L}}\right)\right]^{\alpha}\left[\mathrm{S}_{1}{ }^{*}\left(1+\mathrm{g}_{\mathrm{S}}\right)\right]^{\beta} \\
& =\mathrm{V}_{1}(1+\rho)\left(1+\mathrm{g}_{\mathrm{L}}\right)^{\alpha}\left(1+\mathrm{g}_{\mathrm{S}}\right)^{\beta} \\
& \approx \mathrm{V}_{1}(1+\rho)\left[\alpha\left(1+\mathrm{g}_{\mathrm{L}}\right)+\beta\left(1+\mathrm{g}_{\mathrm{S}}\right)\right]
\end{aligned}
$$

where $1+\rho=\mathrm{p}_{2} / \mathrm{p}_{1}$

where the last approximate equality follows if $\alpha+\beta=1$ and the geometric mean $\left(1+\mathrm{g}_{\mathrm{L}}\right)^{\alpha}\left(1+\mathrm{g}_{\mathrm{S}}\right)^{\beta}$ is approximated by the corresponding arithmetic mean, $\alpha\left(1+\mathrm{g}_{\mathrm{L}}\right)+$ $\beta\left(1+g_{S}\right)$.

Now use the builder's model to value the same properties. Let $\mathrm{p}_{\mathrm{L} 1}$ and $\mathrm{p}_{\mathrm{L} 2}$ be the price levels for land in periods 1 and 2 and let $p_{\mathrm{S} 1}$ and $\mathrm{p}_{\mathrm{S} 2}$ be the constant quality price levels for structures in periods 1 and 2. The builder's model imputes the following values for the properties in the two periods:

$$
\begin{aligned}
(109) \mathrm{V}_{1} & =\mathrm{p}_{\mathrm{L} 1} \mathrm{~L}_{1}+\mathrm{p}_{\mathrm{S} 1} \mathrm{~S}_{1}{ }^{*} ; \\
(110) \mathrm{V}_{2} & =\mathrm{p}_{\mathrm{L} 2} \mathrm{~L}_{2}+\mathrm{p}_{\mathrm{S} 2} \mathrm{~S}_{2}{ }^{*} \\
& =\mathrm{p}_{\mathrm{L} 1}\left(1+\rho_{\mathrm{L}}\right)\left(1+\mathrm{g}_{\mathrm{L}}\right) \mathrm{L}_{1}+\mathrm{p}_{\mathrm{S} 1}\left(1+\rho_{\mathrm{S}}\right)\left(1+\mathrm{g}_{\mathrm{S}}\right) \mathrm{S}_{1}{ }^{*}
\end{aligned}
$$


where the land and structure constant quality price indexes are defined as $1+\rho_{\mathrm{L}}=\mathrm{p}_{\mathrm{L} 2} / \mathrm{p}_{\mathrm{L} 1}$ and $1+\rho_{\mathrm{S}}=\mathrm{p}_{\mathrm{S} 2} / \mathrm{p}_{\mathrm{S} 1}$. Define the land and structure share of property value in period 1 as $\mathrm{s}_{\mathrm{L} 1} \equiv \mathrm{p}_{\mathrm{L} 1} \mathrm{~L}_{1} / \mathrm{V}_{1}$ and $\mathrm{s}_{\mathrm{S} 1} \equiv \mathrm{p}_{\mathrm{S} 1} \mathrm{~S}_{1}{ }^{*} / \mathrm{V}_{1}$ respectively. The Laspeyres quantity and Paasche price indexes for properties, $\mathrm{Q}_{\mathrm{L}}$ and $\mathrm{P}_{\mathrm{P}}$, are defined as follows:

$$
\text { (111) } \begin{aligned}
\mathrm{Q}_{\mathrm{L}} & \equiv \mathrm{s}_{\mathrm{L} 1}\left(\mathrm{~L}_{2} / \mathrm{L}_{1}\right)+\mathrm{s}_{\mathrm{S} 1}\left(\mathrm{~S}_{2}{ }^{*} / \mathrm{S}_{1}{ }^{*}\right) \\
& =\mathrm{s}_{\mathrm{L} 1}\left(1+\mathrm{g}_{\mathrm{L}}\right)+\mathrm{s}_{\mathrm{S} 1}\left(1+\mathrm{g}_{\mathrm{S}}\right) \\
(112) \mathrm{P}_{\mathrm{P}} & \equiv\left[\mathrm{V}_{2} / \mathrm{V}_{1}\right] / \mathrm{Q}_{\mathrm{L}} \\
& =\left[\mathrm{V}_{2} / \mathrm{V}_{1}\right] /\left[\mathrm{s}_{\mathrm{L} 1}\left(1+\mathrm{g}_{\mathrm{L}}\right)+\mathrm{s}_{\mathrm{S} 1}\left(1+\mathrm{g}_{\mathrm{S}}\right)\right]
\end{aligned}
$$

where the last equality follows using (111). Using (108), we have the following approximate expression for $1+\rho$, which is the property price index generated by the traditional hedonic regression model:

(113) $1+\rho \approx\left[\mathrm{V}_{2} / \mathrm{V}_{1}\right] /\left[\alpha\left(1+\mathrm{g}_{\mathrm{L}}\right)+\beta\left(1+\mathrm{g}_{\mathrm{S}}\right)\right]$

Comparing (112) to (113), it can be seen that the Paasche property price index that is generated by the builder's model, $\mathrm{P}_{\mathrm{P}}$, will be approximately equal to the property price index $1+\rho$ that is generated by a traditional log price time dummy hedonic regression model provided that $\alpha$ is approximately equal to the land share $s_{\mathrm{L} 1}$ and $\beta$ is approximately equal to structure share $\mathrm{s}_{\mathrm{S} 1} \cdot{ }^{103}$ Since the hedonic utility function for the traditional model is Cobb Douglas, this approximate equality is likely to hold. Thus the traditional model is likely to generate approximately the same overall property price indexes as would be generated by the builder's model. ${ }^{104}$

The approximation result in the previous paragraph opens up another possible method for obtaining aggregate land values for residential housing. There are residential property price indexes for many countries that are based on traditional hedonic regression models. Consider such a country that also conducts periodic censuses of housing where owners of residential dwelling units are asked to value their properties. Let the estimated value of housing in periods 1 and $t$ be $\mathrm{V}_{1}$ and $\mathrm{V}_{\mathrm{t}}$. Suppose the aggregate housing price index levels for these two periods are $\mathrm{p}_{1}$ and $\mathrm{p}_{\mathrm{t}}$. Using these data, one can form aggregate volume estimates for residential housing as $\mathrm{q}_{1} \equiv \mathrm{V}_{1} / \mathrm{p}_{1}$ and $\mathrm{q}_{\mathrm{t}} \equiv \mathrm{V}_{\mathrm{t}} / \mathrm{p}_{\mathrm{t}}$. From the country's system of national accounts, it should be possible to obtain estimates for the aggregate price and quantity or volume of residential structures which we denote by $\mathrm{p}_{\mathrm{S} 1}$ and $\mathrm{q}_{\mathrm{S} 1}$ for period 1 and $\mathrm{p}_{\mathrm{St}}$ and $\mathrm{q}_{\mathrm{St}}$ for period t. With these data in hand, aggregate Laspeyres, Paasche and Fisher (1922) price and quantity indexes for residential land can be formed using $\left(\mathrm{p}_{1}, \mathrm{p}_{\mathrm{S} 1}\right)$ and $\left(\mathrm{p}_{\mathrm{t}}, \mathrm{p}_{\mathrm{St}}\right)$ as period 1 and $\mathrm{t}$ price vectors and using $\left(\mathrm{q}_{1},-\mathrm{q}_{\mathrm{S} 1}\right)$ and $\left(\mathrm{q}_{\mathrm{t}},-\mathrm{q}_{\mathrm{St}}\right)$ as period 1 and $\mathrm{t}$ quantity vectors. The resulting land prices $\left(\mathrm{p}_{\mathrm{L} 1}, \mathrm{p}_{\mathrm{Lt}}\right)$ and volumes $\left(\mathrm{q}_{\mathrm{L} 1}, \mathrm{q}_{\mathrm{Lt}}\right)$ would fill a gap in the System of National Accounts for the country.

\footnotetext{
${ }^{103}$ To obtain this approximation result, it is also necessary that the depreciation rate that is estimated by the log price time dummy model be reasonable.

${ }^{104}$ For examples of studies where it was found that this approximate equality held, see Diewert $(2010 ; 21)$, Diewert and Shimizu (2015; 1692) and Diewert, Huang and Burnett-Isaacs $(2017 ; 32)$.
} 
For data series on residential property prices for either the sales of properties or the stock of properties, see the European Central Bank (2018) (which lists 228 series for European countries) and the Bank for International Settlements (2018), which lists long series for 18 advanced economies. For additional information on alternative approaches for the measurement of residential property price indexes for sales of properties and for making estimates for the stock of residential properties, see Statistics Portugal (2009), Eurostat (2013) (2017), Hill (2013), Hill, Scholz, Shimizu and Steurer (2018) and Silver (2018).

\section{Price Indexes for Rental Housing}

At first sight, it would seem that the construction of price indexes for rental housing would be fairly straightforward since typically, rents are paid to owners every month. Thus all that seems to be necessary is to collect information on rents paid (from either the tenants or from the owners), say $R_{t n}$ and $R_{t+1 n}$ for rental unit $n$ in periods $t$ and $t+1$, form the price ratios, $R_{t+1 n} / R_{t n}$, and take a suitable average of these ratios to form a rent index. However, the problem is that the quality of the rental unit does not in general remain constant going from one period to the next due to depreciation of the structure and possible renovations and improvements to the structure. Thus the structure is a unique good in general.

Three procedures for dealing with the above problem will be outlined in this section. The first procedure assumes that the builder's model has been run on sales of dwelling units that could be rented and so asset prices, $\mathrm{P}_{\mathrm{Ltn}}$ and $\mathrm{P}_{\mathrm{Stn}}{ }^{105}$ can be assigned to the land and structure areas, $\mathrm{L}_{\mathrm{tn}}$ and $\mathrm{S}_{\mathrm{tn}}$, that can be imputed for rental dwelling $\mathrm{n}$ in period t. The rental price $\mathrm{R}_{\mathrm{tn}}$ is approximated by the sum of its (end of period) user cost components for land and structures, $\mathrm{p}_{\mathrm{Ltn}}$ and $\mathrm{p}_{\mathrm{Stn}}$ respectively. The geometric model of depreciation for structures is used and the one period depreciation rate is $0<\delta<1$. The depreciation rate for land is 0 . The age of the structure for rental unit $\mathrm{n}$ in period $\mathrm{t}$ is $\mathrm{A}(\mathrm{t}, \mathrm{n})$ periods. Setting the rental price of unit $\mathrm{n}$ in period $\mathrm{t}$ and $\mathrm{t}+1$ to the corresponding user costs leads to the following equations:

$$
\begin{aligned}
& \text { (114) } \mathrm{R}_{\mathrm{tn}}=\mathrm{p}_{\mathrm{Ltn}} \mathrm{L}_{\mathrm{tn}}+\mathrm{p}_{\mathrm{Stn}}(1-\delta)^{\mathrm{A}(\mathrm{t}, \mathrm{n})-1} \mathrm{~S}_{\mathrm{tn}} \text {; } \\
& =\left[r_{t}-i_{L t}\right] P_{L t n} L_{t n}+\left[r_{t}-i_{S t}+\left(1+i_{S t}\right) \delta\right] P_{S t n}(1-\delta)^{A(t, n)-1} S_{t n} ; \\
& \text { (115) } \mathrm{R}_{\mathrm{t}+1 \mathrm{n}}=\mathrm{p}_{\mathrm{Lt}+1 \mathrm{n}} \mathrm{L}_{\mathrm{tn}}+\mathrm{p}_{\mathrm{St}+\ln }(1-\delta)^{\mathrm{A}(\mathrm{t}, \mathrm{n})} \mathrm{S}_{\mathrm{tn}} \text {; } \\
& \mathrm{n}=1, \ldots, \mathrm{N} \\
& =\left[\mathrm{r}_{\mathrm{t}+1}-\mathrm{i}_{\mathrm{Lt}+1}\right] \mathrm{P}_{\mathrm{Lt}+1 \mathrm{n}} \mathrm{L}_{\mathrm{tn}}+\left[\mathrm{r}_{\mathrm{t}+1}-\mathrm{i}_{\mathrm{St}+1}+\left(1+\mathrm{i}_{\mathrm{St}+1}\right) \delta\right] \mathrm{P}_{\mathrm{St}+1 \mathrm{n}}(1-\delta)^{\mathrm{A}(\mathrm{t}, \mathrm{n})} \mathrm{S}_{\mathrm{tn}}
\end{aligned}
$$

where $r_{t}$ is the period $t$ opportunity cost of capital for the owner of the rental unit and $i_{L t}$ and $i_{S t}$ are the land and structure price inflation rates that the owner expects at the beginning of period t. Note that the land and structure areas for unit $\mathrm{n}, \mathrm{L}_{\mathrm{tn}}$ and $\mathrm{S}_{\mathrm{tn}}$, do not change over time since by hypothesis, we are collecting rent information for the same units over time. It is well known in the housing literature that user costs for dwelling

\footnotetext{
${ }^{105} \mathrm{P}_{\mathrm{Stn}}$ is the price of a square meter of new structure of the type used by rental unit $\mathrm{n}$ at the beginning of period $t$.
} 
units are much more volatile than the corresponding rents for the same units. ${ }^{106}$ Thus in order for the rents $\mathrm{R}_{\mathrm{tn}}$ and $\mathrm{R}_{\mathrm{t}+1 \mathrm{n}}$ to approximate their corresponding user costs on the right hand sides of (114) and (115), it is necessary to use a nominal smoothed values for the nominal interest rates $r_{t}$ and particularly for the expected asset inflation rates, $i_{L t}$ and $i_{S t}{ }^{107}$ Note that the quantity of constant quality structure for property $n$ in periods $t$ and $t+1$ are $\mathrm{S}_{\mathrm{tn}}{ }^{*} \equiv(1-\delta)^{\mathrm{A}(\mathrm{t}, \mathrm{n})-1} \mathrm{~S}_{\mathrm{tn}}$ and $\mathrm{S}_{\mathrm{t}+1 \mathrm{n}}{ }^{*} \equiv(1-\delta)^{\mathrm{A}(\mathrm{t}, \mathrm{n})} \mathrm{S}_{\mathrm{tn}}$; i.e., the imputed constant quality amount of structure constant quality quantity declines as time increases. The corresponding constant quality amount of land rent, $\mathrm{L}_{\mathrm{tn}}$, remains constant over all periods when the dwelling unit is rented. To form a constant quality overall price index for rents, calculate Laspeyres, Paasche or Fisher indexes where the price data for periods $t$ and $t+1$ are the vectors $\left[\mathrm{p}_{\mathrm{Lt1}}, \ldots, \mathrm{p}_{\mathrm{LtN}} ; \mathrm{p}_{\mathrm{St} 1}, \ldots, \mathrm{p}_{\mathrm{StN}}\right]$ and $\left[\mathrm{p}_{\mathrm{Lt}+11}, \ldots, \mathrm{p}_{\mathrm{Lt}+1 \mathrm{~N}} ; \mathrm{p}_{\mathrm{St}+11}, \ldots, \mathrm{p}_{\mathrm{St}+1 \mathrm{~N}}\right]$ and the quantity data for periods $\mathrm{t}$ and $\mathrm{t}+1$ are the vectors $\left[\mathrm{L}_{\mathrm{t} 1}, \ldots, \mathrm{L}_{\mathrm{tN}} ;(1-\delta)^{\mathrm{A}(\mathrm{t}, 1)-1} \mathrm{~S}_{\mathrm{t} 1}, \ldots,(1-\delta)^{\mathrm{A}(\mathrm{t}, \mathrm{N})-1} \mathrm{~S}_{\mathrm{tN}}\right]$ and $\left[\mathrm{L}_{\mathrm{t} 1}, \ldots, \mathrm{L}_{\mathrm{tN}} ;(1-\delta)^{\mathrm{A}(\mathrm{t}, 1)} \mathrm{S}_{\mathrm{t} 1}, \ldots,(1-\delta)^{\mathrm{A}(\mathrm{t}, \mathrm{N})} \mathrm{S}_{\mathrm{tN}}\right]$.

If estimates for the price of land for the rented units, $\mathrm{P}_{\mathrm{Ltn}}$, are not available, then with some additional simplifying assumptions, it is possible to turn equations (114) into a system of estimating equations. Thus assume that the price of land and the price of a new structure per $\mathrm{m}^{2}$ is constant across the $\mathrm{N}$ rented properties in each period so that $\mathrm{P}_{\mathrm{Ltn}}=\mathrm{P}_{\mathrm{Lt}}$ and $\mathrm{P}_{\mathrm{Stn}}=\mathrm{P}_{\mathrm{St}}$ for $\mathrm{t}=1, \ldots, \mathrm{T}$. Further assume that the new structure price level for period $\mathrm{t}$ is known so that $\mathrm{P}_{\mathrm{St}}$ is a given exogenous variable. Then equations (114) simplify into the following nonlinear regression model:

(116) $\mathrm{R}_{\mathrm{tn}}=\mathrm{p}_{\mathrm{Lt}} \mathrm{L}_{\mathrm{tn}}+\mu_{\mathrm{t}} \mathrm{P}_{\mathrm{St}}(1-\delta)^{\mathrm{A}(\mathrm{t}, \mathrm{n})-1} \mathrm{~S}_{\mathrm{tn}}$;

$$
\mathrm{n}=1, \ldots, \mathrm{N} ; \mathrm{t}=1, \ldots, \mathrm{T}
$$

where the user cost of land in period $t, p_{L t} \equiv\left[r_{t}-i_{L t}\right] P_{L t}$, is a parameter which is estimated and $\mu_{\mathrm{t}} \equiv\left[\mathrm{r}_{\mathrm{t}}-\mathrm{i}_{\mathrm{St}}+\left(1+\mathrm{i}_{\mathrm{St}}\right) \delta\right]^{108}$ is also a parameter which is estimated for $\mathrm{t}=1, \ldots, \mathrm{T}$. The depreciation parameter $\delta$ is also estimated. ${ }^{109}$ The period t price and quantity vectors generated by this model are $\left[\mathrm{p}_{\mathrm{L} 1}, \ldots, \mathrm{p}_{\mathrm{Lt}} ; \mu_{1} \mathrm{P}_{\mathrm{S} 1}, \ldots, \mu_{\mathrm{t}} \mathrm{P}_{\mathrm{St}}\right]$ and $\left[\mathrm{L}_{\mathrm{t} 1}, \ldots, \mathrm{L}_{\mathrm{tN}} ;(1-\delta)^{\mathrm{A}(\mathrm{t}, 1)-1} \mathrm{~S}_{\mathrm{t} 1}, \ldots\right.$, $\left.(1-\delta)^{\mathrm{A}(\mathrm{t}, \mathrm{N})-1} \mathrm{~S}_{\mathrm{tN}}\right]$ and normal index number theory can be applied to these vectors. Of course, this simple model can be generalized along the same lines as was done in sections 12 and 13 above for the basic builder's model. If the geometric model of depreciation for the structure component of the rental unit is changed to another model of depreciation such as one hoss shay depreciation, then the estimating equations must be modified to suit the alternative depreciation model. Finally, a rolling window approach to this model can be implemented which will allow for gradually changing parameters over time.

\footnotetext{
${ }^{106}$ On this point, see Genesove (2003), Verbrugge (2008), Shimizu, Nishimura and Watanabe (2010b), Diewert and Nakamura (2011), Garner and Verbrugge (2011) and Suzuki, Asami and Shimizu (2018).

${ }^{107}$ The expected land inflation rate $\mathrm{i}_{\mathrm{Lt}}$ should be an average of land price inflation over the past 15 to 25 years to reflect the long holding periods that investors have for rental properties and the high transactions costs of buying and selling properties. Diewert and Fox (2018) used a rolling window annualized 25 year inflation rate for land for the 25 years prior to period t to generate very smooth estimates for the expected land inflation rate in their user costs for land in the US.

${ }^{108} \mu_{\mathrm{t}}$ is also known as a capitalization rate; i.e., it is the ratio of the rental price of the structure to its capital value.

${ }^{109}$ If multicollinearity becomes a problem, it may be necessary to set $\mu_{\mathrm{t}}=\mu$ or assume that that the $\mu_{\mathrm{t}}$ are slowly trending over time.
} 
The second method for dealing with the quality adjustment problems for rents due to the aging of the structure does not require as much information and can be implemented with guesses on the magnitude of a few key parameters. Recall that the market rents for rented unit $\mathrm{n}$ in periods $\mathrm{t}$ and $\mathrm{t}+1$ were defined above by (114) and (115). Define a constant quality rent for unit $\mathrm{n}$ in period $\mathrm{t}+1, \mathrm{R}_{\mathrm{t}+1 \mathrm{n}}{ }^{*}$, as follows:

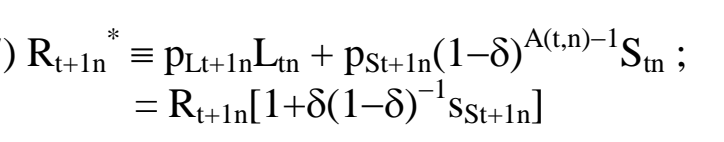

$$
\mathrm{n}=1, \ldots, \mathrm{N}
$$

where $\mathrm{R}_{\mathrm{t}+\mathrm{ln}}$ is the period $\mathrm{t}+1$ market rent for unit $\mathrm{n}$ defined by (115) and $\mathrm{s}_{\mathrm{St}+\mathrm{ln}}$ is the following share of structures in the market rent for unit $\mathrm{n}$ in period $\mathrm{t}+1$ :

$$
\mathrm{S}_{\mathrm{St}+1 \mathrm{n}} \equiv \mathrm{p}_{\mathrm{St}+\ln }(1-\delta)^{\mathrm{A}(\mathrm{t}, \mathrm{n})} \mathrm{S}_{\mathrm{tn}} / \mathrm{R}_{\mathrm{t}+\ln } ; \quad \mathrm{n}=1, \ldots, \mathrm{N} .
$$

Thus $\mathrm{R}_{\mathrm{t}+\ln }{ }^{*} / \mathrm{R}_{\mathrm{tn}}$ is a constant quality rent index for unit $n$ for period $\mathrm{t}+1$ for $\mathrm{n}=1, \ldots, \mathrm{N}$. This index can be calculated if the market rents for both periods, $R_{t n}$ and $R_{t+1 n}$, are known along with the geometric depreciation rate $\delta$ and the imputed share of structures in market rent for unit $\mathrm{n}$ in period $\mathrm{t}+1, \mathrm{~s}_{\mathrm{St}+1 \mathrm{n}}$ defined by (118). Thus if market rents are known and the statistician makes educated guesses on the magnitudes of the geometric depreciation rate $\delta$ and on $\mathrm{s}_{\mathrm{St}+1 \mathrm{n}}$, then $\mathrm{R}_{\mathrm{t}+1 \mathrm{n}}{ }^{*}$ defined by (117) can be calculated as can $1+\delta(1-\delta)^{-1} \mathrm{~S}_{\mathrm{St}+1 \mathrm{n}}$. To form a constant quality price index for rents, calculate the Laspeyres, Paasche or Fisher indexes where the price data for periods $t$ and $t+1$ are the vectors $\left[R_{t 1}, \ldots, R_{t N}\right]$ and $\left[\mathrm{R}_{\mathrm{t} 1}{ }^{*}, \ldots, \mathrm{R}_{\mathrm{tN}}{ }^{*}\right]$ and the quantity data for periods $\mathrm{t}$ and $\mathrm{t}+1$ are the vectors $[1, \ldots, 1]$ and $\left[\left\{1+\delta(1-\delta)^{-1} \mathrm{~S}_{\mathrm{St}+11}\right\}^{-1}, \ldots,\left[\left\{1+\delta(1-\delta)^{-1} \mathrm{~S}_{\mathrm{St}+1 \mathrm{~N}}\right\}^{-1}\right]\right.$. This adjustment to rents for the aging of the units will increase the rental price index for period $\mathrm{t}+1$ and decrease the corresponding quantity index for period $\mathrm{t}+1$ as compared to an index which just assumed that there was no aging bias.

The third method for dealing with the quality adjustment problems for rents due to the aging of the structure is to run a hedonic regression with the logarithm of rents as the dependent variable. Thus recall the demand side hedonic regression for property prices that was described by equations (86)-(91) above. Using these equations, replace the period $t$ selling price for property $n, V_{t n}$, by the observed rent for unit $n$ in period $t, R_{t n}$, and reinterpret the constant quality price for property sales in period $t, \mathrm{p}_{\mathrm{t}}$, as the period $\mathrm{t}$ constant quality price level for rents for the dwelling units in scope. With these changes, the rent counterparts to equations (86) are the following equations:

$$
\text { (119) } \begin{aligned}
\mathrm{V}_{\mathrm{tn}} & =\mathrm{p}_{\mathrm{t}} \mathrm{L}_{\mathrm{tn}}{ }^{\alpha}\left[\mathrm{S}_{\mathrm{tn}}(1-\delta)^{\mathrm{A}(\mathrm{t}, \mathrm{n})}\right]^{\beta} \\
& =\mathrm{p}_{\mathrm{t}} \mathrm{L}_{\mathrm{tn}}{ }^{\alpha} \mathrm{S}_{\mathrm{tn}}{ }^{\beta} \phi^{\mathrm{A}(\mathrm{t}, \mathrm{n})}
\end{aligned}
$$

$$
\mathrm{n}=1, \ldots, \mathrm{N} ; \mathrm{t}=1, \ldots, \mathrm{T}
$$

where $A(t, n)=A_{t n}, L_{t n}$ and $S_{t n}$ are the age, land plot area and floor space area of rental unit $\mathrm{n}$ and the constant $\phi$ is defined as $(1-\delta)^{\beta}$. Define $\rho_{\mathrm{t}}$ as the logarithm of $\mathrm{p}_{\mathrm{t}}$ and $\gamma$ as the logarithm of $\phi$. Take logarithms of both sides of (119) and add error terms in order to obtain the following system of estimating equations:

$$
\text { (120) } \ln R_{\mathrm{tn}}=\rho_{\mathrm{t}}+\alpha \ln \mathrm{L}_{\mathrm{tn}}+\beta \ln \mathrm{S}_{\mathrm{tn}}+\gamma \mathrm{A}_{\mathrm{tn}}+\varepsilon_{\mathrm{tn}} ;
$$

$$
\mathrm{t}=1, \ldots, \mathrm{T} ; \mathrm{n}=1, \ldots, \mathrm{N} .
$$


Once the unknown parameters in the linear regression model (120) have been determined, the geometric depreciation rate $\delta$ which appears in equations (119) can be recovered from the regression parameter estimates as $\delta \equiv 1-\mathrm{e}^{\gamma / \beta}$. The sequence of constant quality rent levels can be recovered as $\mathrm{p}_{\mathrm{t}} \equiv \exp \left[\rho_{\mathrm{t}}\right]$ for $\mathrm{t}=1, \ldots, \mathrm{T}$.

The estimated depreciation rate $\delta$ could equal 0 . In this case, renters do not experience any reduction in the quality of the rented structure as the structure ages. This corresponds to one hoss shay or light bulb depreciation. It this case were to occur, it would imply that the aging bias adjustments made in the above two models are not warranted and the estimating equations for those two models would need to be changed to reflect the one hoss shay depreciation of the structures. However, the available empirical evidence indicates that depreciation rates are positive. ${ }^{110}$

Other explanatory variables could be added to the basic log price time dummy hedonic regression model. ${ }^{111}$ The explanatory variables that were used in sections 12 and 13 could also be added to the present model defined by equations (120).

\section{Valuing the Services of $\mathrm{OOH}$ : User Cost versus Rental Equivalence}

In this section, various factors that cause the user cost of an owned dwelling unit to differ from a rental price for a comparable property will be examined. ${ }^{112}$ In addition, other factors that affect user costs in general will be discussed.

- Utilities such as electricity, water and natural gas may be included in the rent for a dwelling unit that is similar to an owned unit. The net benefit of renting an owned unit should exclude these costs since these expenditures are covered in other categories of a Consumer Price Index.

- When calculating the benefit to the owner of a dwelling unit of renting the unit, there is a problem of determining what is the correct market rental opportunity cost. It turns out that all rents paid in say period t for comparable units to an

\footnotetext{
110 "The average [annual] depreciation rate for rental property is remarkably constant, ranging from $0.58 \%$ to $0.60 \%$ over the 25 year period. Depreciation rates for owner occupied units show more variation than the estimated rates for renter occupied units. The average depreciation rate for owner occupied housing ranges from $0.9 \%$ in year 1 to $0.28 \%$ in year 20 ." Stephen Malpezzi, Larry Ozanne and Thomas G. Thibodeau $(1987 ; 382)$. Note that these depreciation rates are underestimates for the "true" rates since demolition depreciation is not taken into account using this methodology. Put another way, the geometric model of depreciation may not be the "right" model of depreciation for rental housing. A blending of the geometric and one hoss shay models of depreciation may be more appropriate.

${ }^{111}$ For example, see Malpezzi, Ozanne and Thibodeau (1987), Crone, Nakamura and Voith (2000) (2011), Verbrugge (2008), Shimizu, Nishimura and Watanabe (2010a) and Garner and Verbrugge (2011).

${ }^{112}$ Our discussion here is similar to that of Hill, Steurer and Waltl $(2017$; 7): "The services a household obtains from renting a dwelling are not the same as the services obtained by owner-occupying." They consider some additional factors that can cause rents to differ from user costs. They also assert that since $\mathrm{OOH}$ services are derived from both the structure and land, it follows that there is no need to try and separate land from structure in the rental house price index. However, depreciation affects only the structure part of rents and if one attempts to adjust a market rent for this aging factor, it is necessary to apply the depreciation adjustment to only the structure part of rents.
} 
owned unit can be classified into 3 categories: (i) the rental agreement is not being renegotiated during this period; (ii) the rental agreement is renegotiated during this period with the same tenants and (iii) the rental agreement is a new one with new tenants. Typically, there are no escalations of rents for continuing tenants during the leasehold period and often, renegotiated rents with continuing tenants are also sticky; i.e., there is not much change in these renegotiated rents. ${ }^{113}$ For purposes of measuring the net benefit to an owner of renting an owned unit, category (iii) rents should be used as the appropriate comparable market rent. ${ }^{114}$

- Property taxes will be included in market rents and they should also be included in an owner's user cost. However, if property tax payments are treated as a separate category in the CPI, then property taxes should be deducted from the comparable market rents to avoid double counting of these tax expenditures.

- Normal maintenance expenditures on the structure will be part of market rents. These expenditures should be deducted from the comparable market rents since these expenditures by home owners should already be included in other expenditure categories in the CPI. Again, it is necessary to avoid double counting these expenditures. Landlords may also have considerable overhead expenses that are associated with the management of rental properties. These expenses can perhaps be grouped together with maintenance expenditures.

- The structure depreciation rate for rented dwelling units will probably be higher than the rate for comparable owned dwelling units, since owners are likely to take better care of their property and will avoid property damage. This expected difference in the value of depreciation should be deducted from the market rent that is applied to a comparable owned home.

- The owners of rental properties need to charge a small premium to the rents that they receive from rented units in order to cover the loss of rental income due to vacancies. This vacancy premium does not apply to the user cost of an owned unit and thus the comparable market rent for an owned unit should be adjusted downward to account for this vacancy factor.

- Insurance payments are included in market rents. However, in the CPI, insurance payments may be included in another category so in this case, the imputed insurance premiums should be deducted from the market rent that is applied to a comparable owned home.

- The opportunity cost of capital for a landlord and for an owner may be different. In particular, the owner of a house may be risk averse and have a very low opportunity cost of capital. A landlord who rents properties to tenants will have to include a risk premium in his or her cost of capital to account for possible downturns in the rental market.

\footnotetext{
${ }^{113}$ On the stickiness of rents, see Shimizu, Nishimura and Watanabe (2010b), Lewis and Restieaux (2015; 72-75), Suzuki, Asami and Shimizu (2018) and Hill, Steurer and Waltl (2017; 9). Lewis and Restieaux label their three categories as (i) Occupied Let, (ii) Renewal and (iii) New Let. Their category (i) is a stock measure that includes all occupied rental units while their categories (ii) and (iii) match up with categories (ii) and (iii) in the text above. Rents in categories (ii) and (iii) may be subject to rent controls which means that rents in these categories do not reflect current opportunity costs.

${ }^{114}$ However, when constructing a rental price index for renters, rents for all 3 categories should be used.
} 
Consider the user cost formula for a dwelling unit that was defined by the right hand side of (114) in section 15. Using the same notation for property $\mathrm{n}$, define period t property value for property $n$ as:

(121) $\mathrm{V}_{\mathrm{tn}} \equiv \mathrm{P}_{\mathrm{Ltn}} \mathrm{L}_{\mathrm{tn}}+\mathrm{P}_{\mathrm{Stn}}(1-\delta)^{\mathrm{A}(\mathrm{t}, \mathrm{n})-1} \mathrm{~S}_{\mathrm{tn}}$

$\mathrm{n}=1, \ldots, \mathrm{N}$.

Define the period $t$, property $n$ share of property land value as $\mathrm{s}_{\mathrm{Ltn}} \equiv \mathrm{P}_{\mathrm{Ltn}} \mathrm{L}_{\mathrm{tn}} / \mathrm{V}_{\mathrm{tn}}$ and the share for constant quality structure as $\mathrm{S}_{\mathrm{Stn}} \equiv \mathrm{P}_{\mathrm{Stn}}(1-\delta)^{\mathrm{A}(\mathrm{t}, \mathrm{n})-1} \mathrm{~S}_{\mathrm{tn}} / \mathrm{V}_{\mathrm{tn}}$ for $\mathrm{n}=1, \ldots, \mathrm{N}$. The using (114) and the above definitions the ratio of user cost to property value (or the implied rent capitalization ratio) can be written as follows:

$$
\mathrm{R}_{\mathrm{tn}} / \mathrm{V}_{\mathrm{tn}}=\left[\mathrm{r}_{\mathrm{t}}-\mathrm{i}_{\mathrm{Lt}}\right] \mathrm{s}_{\mathrm{Ltn}}+\left[\mathrm{r}_{\mathrm{t}}-\mathrm{i}_{\mathrm{St}}+\left(1+\mathrm{i}_{\mathrm{St}}\right) \delta\right] \mathrm{s}_{\mathrm{Stn}} ; \quad \mathrm{n}=1, \ldots, \mathrm{N}
$$

Recall that $r_{t}$ is a smoothed longer term opportunity cost of capital for period $t, i_{L t}$ is the long term expected land price inflation rate, $i_{S t}$ is a long term expected structure price inflation rate and $\delta$ is the geometric structure depreciation rate. The rent to capital value ratio defined by (122) or capitalization rate ${ }^{115}$ does not take into account the complications that were discussed above. Thus it is necessary to modify (122) to take into account these complications. Define $v_{t}$ as the period t rate of expected loss of rental income due to vacancies (as a fraction of period $t$ capital value), define $\mathrm{m}_{\mathrm{tn}}$ as expected period $\mathrm{t}$ maintenance and overhead expenditures for property $\mathrm{n}$ divided by the corresponding period $t$ structure value, ${ }^{116}$ define the land tax rate $\tau_{\mathrm{Ltn}}$ as the ratio of land taxes paid by the owners of property $n$ in period $t$ to the imputed land value $P_{L t n} L_{t n}$ and the structure tax rate $\tau_{\mathrm{Stn}}$ as the ratio of structure property taxes paid in period $\mathrm{t}$ for property $n$ to imputed structure value, $\mathrm{P}_{\mathrm{Stn}}(1-\delta)^{\mathrm{A}(\mathrm{t}, \mathrm{n})-1} \mathrm{~S}_{\mathrm{tn}}$. Finally define $\pi_{\mathrm{tn}}$ as the ratio of insurance payments made in period $t$ by property $n$ to imputed structure value, $P_{S t n}$ $(1-\delta)^{\mathrm{A}(\mathrm{t}, \mathrm{n})-1} \mathrm{~S}_{\mathrm{tn}}$. Using the above discussion on complications to the standard user cost model, it can be seen that a more meaningful rent to value ratio decomposition for property $n$ in period $t$ is given by the following modification of (122) for $n=1, \ldots, N$ :

$$
\mathrm{R}_{\mathrm{tn}} / \mathrm{V}_{\mathrm{tn}}=\left[\mathrm{r}_{\mathrm{t}}-\mathrm{i}_{\mathrm{Lt}}+\mathrm{v}_{\mathrm{t}}+\tau_{\mathrm{Ltn}}\right] \mathrm{s}_{\mathrm{Ltn}}+\left[\mathrm{r}_{\mathrm{t}}-\mathrm{i}_{\mathrm{St}}+\left(1+\mathrm{i}_{\mathrm{St}}\right) \delta+\mathrm{v}_{\mathrm{t}}+\tau_{\mathrm{Stn}}+\mathrm{m}_{\mathrm{tn}}+\pi_{\mathrm{tn}}\right] \mathrm{s}_{\mathrm{Stn}}
$$

If property tax payments are not a separate category in the CPI, then the appropriate user cost for an owner of property $\mathrm{n}$ in period $\mathrm{t}, \mathrm{U}_{\mathrm{tn}}$, as a fraction of property value, $\mathrm{V}_{\mathrm{tn}}$, is equal to the following expression:

$$
\mathrm{U}_{\mathrm{tn}} / \mathrm{V}_{\mathrm{tn}}=\left[\mathrm{r}_{\mathrm{t}}-\mathrm{i}_{\mathrm{Lt}}+\tau_{\mathrm{Ltn}}\right] \mathrm{s}_{\mathrm{Ltn}}+\left[\mathrm{r}_{\mathrm{t}}-\mathrm{i}_{\mathrm{St}}+\left(1+\mathrm{i}_{\mathrm{St}}\right) \delta+\tau_{\mathrm{Stn}}\right] \mathrm{s}_{\mathrm{Stn}}
$$

\footnotetext{
${ }^{115}$ Crone, Nakamura and Voith (2000) used hedonic techniques to estimate both a rent index and a selling price index for housing in the U.S. They also suggested that capitalization rates (i.e., the ratio of the market rent of a housing property to its selling price) can be applied to an index of housing selling prices in order to obtain an imputed rent index for $\mathrm{OOH}$. As will be shown below, capitalization rates are functions of many variables, some of which can change considerably over time. Also it will be seen that capitalization rates for rented houses are not exactly appropriate as estimators for capitalization rates for owned houses.

${ }^{116}$ Older structures will probably have higher $\mathrm{m}_{\mathrm{tn}}$ ratios.
} 
Note that the terms $\mathrm{v}_{\mathrm{t}}, \mathrm{m}_{\mathrm{tn}}$ and $\pi_{\mathrm{tn}}$ have been dropped from (124). Thus the differences between (123) and (124) are equal to the following expressions for $n=1, \ldots, N$ :

$$
\mathrm{R}_{\mathrm{tn}} / \mathrm{V}_{\mathrm{tn}}-\mathrm{U}_{\mathrm{tn}} / \mathrm{V}_{\mathrm{tn}}=\mathrm{v}_{\mathrm{t}}+\left[\mathrm{m}_{\mathrm{tn}}+\pi_{\mathrm{tn}}\right] \mathrm{s}_{\mathrm{Stn}}
$$

Thus looking at (125), it can be seen that simply applying the rent of a comparable rented dwelling unit to an owned unit will overstate the appropriate user cost that should be applied to the owned unit. However, the above computations did not take into account the likelihood that the depreciation rate for a rental property is greater than the corresponding depreciation rate for a similar owned property. Thus let $\delta_{\mathrm{O}}$ be the depreciation rate for an owned property and suppose that $0<\delta_{O}<\delta$ where $\delta$ is the depreciation rate for a comparable rented property. Rewriting (123) in absolute form rather than in ratio form leads to the following expression for the user cost value of rented property $n$ in period $t$ :

$$
\mathrm{R}_{\mathrm{tn}}=\left[\mathrm{r}_{\mathrm{t}}-\mathrm{i}_{\mathrm{Lt}}+\mathrm{v}_{\mathrm{t}}+\tau_{\mathrm{Ltn}}\right] \mathrm{P}_{\mathrm{Ltn}} \mathrm{L}_{\mathrm{tn}}+\left[\mathrm{r}_{\mathrm{t}}-\mathrm{i}_{\mathrm{St}}+\left(1+\mathrm{i}_{\mathrm{St}}\right) \delta+\mathrm{v}_{\mathrm{t}}+\tau_{\mathrm{Stn}}+\mathrm{m}_{\mathrm{tn}}+\pi_{\mathrm{tn}}\right] \mathrm{P}_{\mathrm{Stn}}(1-\delta)^{\mathrm{A}(\mathrm{t}, \mathrm{n})-1} \mathrm{~S}_{\mathrm{tn}}
$$

Taking into account that the depreciation rate is different, the corresponding user cost of a similar owned property $\mathrm{n}$ in period $\mathrm{t}$ is the following one:

$$
\mathrm{U}_{\mathrm{tn}}=\left[\mathrm{r}_{\mathrm{t}}-\mathrm{i}_{\mathrm{Lt}}+\tau_{\mathrm{Ltn}}\right] \mathrm{P}_{\mathrm{Ltn}} \mathrm{L}_{\mathrm{tn}}+\left[\mathrm{r}_{\mathrm{t}}-\mathrm{i}_{\mathrm{St}}+\left(1+\mathrm{i}_{\mathrm{St}}\right) \delta_{\mathrm{O}}+\tau_{\mathrm{Stn}}\right] \mathrm{P}_{\mathrm{Stn}}\left(1-\delta_{\mathrm{O}}\right)^{\mathrm{A}(\mathrm{t}, \mathrm{n})-1} \mathrm{~S}_{\mathrm{tn}}
$$

If $\delta_{\mathrm{O}}$ is considerably smaller than $\delta$, then $\mathrm{P}_{\mathrm{Stn}}\left(1-\delta_{\mathrm{O}}\right)^{\mathrm{A}(\mathrm{t}, \mathrm{n})-1} \mathrm{~S}_{\mathrm{tn}}$ will be considerably larger than $\mathrm{P}_{\mathrm{Stn}}(1-\delta)^{\mathrm{A}(\mathrm{t}, \mathrm{n})-1} \mathrm{~S}_{\mathrm{tn}}$ and thus in this case, it is likely that $\mathrm{U}_{\mathrm{tn}}$ will be larger than $\mathrm{R}_{\mathrm{tn}}$ for older properties. Thus the rental equivalence imputation for the services of a comparable owned unit could be considerably smaller than the corresponding imputed long run user cost for the owned unit. ${ }^{117}$

The user cost formulae defined by (124)-(127) look rather complicated and they require information that may not be available to the statistician. Thus additional assumptions may have to be made which allow approximate user costs for owned dwelling units to be calculated. In situations where equivalent rental prices are not available, this may be the only feasible method to value the services of $\mathrm{OOH}$. For example, the European Union issued the following regulation in 2005 that gives guidance in forming estimates of the services of $\mathrm{OOH}$ when equivalent rental prices are not available:

"Under the user-cost method, the output of dwelling services is the sum of intermediate consumption, consumption of fixed capital (CFC), other taxes less subsidies on production and net operating surplus (NOS). For owner occupied dwellings, no labour input is recorded for work done by the owners (1). Experience suggests that CFC and NOS are the two largest items, each representing 30 to $40 \%$ of output. CFC should be calculated based on a perpetual inventory model (PIM) or other approved methods. A separate estimate for the owner-occupied residential buildings should be available.

The net operating surplus should be measured by applying a constant real annual rate of return of $2.5 \%$ to the net value of the stock of owner-occupied dwellings at current prices (replacement costs). The real rate of return of $2.5 \%$ is applied to the value of the stock at current prices since the increase in current value of dwellings is already taken account of in the PIM. The same rate of return should be applied to the value of the land at current prices on which the owner-occupied dwellings are located.

${ }^{117}$ The algebra will be different for different models of depreciation but the same conclusion will follow. 
The value of land at current prices may be difficult to observe annually. Ratios of land value to the value of buildings in different strata may be derived from an analysis of the composition of the costs of new houses and associated land." Eurostat (2005).

To value the services of $\mathrm{OOH}$ in Iceland, the highly simplified user cost formula $\mathrm{U}_{\mathrm{t}}=\left(\mathrm{r}_{\mathrm{t}}{ }^{*}\right.$ $+\delta) \mathrm{P}_{\mathrm{t}}$ was used where $\mathrm{U}_{\mathrm{t}}$ is the period t property user cost, $\mathrm{r}_{\mathrm{t}}{ }^{*}$ is a real interest rate (varied between $3.6 \%$ and $4.3 \%$ ), $\delta$ is a property depreciation rate (set equal to $1.25 \%$ ) and $\mathrm{P}_{\mathrm{t}}$ is a period t constant quality property price index. ${ }^{118}$

The Office for National Statistics in the UK used the user cost formula $U_{t}=(r+m+\delta-$ i) $\mathrm{P}_{t}$ to value the services of $\mathrm{OOH}$ where $r$ is a rate of return which includes a risk premium, $\delta$ is a depreciation rate, $\mathrm{m}$ is the maintenance rate, $\mathrm{i}$ is the expected capital appreciation rate of the unit and $\mathrm{P}_{\mathrm{t}}$ is a period $\mathrm{t}$ property price index. ${ }^{119}$

Returning back to the user cost formulae defined by (126) and (127), there is another factor which will tend to make the user cost valuation of the services of an owned dwelling unit much bigger than the corresponding actual rental price: households who rent tend to be poorer than households who own. Thus renters simply cannot afford to rent high end housing units. High end dwelling units that do rent will tend to rent for prices that are much less than their long run user costs. ${ }^{120}$ In advanced countries, the rent to property value ratio for the more expensive properties tends to be about one half the rent to property value ratio for the least expensive properties. ${ }^{121}$ Thus it is likely that the widespread use of the rental equivalence approach to the valuation of the services of owner occupied housing results in a measures of the value of housing services which give much lower valuations than valuations based on long run user costs.

There is one additional troublesome issue that has not been discussed thus far and that is the issue of what to do with transfer costs. Transfer costs are the costs associated with the purchase of a dwelling unit. These costs include transactions taxes, legal fees and real estate agent fees. These costs can be substantial. Thus when a household purchases a dwelling unit, the final cost of the purchase should include all of the associated transfer costs. According to user cost theory, the appropriate valuation of the property at the end of the period should be the value of the sale of the house after transfer costs. This viewpoint suggests that the transactions costs of the purchaser should be immediately expensed in the period of purchase. However, from the viewpoint of a landlord who has just purchased a dwelling unit for rental purposes, it would not be sensible to charge the tenant the full cost of these transaction fees in the first month of rent. The landlord would tend to capitalize these costs and recover them gradually over the time period that the

\footnotetext{
${ }^{118}$ See Gudnason and Jonsdottir $(2011 ; 148)$. Note that as in the case of Iceland, the depreciation rate is applied to total property value and not to just the structure value. This may be an acceptable approximation if the shares of land and structure in total property value remain roughly constant over time.

${ }^{119}$ See Lewis and Restieaux $(2015 ; 156)$. We have changed their notation to match up with our notation.

${ }^{120}$ Often high end houses that are not being used by their owners are rented out at prices that are far below their user costs just so someone will be in the house to maintain it and deter theft and vandalism.

${ }^{121}$ See Heston and Nakamura (2011). Hill, Steurer and Waltl $(2017 ; 8)$ find similar results for Australia and Aten (2018) finds similar results for the US. Shimizu, Diewert, Nishimura and Watanabe (2012) found that user cost valuations for $\mathrm{OOH}$ in Tokyo were about 1.7 times as big as the equivalent rent estimates.
} 
landlord expects to own the property. Thus take the capitalized transfer costs that are charged to property $\mathrm{n}$ in period $\mathrm{t}$ and divide by total property value $\mathrm{V}_{\mathrm{tn}}$ to obtain the imputed property transfer cost ratio, $\lambda_{\text {tn }}$. The new rental cost formula for rented unit $n$ in period $t$, the counterpart to (126), becomes the following formula:

$$
\begin{aligned}
\mathrm{R}_{\mathrm{tn}}=\left[\mathrm{r}_{\mathrm{t}}-\mathrm{i}_{\mathrm{Lt}}+\mathrm{v}_{\mathrm{t}}+\tau_{\mathrm{Ltn}}+\lambda_{\mathrm{tn}}\right] & \mathrm{P}_{\mathrm{Ltn}} \mathrm{L}_{\mathrm{tn}} \\
& +\left[\mathrm{r}_{\mathrm{t}}-\mathrm{i}_{\mathrm{St}}+\left(1+\mathrm{i}_{\mathrm{St}}\right) \delta+\mathrm{v}_{\mathrm{t}}+\tau_{\mathrm{Stn}}+\mathrm{m}_{\mathrm{tn}}+\pi_{\mathrm{tn}}+\lambda_{\mathrm{tn}}\right] \mathrm{P}_{\mathrm{Stn}}(1-\delta)^{\mathrm{A}(\mathrm{t}, \mathrm{n})-1} \mathrm{~S}_{\mathrm{tn}}
\end{aligned}
$$

From the viewpoint of an owner of a newly purchased dwelling unit, the owner does not actually sell the unit in the next period; the owner holds on to the dwelling unit for average periods that range from 10 to 20 years. Thus it is probably best to regard the transfer costs as a fixed cost that should be amortized over the expected holding period before the dwelling unit is sold again. If this amortisation is appropriate, then the new user cost formula that is the counterpart to (127) is the following formula which should be used to value the services of the owned unit if it is not rented out to tenants:

$$
\mathrm{U}_{\mathrm{tn}}=\left[\mathrm{r}_{\mathrm{t}}-\mathrm{i}_{\mathrm{Lt}}+\tau_{\mathrm{Ltn}}+\lambda_{\mathrm{tn}}\right] \mathrm{P}_{\mathrm{Ltn}} \mathrm{L}_{\mathrm{tn}}+\left[\mathrm{r}_{\mathrm{t}}-\mathrm{i}_{\mathrm{St}}+\left(1+\mathrm{i}_{\mathrm{St}}\right) \delta_{\mathrm{O}}+\tau_{\mathrm{Stn}}+\lambda_{\mathrm{tn}}\right] \mathrm{P}_{\mathrm{Stn}}\left(1-\delta_{\mathrm{O}}\right)^{\mathrm{A}(\mathrm{t}, \mathrm{n})-1} \mathrm{~S}_{\mathrm{tn}}
$$

The above discussion indicates that it is not a straightforward matter to determine the conceptually correct rental equivalent price to value the services of an owned dwelling unit. $^{122}$

\section{The Payments Approach and Household Costs Indexes}

A fifth possible approach to the treatment of owner occupied housing in a CPI, the payments approach, was described by Goodhart as follows:

"The second main approach is the payments approach, measuring actual cash outflows, on down payments, mortgage repayments and mortgage interest, or some subset of the above. ... Despite its problems, such a cash payment approach was used in the United Kingdom until 1994 and still is in Ireland.” Charles Goodhart (2001; F350-F351).

Thus the payments approach to owner occupied housing is a modified cash flow approach to the costs of operating an owner occupied dwelling. ${ }^{123}$ It consists mainly of mortgage interest and principal payments along with property taxes. Imputations for capital gains, for the cost of capital tied up in house equity and depreciation are ignored in this approach. This leads to the following objections to this approach; i.e., it ignores the opportunity costs of holding the equity in the owner occupied dwelling, it ignores

\footnotetext{
${ }^{122}$ For a more comprehensive decomposition of the user cost formula for an owned dwelling unit with a mortgage on the unit, see Diewert, Nakamura and Nakamura (2009) and Diewert and Nakamura (2011).

${ }^{123}$ It is not a true cash flow approach because it omits the outlays for the purchase of a dwelling unit and it omits the potential benefits from the eventual sale of the unit. The Office for National Statistics (ONS) in the United Kingdom correctly labels this class of index as a Household Costs Index (HCI). The ONS describes this type of index as follows: "More specifically, they will aim to measure how much the nominal disposable income of different household groups would need to change, in response to changes in costs, to enable households to purchase the same quantity of goods and services of the same quality. Put simply, the broad approach of the HCI is to measure the outgoings of households." ONS (2017; 2).
} 
depreciation and it uses nominal interest rates without any offset for anticipated changes in the price of land and the structure over the accounting period. In general, due to its omission of depreciation, the payments approach will tend to lead to smaller monthly expenditures on owner occupied housing than the rental equivalence, user cost and opportunity cost approaches, except during periods of high inflation, when the nominal mortgage rate term may become very large without any offsetting item for possible house price inflation. ${ }^{124}$ This feature of the payments approach makes it unsuitable for central bank monitoring of consumer price inflation.

The payments approach (like the acquisitions approach) is not a suitable approach if the goal of consumer price measurement is to measure the flow of consumption services. The rental equivalence, user cost and opportunity cost approaches are useful for measuring the flow of consumption services. The acquisitions approach is useful for central bank monitoring of marketplace consumer price inflation due to its avoidance of imputations (except imputations for quality change are allowed). A rational for the payments approach has been developed by Astin and Leyland and we outline it below.

Astin and Leyland $(2015 ; 1)$ labeled their index version of the payments approach as a Household Inflation Index (HII) and they described it as a measure of "inflation as perceived and experienced by households in their role as consumers". Thus broadly speaking, they wanted to produce a consumer price index which would more closely reflect consumer experience and perceptions of the inflation that they are experiencing. On page 3 of their paper, they outlined more specifically how their HII would differ from say the European Union's Harmonized Index of Consumer Prices (HICP) which Astin was instrumental in setting up:

- The HII would be a democratic index rather than a plutocratic index; ${ }^{125}$

- Interest paid on car loans, student loans and credit cards are household expenditures which would be in scope for their index;

- The HII would include domestic household tourist expenditures abroad and exclude the consumption expenditures of foreign tourists in the home country; ${ }^{126}$

\footnotetext{
${ }^{124}$ See the comparison of alternative $\mathrm{OOH}$ price indexes for the United Kingdom using the rental equivalence approach and the payments approach made by the ONS $(2017 ; 10)(2018 ; 3)$. The latter publication also implements the acquisitions approach and compares the three indexes for the UK. The payments approach index is much more volatile than the other two indexes.

${ }^{125}$ This terminology dates back to Prais (1959). In practical terms, what the authors suggested is that national statistical agencies should construct separate consumer price indexes for different groups of households that are demographically homogeneous. This is sensible advice. The demographic groups should be further classified into at least two subgroups depending on whether the households are renters or owners of dwelling units. The owners of dwelling units could be further decomposed into groups depending on the size of their mortgage debt. Owners of houses with no outstanding mortgages do not require the same compensation to maintain their level of housing service consumption as renters. As cash transactions become obsolete, banks and other financial institutions that issue household credit and debit cards will have information on household purchases at the individual household level. Thus in the future, it will become easier to construct consumer price indexes for groups of households classified by their demographic characteristics and location.

${ }^{126}$ Including expenditures made by foreign visitors in a CPI is called the domestic treatment of household transactions and excluding foreign visitor expenditures while including national expenditures made by
} 
- The HII would include gross insurance premiums paid by households for cars, travel and health. ${ }^{127}$

Astin and Leyland (2015) suggest that if the main purpose of a CPI is for the national indexation of pensions and only one CPI is available for this purpose, then a democratic CPI is better for this purpose than the usual plutocratic CPI. ${ }^{128}$ Note that interest paid on car loans would be explicitly included in a user cost approach to household vehicle services and interest on capital tied up would be implicitly included in the monthly or annual fee for a leased car. Thus interest payments made explicitly or implicitly by households appear in the non payment approaches to the treatment of durables.

Astin and Leyland $(2015 ; 3,22)$ also made the following specific suggestions on how expenditures on $\mathrm{OOH}$ should be treated in their proposed HII; their proposed HII should include the following categories of household expenditure:

- Total mortgage payments (interest and principal) for the dwelling;

- The transactions costs associated with the purchase of a house (transactions taxes; legal fees; real estate agent fees);

- State and local property taxes;

- Insurance;

- Spending on renovations and extensions;

- Minor repairs and maintenance.

Typically, the payments approach applied to owner occupied housing would not include the principal component of mortgage payments but Astin and Leyland properly note that these payments are experienced by households and hence they advocated including total mortgage payments in their Household Inflation Index.

national residents abroad is called the national treatment. Thus Astin and Leyland argued for the national treatment of tourist expenditures in their CPI concept. On the other hand, Astin (1999, 6-7) argued for the domestic treatment of tourist expenditures for the HICP, which is satisfactory if one wants an inflation index which is suitable for central bank monitoring of inflation. Diewert (2002; 595-596) argued that the domestic perspective was appropriate if one wanted a measure of consumer price inflation from a domestic producer perspective but the national perspective was preferred for a measure of consumer inflation faced by residents in the country under consideration.

${ }_{127}$ The gross premiums approach simply uses the total premium amount as the value of a property insurance policy held by a household. The net premiums approach subtracts either actual claims or the expected value of payments for claims on the policies in force for the period under consideration. From a national accounts perspective, the net claims approach can be justified. But the gross claims approach can be justified on a consumer theory basis; see Diewert (1993; 415-423). However, in either case, the separation of the net or gross premium payments into price and quantity components is a complex matter where standard practice has not yet emerged. For example, suppose the risk associated with a claim increases over time. Should the price of the policy be quality adjusted downward which would be consistent with insurance services as a payment per unit risk?

${ }^{128}$ A plutocratic CPI implicitly gives a higher expenditure weight to the consumer price index of a well off household. In theory, a democratic CPI should give an equal weight to all households when forming the aggregate CPI. However, if a democratic CPI could be produced where each household received an equal weight, it would be preferable to divide the population into relatively homogeneous groups and apply a separate CPI that reflected the spending habits of the particular group under consideration; i.e., it would be preferable to publish CPIs for different demographic groups. 
The transactions costs associated with the purchase of a house should be in scope for an acquisitions CPI as well as in a CPI that was based on the user cost approach. ${ }^{129}$ If the $\mathrm{OOH}$ component of the CPI were based on the rental equivalence approach, these transactions costs may be partially included in the imputed rent applied to the owned dwelling unit. ${ }^{130}$

State and local property taxes paid by home owners on a continuing basis are definitely part of the costs of the services of owned housing and should be included in the user cost approach to housing. These costs are implicitly included in the rental equivalence approach.

Property insurance costs are imbedded in rents and so these costs are included in market rents. Thus using the rental equivalence approach to $\mathrm{OOH}$, housing insurance payments should not be added to the equivalent rent. However, if the user cost approach is used for valuing the services of $\mathrm{OOH}$, then housing insurance payments should be included in the user cost formula (along with property taxes). If insurance payments are separate elementary category in the CPI, housing insurance payments could be included in the insurance subindex; i.e., it is necessary to avoid double counting of household expenditures in constructing a CPI.

Household expenditures on renovations and extensions of an owned dwelling unit should be taken into account in a CPI. If a user cost approach is being used, then these expenditures should be applied to the structure component of the overall property user cost; i.e., these expenditures should be deflated and added to the owned structure stock for the following period. Thus a renovation to an owned property should lead to an increase in the real quantity of the structure on the property but it may be difficult to capture this quality improvement using the rental equivalence approach. Depending on the details of how the rental equivalence approach to $\mathrm{OOH}$ is being implemented, it may be necessary to treat household expenditures on renovations of an owned dwelling unit as a separate category in the CPI. These expenditures should be amortized but it may be acceptable to simply treat these expenditures as current expenditures instead of recognizing that the benefits of these renovation expenditures extend over time. Minor repairs and maintenance also have benefits that extend over time but the time horizon of these benefits will tend to be relatively short and so immediate expensing of these expenditures is an acceptable approximation.

The above discussion of the Astin and Leyland proposal shows that many aspects of their suggested index are reasonable and not entirely inconsistent with the other approaches to the treatment of durables that we have considered in this paper. ${ }^{131}$ However, while their

\footnotetext{
${ }^{129}$ Conceptually, these transactions costs should be amortized over the expected holding period for a house purchase if one uses the user cost approach.

${ }^{130}$ However, the transactions costs of purchasing a rental property could have a longer amortization period if the rental property were held by the landlord for a longer time period than the average holding period for an owner of a property using the property to provide personal housing services.

${ }^{131}$ For a more complete discussion of the Astin and Leyland proposals, see the ONS (2017).
} 
proposed Household Inflation Index is a reasonable index that can reflect household experience and perceptions of inflation, it is not an index that can measure household consumption of the services of durable goods because it focuses on the immediate costs associated with the purchase of durable goods and ignores possible future benefits of these purchases. Thus the payments approach does not lead to indexes which are suitable for indexation purposes.

The Office for National Statistics (ONS) in the United Kingdom has basically implemented much of the Astin and Leland proposed Household Inflation Index on an ongoing basis ${ }^{132}$ and compared their new index with traditional acquisition and rental equivalence type CPIs; see the ONS (2018). However, the ONS (properly) recognized that the HII is focused on costs and so they renamed the index as a Household Costs Index (HCI). The ONS describes their HCI in a methodology paper as follows:

"The Household Costs Indices (HCIs) are a set of experimental measures, currently in development 1, that aim to more closely reflect UK households' experience of changing prices and costs. More specifically, they will aim to measure how much the nominal disposable income of different household groups would need to change, in response to changes in costs, to enable households to purchase the same quantity of goods and services of the same quality. Put simply, the broad approach of the HCIs is to measure the outgoings of households.” Office for National Statistics (2017; 2).

The ONS $(2017 ; 2)$ noted that its HCI differs from a traditional consumer price index ${ }^{133}$ that uses the rental equivalence approach to the treatment of $\mathrm{OOH}$ in the following four ways:

- The use of democratic weighting;

- The use of a payments approach for measuring owner occupiers' housing costs $(\mathrm{OOH})$;

- The inclusion of a measure of interest costs on credit card debt;

- The use of gross expenditure to calculate the weight for insurance premiums.

The above dot points show that the ONS Household Costs Index is very similar to the Astin and Leyland Household Inflation Index. Both indexes are versions of the payments approach. One major difference is that the ONS treatment of the payments approach includes mortgage interest on owned dwellings but excludes repayment of principle (whereas the HHI includes repayment of principle). ${ }^{134}$

The ONS cautions users that there are problems with the use of the payments approach:

\footnotetext{
${ }^{132}$ See the Office for National Statistics (2018).

${ }^{133}$ The traditional CPI that the ONS uses for comparison purposes (which they call the CPIH) is identical to Eurostat's Harmonized Index of Consumer Prices (HICP) except that the services of OOH are measured by the rental equivalence approach plus local property taxes (Council Taxes); see the ONS (2016; 3). The HICP simply omits the services of $\mathrm{OOH}$.

${ }^{134}$ See the ONS $(2017 ; 8-9)$. The ONS payments approach to OOH is compared to the rental equivalence approach for the UK over the years 2006-2016. In the future, the ONS intends to produce HCIs with and without principal payments.
} 
Using a payments-based approach is commonly considered to be the best construct for assessing changes in net money incomes over time. This is in line with the stated aims of the HCIs, as briefly set out in section 1 of this article. However, the inclusion of nominal interest payments on mortgage debt is not without its problems conceptually. Its inclusion has been criticised as the treatment of interest flows is not consistent across persons (or households). For example, Charles Goodhart (2001) describes that if a borrower is worse off in some way when interest rates rise, then equivalently a lender owning an interest bearing asset is better off, and it may be analytically unsound to include one but not the other. Office for National Statistics $(2017 ; 10)$.

The Goodhart objection to the payments approach is similar to our major objection: the approach measures the costs facing households but does not always recognize possible offsetting benefits that may accrue to households. However, a payments type index can be useful as an index of household outlays and hence perceptions of inflation, which was the reason why Astin and Leyland introduced their version of the payments approach to the measurement of household inflation.

The ONS compares its versions of the rental equivalence, acquisitions and payments approaches to the measurement of the services of owner occupied dwellings on a regular ongoing basis; see ONS $(2018$; 3 ) for a chart of the three types of index for the UK over the years 2005-2018 on a quarterly basis. This chart shows the volatility of the payments based index as compared to the other two indexes. The rental equivalence index shows a steady upward growth with the net acquisitions index being slightly more volatile and finishing above the rental equivalence index. The payments index finished up far below the other two indexes. This work by the ONS shows that the choice of methodology for the treatment of $\mathrm{OOH}$ in a CPI matters.

The ONS has provided a number of publications that explain in some detail both the rational for the four main approaches to the treatment of $\mathrm{OOH}$ as well as data sources and methods; see ONS (2016) (2017) (2018). These publications should be useful for statistical agencies who are planning to offer alternative analytical indexes for the treatment of Owner Occupied Housing in a consumer price index. However, some comments on how the ONS constructs its rental equivalence and acquisitions indexes for $\mathrm{OOH}$ may be useful.

The ONS (2016; 33) explains that it constructs its net acquisitions approach index for $\mathrm{OOH}$ as follows: prices are based on a price index for new house sales but the weights for these prices are set equal to the value of residential construction during the time period under consideration. The underlying price concept which the ONS would like to implement for its net acquisitions index is the price of the structure component of new dwelling unit sales to owners of houses who live in them. In other words, the land component of the selling price is to be stripped out of the sale price. The ONS recognizes that its empirical measures of price and expenditure are flawed for this treatment of OOH: the prices collected are sales of new dwelling units to all purchasers (purchasers who intend to live in the dwelling unit and hence are in scope and purchasers who plan to rent the dwelling unit to tenants and hence are not in scope for $\mathrm{OOH}$ ) and more importantly, the selling prices of new dwelling units include a land component which is supposed to be excluded. The residential investment weights are also flawed because the investment includes investments in new rental units which should be excluded. The 
reason for the above desired treatment of the acquisitions approach applied to new dwelling units is that Eurostat would like to implement this net approach ${ }^{135}$ to new house sales for its Harmonized Index of Consumer Prices. ${ }^{136}$ A possible better solution to implementing this pricing concept is to simply use the deflator for residential building investments which is already constructed by countries as part of their national accounts. This deflator could be improved if the residential building price index could be decomposed into two strata: one stratum for sales intended for purchasers who plan to live in the new residential structure and another stratum for investments in rental properties. But even if this latter decomposition of the residential construction price index were not made, using an overall residential construction price index along with estimates for the value of new rental buildings and for total residential construction ${ }^{137}$ would lead to a price index which should be much closer to the desired (by Eurostat) price index for $\mathrm{OOH}$. The above limitations of the ONS acquisitions price index for $\mathrm{OOH}$ should be kept in mind when looking at their chart for the acquisitions, rental equivalence and payments indexes for $\mathrm{OOH}$ in the UK; see the ONS $(2018 ; 3) .{ }^{138}$

There are also problems with the ONS $(2018 ; 3)$ rental equivalence price index series. In ONS (2016; 21-23), the ONS explains how it constructs its rental equivalence index. A sample of rental prices is collected across the UK and then the prices are stratified according to: (i) type of dwelling unit; ${ }^{139}$ (ii) postal code; (iii) number of bedrooms and (iv) furnished or unfurnished. Given our earlier discussion of the application of hedonic regression models to the construction of house price indexes and rental indexes, it can be seen that the list of stratifying characteristics is not ideal. The number of bedrooms can act as a proxy for floor space area but there is no information on land plot area and no information on the age of the structure. The latter omission is particularly important. The evidence from hedonic regressions for both selling prices and rental prices indicates that the aging of the structure leads to a quality decline in structure service of about $1 \%$ per year for a residential property. Thus if the land and structure components of property value are equal, the neglect of structure depreciation could lead to a downward bias of about $0.5 \%$ per year in a rental price index that does not take into account the quality decline due to aging of the property. This is a substantial bias. The ONS should stratify rental properties according to the age of the structure in order to take this bias into

\footnotetext{
${ }^{135}$ It is a net approach because the gross purchase price of a new dwelling unit is to be net of the land price component of the selling price. It is also a net approach because it excludes intra-household sales of residential housing units.

136 There is already an EU regulation that requires member countries to produce such a monthly acquisitions type index for $\mathrm{OOH}$ but since all EU countries are not yet able to comply with the regulation, the current HICP still ignores $\mathrm{OOH}$.

${ }^{137}$ The $\mathrm{OOH}$ expenditure weight could be obtained by subtracting the value of rental residential investment from total residential investment value. A possible reason for not implementing this version of the net acquisitions approach to $\mathrm{OOH}$ is that national statistical agencies are not in a position to produce a monthly construction cost index in a timely manner.

${ }^{138}$ It is likely that the ONS $(2018 ; 3)$ acquisitions index has an upward bias relative to the Eurostat target net acquisitions index because the ONS price index has a substantial land price component in it which will reflect rapidly increasing land prices in the UK over the sample period.

${ }^{139}$ The four categories are: (i) detached house; (ii) semi-detached house; (iii) terraced house and (iv) flat or maisonette.
} 
account (or move to a hedonic regression framework with the age of the structure as an explanatory variable).

There is another potential bias in the ONS rental equivalence index for OOH. The rental equivalence approach to valuing the services of $\mathrm{OOH}$ is an opportunity cost approach. The choice to live in an owned dwelling unit rather than rent it out indicates means that the owner of the structure is giving up the current market rent that the owner of the unit could get if the unit were rented. This is the appropriate opportunity cost from the viewpoint of the rental equivalence approach to valuing the services of an owned dwelling unit. Thus the appropriate opportunity cost is the current rent for a property that is similar to the owned property to a new tenant but the opportunity cost that the ONS (2016) uses is the average of all existing rental prices for similar properties. ${ }^{140}$ The latter average will tend to be lower than new rents if there is rental price inflation and higher if there is rental price deflation. ${ }^{141}$ Thus the ONS procedures undervalue the rental opportunity costs of living in an owned dwelling unit under conditions of general inflation. ${ }^{142}$

Recall the discussion in the previous section that compared the rental equivalence approach to the opportunity cost approach to the valuation of owned housing services. The opportunity cost approach sets the true opportunity cost of living in an owned dwelling unit as the maximum of its market rental price and its user cost. In many countries, the ratio of house rent to property value approximately doubles as we move from less expensive to more expensive properties. ${ }^{143}$ This means that, in general, the rental equivalence approach to the valuation of $\mathrm{OOH}$ will give a much smaller expenditure weight to the services of $\mathrm{OOH}$ as compared to the user cost and opportunity cost approaches.

The above limitations of the ONS rental equivalence price index for $\mathrm{OOH}$ should be kept in mind when looking at the ONS charts for the acquisitions, rental equivalence and payments indexes for $\mathrm{OOH}$ in the UK; see the charts in ONS $(2018 ; 3)$.

We conclude this section by reviewing some issues concerning the timing of payments made by households for the consumption of durable goods. Consider the following quotation from the Office for National Statistics $(2010 ; 6)$ :

"Consumption expenditure can be measured in three ways which it is important to distinguish. These ways are:

\footnotetext{
${ }^{140}$ Existing (contractual) rental prices are appropriate for valuing rental properties in a CPI. But they are not appropriate for use in the rental equivalence approach (except as an approximation): the rental equivalence approach requires the use of current opportunity costs, not historical costs.

${ }^{141}$ The ONS is well aware of this difference: "There is an important difference between newly let properties and existing tenants; price rises are highest when properties are newly let compared with existing tenants renewing a lease." Office for National Statistics $(2016$; 50).

${ }^{142}$ The use of all contract rents instead of renewal contract rents to value the services of a house will lead to a lower weight in the CPI (under conditions of general inflation) but it may not affect the corresponding rate of change in the price index.

${ }^{143}$ See footnotes 120 and 121 in the previous section.
} 
Acquisition means that the total value of all goods and services delivered during a given period is taken into account, whether or not they were wholly paid for during the period.

Use means that the total value of all goods and services consumed during a given period is taken into account.

Payment means that the total payments made for goods and services during a given period is taken into account, whether or not they were delivered.

For practical purposes, these three concepts cannot be distinguished in the case of non-durable items bought for cash, and they do not need to be distinguished for many durable items bought for cash. The distinction is, however, important for purchases financed by some form of credit, notably major durable goods, which are acquired at a certain point of time, used over a considerable number of years, and paid for, at least partly, some time after they were acquired, possibly in a series of installments. Housing costs paid by owner-occupiers are an obvious example."

In what follows, we will look at the problems associated with the three methods of valuation in a number of specific cases. ${ }^{144}$

Case 1: The payment period coincides with the acquisition period. Let $\mathrm{P}_{1}$ be the acquisition price for such a unit of a durable good in period 1 . Then the acquisition price in period 1 is obviously $\mathrm{P}_{1}$, the payments price is also $\mathrm{P}_{1}$ and the period 1 user cost price is $\mathrm{p}_{1}$ and its exact form depends on the model of depreciation that is applicable for this particular durable good. In other words, there are no problems in sorting out the three methods of valuation in this case.

Case 2: The initial payment period coincides with the acquisition period but payments for the purchase of the durable continue on for subsequent periods. Suppose that payments must be made for $\mathrm{T}$ periods and the sequence of monetary payments is $\pi_{1}, \pi_{2}, \ldots, \pi_{\mathrm{T}}$. Suppose also that the sequence of expected one period financial opportunity costs of capital for the purchasing household is $\mathrm{r}_{1}, \mathrm{r}_{2}, \ldots, \mathrm{r}_{\mathrm{T}-1}$. Then the discounted stream of payments, $\mathrm{P}_{1}$, is the period 1 (expected) cost of purchasing the good where $\mathrm{P}_{1}$ is defined as follows:

(130) $\mathrm{P}_{1} \equiv \pi_{1}+\left(1+\mathrm{r}_{1}\right)^{-1} \pi_{2}+\left(1+\mathrm{r}_{1}\right)^{-1}\left(1+\mathrm{r}_{2}\right)^{-1} \pi_{3}+\ldots+\left(1+\mathrm{r}_{1}\right)^{-1}\left(1+\mathrm{r}_{2}\right)^{-1} \ldots\left(1+\mathrm{r}_{\mathrm{T}-1}\right)^{-1} \pi_{\mathrm{T}}$.

In this case, the acquisitions price for the durable good in period 1 is defined to be $\mathrm{P}_{1}$, the payments price is $\pi_{1}$ and the user cost will be determined using the appropriate depreciation model where $\mathrm{P}_{1}$ is taken to be the beginning of the period price for the durable good. In a subsequent period $\mathrm{t} \leq \mathrm{T}$, the acquisitions price for the used durable good will be 0 , the payments price will be $\pi_{\mathrm{t}}$ and the period t user cost value $\mathrm{v}_{\mathrm{t}}$ will be determined using the appropriate depreciation model for this type of durable good. If the useful life of the durable good happens to equal $\mathrm{T}$ and if the period t payment is equal to

\footnotetext{
${ }^{144}$ We will address the problems from the viewpoint of the approach to intertemporal consumption theory that dates back to Hicks (1946).
} 
the corresponding period $t$ user cost valuation $v_{t}$ for $t=1,2, \ldots, T$, then obviously, the period $t$ user cost valuation $v_{t}$ will be equal to the observable period t payment $\pi_{t} .{ }^{145}$

There are problems associated with the computation of the $\mathrm{P}_{1}$ defined by (130); i.e., in order to compute $\mathrm{P}_{1}$ when the durable good is purchased during period 1 , the sequence of future payments $\pi_{\mathrm{t}}$ has to be known and guesses will have to be made on the magnitudes of the sequence of expected nominal interest rates $r_{t}$. However, the important point to be made here is that $\mathrm{P}_{1}$ defined by (130) will be less than the simple sum of the $\pi_{t}, \Sigma_{t=1}{ }^{\mathrm{T}} \pi_{\mathrm{t}}$, provided that the nominal interest rates $r_{t}$ are positive.

Case 3: The full payment for the good (or service) is made in period 1 but the services of the commodity are not delivered until period $t$. Let the period 1 payment be $\pi_{1}$ as usual. Thus the sequence of payments associated with the purchase of the commodity under consideration is $\pi_{1}$ for period 1 and 0 for all subsequent periods. The acquisition of the commodity does not take place until period $t$ but the appropriate acquisition price $\mathrm{P}_{\mathrm{t}}$ is not the period 1 payment, $\pi_{1}$, but the following escalated period 1 price:

(131) $\mathrm{P}_{\mathrm{t}} \equiv\left(1+\mathrm{r}_{1}\right)\left(1+\mathrm{r}_{2}\right) \ldots\left(1+\mathrm{r}_{\mathrm{t}-1}\right) \pi_{1}$

The logic behind this valuation is the following one. During period 1 when the product was paid for, the payment could have been used to pay down debt (at the interest rate $r_{1}$ ) or the payment could have been used to invest in an asset that earned the rate of return $r_{1}$. Thus after one period, the opportunity cost of the investment in the pre-purchased product has grown to $\pi_{1}\left(1+r_{1}\right)$, after 2 periods, the opportunity cost has grown to $\pi_{1}\left(1+r_{1}\right)\left(1+r_{2}\right), \ldots$, and by period $t$ when the good or service is acquired, the opportunity cost has grown to $\pi_{1}\left(1+r_{1}\right)\left(1+r_{2}\right) \ldots\left(1+r_{t-1}\right)$, which is (131). The important point to be made here is that $P_{t}$ defined by (131) will be greater than the period 1 prepayment, $\pi_{1}$, provided that the nominal interest rates $r_{t}$ are positive. Since the product has not been acquired by the household for periods $1,2, \ldots, \mathrm{t}-1$, the corresponding user cost valuations, $\mathrm{v}_{1}, \mathrm{v}_{2}, \ldots, \mathrm{v}_{\mathrm{t}-1}$ should be set equal to 0 . However, when period $t$ is reached, "normal" user costs can be calculated for durable goods using the $\mathrm{P}_{\mathrm{t}}$ defined by (131) as the beginning of period $\mathrm{t}$ price of the durable, assuming that the form of depreciation is known.

Prepayment for services or durable goods is widespread; e.g., trip and hotel reservations made in advance and paid for in advance are service examples and prepayment for condominium units that are under construction is a durable good example.

Case 4: The good or service is acquired in period 1 but is not paid for until period 2. In this case, the sequence of payments is $0, \pi_{2}, 0, \ldots, 0$. The commodity is acquired in period 1 and the appropriate period 1 acquisition price is $P_{1}$ defined as follows:

\footnotetext{
${ }^{145}$ The period $t$ user cost valuation $\mathrm{v}_{\mathrm{t}}$ for a unit of the durable good that is $\mathrm{t}$ periods old can be converted into an equivalent amount of a new unit of a durable good if the geometric or one hoss shay model of depreciation is applicable for the durable good under consideration. Otherwise, units of the durable good of different ages at the same point in time need to be aggregated using an index number formula.
} 
(132) $\mathrm{P}_{1} \equiv\left(1+\mathrm{r}_{1}\right)^{-1} \pi_{2}$

The justification for this acquisition price runs as follows: The purchasing household lays aside the amount of money $\mathrm{P}_{1}$ to buy the product in period 1 . This money is invested and earns the one period rate of return $r_{1}$. Thus when period 2 comes along, the household has $\mathrm{P}_{1}\left(1+\mathrm{r}_{1}\right)=\pi_{2}$ which is just enough money to complete the purchase in period 2 . Thus $\mathrm{P}_{1}$ is an appropriate period 1 acquisitions price. If the commodity is a durable good, then assuming that the form of depreciation is known, $\mathrm{P}_{1}$ defined by (132) can be used as the beginning of period 1 price for the period 1 user cost and the entire sequence of user costs can be calculated.

This form of pricing is used as a way of offering lower prices for a wide variety of products. A particular application of this model to a service is the use of credit cards to purchase consumption items. A household that pays its balance owing on time can avoid interest charges and thus can postpone payment for its household purchases for up to one month in many cases. ${ }^{146}$

If interest rates are very low, then statistical agencies may well find it is not worth taking into account the above refinements. However, if nominal interest rates are high, it may be necessary to make some of the above adjustments. ${ }^{147}$

\section{Summary and Conclusion}

It is clear that constructing constant quality price indexes for consumer durables is not as conceptually simple as constructing price indexes for nondurables and services where the matched model approach can guide index construction. The fundamental problem of accounting arises when constructing a price index for the services of a durable good: imputations will have to be made in order to decompose the initial purchase cost into period by period components over the life time of the durable good. The method of imputation will involve assumptions which may not be accepted by all interested parties. In spite of this difficulty, it will be useful for statistical agencies to construct analytical series for the services of long lived consumer durables that can be made available to the public. This will meet the needs of different users. ${ }^{148}$

When constructing property price indexes based on sales of properties, there is another factor that reinforces the argument for multiple price indexes: when transactions are sparse, property indexes based on the sparse data can be very volatile. Thus for some

\footnotetext{
${ }^{146}$ However, a household that does not pay off its balance owing in a timely fashion will find itself in Case 3 above.

${ }^{147}$ We note that the above adjustments for the timing of payments have implications for the system of national accounts that have not been fully worked out.

${ }^{148}$ Hill, Steurer and Waltl (2017), using Australian data, found substantial differences using the three main approaches to the valuation of $\mathrm{OOH}$. This emphasizes the need for statistical agencies to produce estimates for all three approaches if possible.
} 
purposes, it may be useful to construct a smoothed index (that is revised for a certain number of months) in addition to a volatile real time index. ${ }^{149}$

For non-housing consumer durables, at present, statistical agencies produce consumer price indexes based on the acquisitions approach. This type of index is useful for measuring consumer price inflation based on market transactions, with minimal imputations (except for possible quality change). In addition to this standard index, statistical agencies should produce supplementary indexes based on the user cost approach in order to more accurately measure the flow of services generated by stocks of consumer durables. ${ }^{150}$

The valuation of the services of housing is very difficult due to the fact that housing services are unique: the location of each dwelling unit is unique and the location affects the land price component of the property and thus affects rents and user costs. Moreover, the structure component of housing does not remain constant over time due to depreciation of the structure and to renovation expenditures. Various methods that can deal with these difficulties (to some degree at least) were explained in sections 12-16. The details of the methods are too complex to summarize here but the suggested methods based on various hedonic regression models have been applied and offer possible ways forward.

For Owner Occupied Housing, the three main approaches should be implemented. There are two possible versions for the acquisitions approach: (i) construct a price index for the purchase of new dwelling units in an inclusive basis, including the price of land and (ii) exclude land cost from the purchase cost. The latter index should be well approximated by a construction cost index (with appropriate margins added for developer margins). The inclusive index will be useful for new house buyers, who have to pay for the land plot as well as the new structure. A rental equivalence price index for the services of $\mathrm{OOH}$ should also be constructed. For many countries, such an (implicit) index is already available as part of the national accounts valuation for the services of $\mathrm{OOH}^{151} \mathrm{~A}$ user cost index for the services of $\mathrm{OOH}$ should also be constructed since the user cost valuation for the services of a high end dwelling unit will typically be much greater than the corresponding price that the unit could rent for. ${ }^{152}$ If the rental equivalent rent and user cost for an owned unit are constructed and are of the same quality, then applying the opportunity cost approach to the valuation of the services of the owned unit is appropriate.

\footnotetext{
${ }^{149}$ See Rambaldi and Fletcher (2014) on various smoothing methods that could be used. Diewert and Shimizu (2017b) suggested a very simple method which worked well in their empirical application.

${ }^{150}$ The rental equivalence approach could be used for durables that are rented or leased but typically, most consumer durables are not rented. Depreciation rates will in most cases be based on educated guesses. Durable stock estimates can be made once depreciation rates have been determined. The current value of household stocks of consumer durables should also be constructed and added to household balance sheets.

${ }^{151}$ However, the equivalent rents should be based on new contract rents if possible in order to provide a current opportunity cost for using the services of an owned dwelling unit; recall the discussion on this point in section 16.

${ }^{152}$ Recall the evidence on this point in Heston and Nakamura (2011).
} 
For rented housing, the measurement problems are perhaps not so severe; monthly or weekly rents can be observed for the same rental unit and so it would seem that the usual matched model methodology could be applied in this situation. However, an index based on the matched model methodology and normal index number theory will generally have an upward bias due to the neglect of depreciation or a lowering of quality due to the aging of the structure. In order to deal with this bias, it will in general require a hedonic regression approach with age as one of the explanatory variables.

We will conclude by noting some specific recommendations that emerge from the paper:

- There are three main approaches for the treatment of consumer durables in a CPI: the acquisitions approach, the rental equivalence approach and the user cost approach.

- The acquisitions approach is suitable (for most purposes) for durable goods with a relatively short expected useful life.

- The acquisitions approach is particularly useful for central bankers who want consumer inflation indexes that are largely free from imputations.

- The acquisitions approach provides an index for purchases of a durable good and this index is a required input into the construction of a user cost index.

- The remaining two approaches are useful for measuring the flow of services yielded by consumer durables over their useful lives.

- At present, only the flow of services for $\mathrm{OOH}$ is estimated by national statistical agencies (using the rental equivalence or user cost approaches) because this information is required for the international System of National Accounts; i.e., the flow of services for other durable goods is not measured at present.

- The acquisitions approach will substantially understate the value of the service flow from consumer durables that have relatively long lives. Hence at least one of the rental equivalence or user cost approaches should be implemented by statistical agencies for durables with long lives. ${ }^{153}$ Examples of long lived durables are automobiles and household furnishings.

- The rental equivalence approach to the valuation of the services provided by consumer durables is the preferred method of valuation (with the exception of $\mathrm{OOH})$ when rental or leasing markets for the class of durables exist, because, in principle, no imputations are required to implement this method. ${ }^{154}$

- However, when rental markets for the durable good under consideration are thin or do not exist, then the user cost approach should be used to value the services of the durable good.

- The user cost approach requires the construction of a price index for new acquisitions of the durable. It also requires a model of depreciation and assumptions about the opportunity cost of capital and about expected asset inflation rates. Thus the user cost approach necessarily involves imputations.

\footnotetext{
${ }^{153}$ If the acquisitions approach is used in the headline CPI, the alternative approaches can be published as experimental or supplementary series.

${ }^{154}$ However, for housing, the "comparable" rental property may not be exactly the same as the owned unit. Moreover, the observed rents may include insurance services and the services of some utilities and possibly furniture. It will be difficult to extract these costs from the observed rent.
} 
- In order to avoid unnecessary volatility in the user costs, long run expected asset inflation rates should be used in the user cost formula. ${ }^{155}$

- Rental markets for high end dwelling units are generally nonexistent or very thin and hence, it may not be possible to use the rental equivalence approach for high end $\mathrm{OOH}$. Even if some rental information on high end housing units is available, usually these rents are far below the corresponding user costs.

- The "true" opportunity cost for using the services of a consumer durable is the maximum of its rental price (if it exists) and its user cost. Thus the use of the rental equivalence approach to value the services of a high end housing unit will understate the "true" service flow by a substantial amount. ${ }^{156}$

- In order to construct national balance sheets and to measure national multifactor productivity, it is necessary to decompose the selling prices of dwelling units into structure and land components. This can be done for both detached housing and condominium units using hedonic regression techniques; see sections 12 and 13 above. This decomposition is also required in order to construct accurate user costs for housing units since depreciation applies to the structure but not to the land component of the property.

- When constructing price indexes for rental housing, statistical agencies need to make an adjustment to observed rents for the same unit for depreciation of the structure and possible improvements to the structure.

- When using observed rents to measure the service flow for comparable owned properties, statistical agencies should use new contract rents to evaluate the service flow for the owned units since rents for continuing tenants may be sticky and not reflect current opportunity costs.

- When constructing user costs for $\mathrm{OOH}$, statistical agencies need to avoid double counting of some housing related costs that may appear elsewhere in the CPI such as insurance costs. Similar double counting problems may arise with housing rents, which may include the services of some utilities or furniture and of course, the housing rent will include insurance costs. In principle, these associated costs should be deducted from the observed rent and placed in the appropriate classification of the CPI. In practice, this is a difficult imputation problem.

- A variant of the acquisitions approach is sometimes applied to $\mathrm{OOH}$. This variant excludes the land component of the purchase of a new house. Thus this variant reduces to a construction cost index for housing with some allowance made for builders' profit margins. This variant generates valuations for $\mathrm{OOH}$ that may be

\footnotetext{
${ }^{155}$ The long run asset inflation rate over the past 20 or 25 years or the long run rate of inflation in housing rents could be used to predict future asset inflation rates. Many other prediction methods could be used; see for example Verbrugge (2008). However, the focus should be on predicting long run asset inflation rather than period to period inflation.

${ }^{156}$ Long run user costs and rents will tend to be approximately equal to each other for lower end housing units since this type of housing unit will be built by property developers who provide rental housing and they need to set rents that are approximately equal to their long run user costs. However, short run dynamics can cause user costs and rents to diverge even for lower end housing units.
} 
far below the comparable rental equivalent and user cost valuations. It is difficult to justify the use of this variant in a CPI. ${ }^{157}$

Which of the three main methods for valuing the purchase of a consumer durable should be used for indexing pensions or indexing salaries for consumer inflation? This is a difficult question to answer. If we start out with the idea that we want a national consumer price index, then if there were no durable goods, a national acquisitions price index would be the target index. But it is not clear that this is the "correct" price index once we recognize the existence of consumer durables: an acquisitions index does not recognize the imputed costs of previously purchased consumer durable goods. Thus in order to deal with this difficulty, we need to move to a rental equivalence index or a user cost index if rental markets are thin. But if a national index based on say the rental equivalence approach were used to determine pension payments for veterans or retired civil servants or for employees in an industry, the resulting payments do not take into account that different households have different holdings of consumer durables (housing in particular) and they do not need to be compensated for their consumption of existing holdings. There are additional complications that need to be addressed:

- If the goal is to maintain the purchasing power of a certain group of households (such as retirees or veterans), then an appropriate index needs to be constructed for the relevant group.

- The relevant group may live in different regions of the country and so in principle, separate indexes need to be constructed for each region by group.

- The index may be a plutocratic one (where well off members of the group get a higher weight in the index) or a democratic one (where each individual gets an equal weight in the index).

\section{References}

Astin, J. (1999), “The European Union Harmonized Indices of Consumer Prices (HICP)”, Statistical Journal of the United Nations ECE 16 (1999), 123-135.

Astin, J. and J. Leyland (2015), “Towards a Household Inflation Index", unpublished paper prepared for the Royal Statistical Society.

Aten, B.H. (2018), "Valuing Owner-Occupied Housing: An Empirical Exercise Using the American Community Survey (ACS) Housing Files", Research Paper, Bureau of Economic Analysis, Washington DC, March.

\footnotetext{
${ }^{157}$ It is not a "true" acquisitions price that is observed in the marketplace since it involves imputations to subtract the land value from the property sale. The resulting acquisitions price obviously does not reflect the total services provided by the purchase.
} 
Australian Bureau of Statistics (2016), "Making Greater Use of Transactions Data to Compile the Consumer Price Index", Information Paper 6401.0.60.003, November 29, Canberra: ABS.

Bank for International Settlements (2018), "BIS Property Prices", BIS Statistics Warehouse, Basel: BIS.

Bailey, M.J., R.F. Muth and H.O. Nourse (1963), "A Regression Method for Real Estate Price Construction”, Journal of the American Statistical Association 58, 933-942.

Beidelman, C. (1973), Valuation of Used Capital Assets, Sarasota Florida: American Accounting Association.

Beidelman, C.R. (1976), "Economic Depreciation in a Capital Goods Industry", National Tax Journal 29, 379-390.

Böhm-Bawerk, E. V. (1891), The Positive Theory of Capital, W. Smart (translator of the original German book published in 1888), New York: G.E. Stechert.

Bostic, R.W., S.D. Longhofer and C.L. Readfearn (2007), "Land Leverage: Decomposing Home Price Dynamics", Real Estate Economics 35:2, 183-2008.

Bureau of Labor Statistics (1983), "Changing the Home Ownership Component of the Consumer Price Index to Rental Equivalence", CPI Detailed Report, Washington DC: BLS.

Burnett-Issacs, K., N. Huang and W.E. Diewert (2016), "Developing Land and Structure Price Indexes for Ottawa Condominium Apartments", Discussion Paper 16-09, Vancouver School of Economics, University of British Columbia, Vancouver, B.C., Canada.

Cairns, R.D. (2013), “The Fundamental Problem of Accounting”, Canadian Journal of Economics 46:2, 634-655.

Canning, J.B. (1929), The Economics of Accountancy, New York: The Ronald Press Co.

Christensen, L.R. and D.W. Jorgenson (1969), "The Measurement of U.S. Real Capital Input, 1929-1967," Review of Income and Wealth 15(4): 293-320.

Church, A.H. (1901), "The Proper Distribution of Establishment Charges, Part III", The Engineering Magazine 21, 904-912.

Clapp, J.M. (1980), "The Elasticity of Substitution for Land: The Effects of Measurement Errors", Journal of Urban Economics 8, 255-263. 
Court, A. T. (1939), "Hedonic Price Indexes with Automotive Examples", pp. 98-117 in The Dynamics of Automobile Demand, New York: General Motors Corporation.

Crone, T.M., L.I. Nakamura and R. Voith (2000), "Measuring Housing Services Inflation", Journal of Economic and Social Measurement 26, 153-171.

Crone, T.M., L.I Nakamura and R.P. Voith (2011), "Hedonic Estimates of the Cost of Housing Services: Rental and Owner Occupied Units", pp. 51-68 in Diewert, W.E., B.M. Balk, D. Fixler, K.J. Fox and A.O. Nakamura, Price and Productivity Measurement: Volume 1: Housing, Victoria: Trafford Press.

Crosby, N.S. Devaney and V. Law (2012), "Rental Depreciation and Capital Expenditure in the UK Commercial Real Estate Market, 1993-2009”, Journal of Property Research 29:3, 227-246.

de Haan, J. (2015), "Rolling Year Time Dummy Indexes and the Choice of Splicing Method", Room Document at the 14th meeting of the Ottawa Group, May 22, Tokyo. http://www.stat.go.jp/english/info/meetings/og2015/pdf/t1s3room

Diewert, W.E. (1974), "Intertemporal Consumer Theory and the Demand for Durables," Econometrica 42, 497-516.

Diewert, W.E. (1980), “Aggregation Problems in the Measurement of Capital”, pp. 433528 in The Measurement of Capital, Dan Usher (ed.), University of Chicago Press, Chicago.

Diewert, W.E. (1993), "Symmetric Means and Choice under Uncertainty", pp. 355-433 in Essays in Index Number Theory, Volume 1 (W.E. Diewert and A.O. Nakamura editors), Amsterdam: North-Holland.

Diewert, W.E. (2002), "Harmonized Indexes of Consumer Prices: Their Conceptual Foundations", Swiss Journal of Economics and Statistics 138:4, 547-637.

Diewert, W.E. (2005a), "Issues in the Measurement of Capital Services, Depreciation, Asset Price Changes and Interest Rates", pp. 479-542 in Measuring Capital in the New Economy, C. Corrado, J. Haltiwanger and D. Sichel (eds.), Chicago: University of Chicago Press.

Diewert, W.E. (2005b), “Adjacent Period Dummy Variable Hedonic Regressions and Bilateral Index Number Theory”, Annales d'Économie et de Statistique 79/80, 759-786.

Diewert, W.E. (2008), "OECD Workshop on Productivity Analysis and Measurement: Conclusions and Future Directions", pp. 11-36 in Proceedings From the OECD Workshops on Productivity Measurement and Analysis, Paris: OECD. 
Diewert, W.E. (2010), “Alternative Approaches to Measuring House Price Inflation”, Discussion Paper 10-10, Department of Economics, The University of British Columbia, Vancouver, Canada, V6T 1 Z1.

Diewert, W.E. and K.J. Fox (2016), "Sunk Costs and the Measurement of Commercial Property Depreciation”, Canadian Journal of Economics 49:4; 1340-1366.

Diewert, W.E. and K.J. Fox (2017), "Substitution Bias in Multilateral Methods for CPI Construction using Scanner Data", Discussion Paper 17-02, Vancouver School of Economics, The University of British Columbia, Vancouver, Canada, V6T 1L4.

Diewert, W.E. and K.J. Fox (2018), "Alternative User Costs, Productivity and Inequality in US Business Sectors", pp. 21-69 in Productivity and Inequality, W.H. Greene, L. Khalaf, P. Makdissi, R. Sickles, M. Veall and M.-C. Voia (eds.), New York: Springer.

Diewert, W.E. and D.A. Lawrence (2000), "Progress in Measuring the Price and Quantity of Capital", pp. 273-326 in Econometrics Volume 2: Econometrics and the cost of Capital: Essays in Honor of Dale W. Jorgenson, L. J. Lau (ed.), Cambridge, MA: The MIT Press.

Diewert, W.E. and A.O. Nakamura (2011), Accounting for Housing in a CPI”, pp. 7-32 in Diewert, W.E., B.M. Balk, D. Fixler, K.J. Fox and A.O. Nakamura, Price and Productivity Measurement: Volume 1: Housing, Victoria: Trafford Press.

Diewert, W.E., A.O. Nakamura and L.I. Nakamura (2011), "The Housing Bubble and a New Approach to Accounting for Housing in a CPI", Journal of Housing Economics 18:3, 156-171.

Diewert, W. E. and C. Shimizu (2015), "Residential Property Price Indexes for Tokyo," Macroeconomic Dynamics 19, 1659-1714.

Diewert, W. E. and C. Shimizu (2016), "Hedonic Regression Models for Tokyo Condominium Sales," Regional Science and Urban Economics 60, 300-315.

Diewert, W. E. and C. Shimizu (2017a), "Alternative Approaches to Commercial Property Price Indexes for Tokyo," Review of Income and Wealth 63:3, 492-519.

Diewert, W.E. and C. Shimizu (2017b), "Alternative Land Prices for Commercial Properties in Tokyo", Discussion Paper 17-07, Vancouver School of Economics, The University of British Columbia, Vancouver, Canada, V6T 1L4.

Diewert, W.E., J. de Haan and R. Hendriks (2011), "The Decomposition of a House Price Index into Land and Structures Components: A Hedonic Regression Approach", The Valuation Journal 6, 58-106. 
Diewert, W.E., J. de Haan and R. Hendriks (2015), "Hedonic Regressions and the Decomposition of a House Price index into Land and Structure Components", Econometric Reviews 34, 106-126.

Diewert, W.E., N. Huang and K. Burnett-Issacs (2017), “Alternative Approaches for Resale Housing Price Indexes", Discussion Paper 17-05,Vancouver School of Economics, The University of British Columbia, Vancouver, Canada, V6T 1L4.

Diewert, W.E, A.O Nakamura and L.E. Nakamura (2009), "The Housing Bubble and New Approach to Accounting for Housing in a CPI", Journal of Housing Economics, 18, 156-171.

Diewert, W.E. and H. Wei (2017), "Getting Rental Prices Right for Computers: Reconciling Different Perspectives on Depreciation", Review of Income and Wealth, 63:S1,149-168.

European Central Bank (2018), Residential Property Price Index Statistics, Statistical Data Warehouse, Frankfurt: European Central Bank.

Eurostat, IMF, OECD, UN and World Bank (1993), System of National Accounts 1993, United Nations: New York.

Eurostat (2001), Handbook on Price and Volume Measures in National Accounts, Luxembourg: European Commission.

Eurostat (2005), "On the principles for estimating dwelling services for the purpose of Council Regulation (EC, Euratom) No 1287/2003 on the harmonisation of gross national income at market prices", Official Journal of the European Union, Commission Regulation (EC) No 1722/2005, October 20.

Eurostat (2013), Handbook on Residential Property Prices Indices (RPPIs), Luxembourg: Publications Office of the European Union.

Eurostat (2017), Technical Manual on Owner-Occupied Housing and House Price Indices, Brussels: European Commission.

Fenwick, D. (2009), “A Statistical System for Residential Property Price Indices", Eurostat-IAOS-IFC Conference on Residential Property Price Indices, Bank for International Settlements, November.

Fenwick, D. (2012), “A Family of Price Indices", The Meeting of Groups of Experts on Consumer Price Indices, UNECE/ILO, United Nations Palais des Nations, Geneva Switzerland, May 30-June 1.

Fisher, I. (1922), The Making of Index Numbers, Boston: Houghton-Mifflin. 
Francke, M.K. (2008), “The Hierarchical Trend Model”, pp. 164-180 in Mass Appraisal Methods: An International Perspective for Property Valuers, T. Kauko and M. Damato (eds.), Oxford: Wiley-Blackwell.

Francke, M. K. and G. A. Vos. (2004), “The Hierarchical Trend Model for Property Valuation and Local Price Indices," Journal of Real Estate Finance and Economics 28, 179-208.

Garcke, E. and J.M. Fells (1893), Factory Accounts: Their Principles and Practice, Fourth Edition, (First Edition 1887), London: Crosby, Lockwood and Son.

Garner, T.I. and R. Verbrugge (2011), "The Puzzling Divergence of Rents and User Costs, 1980-2004: Summary and Extensions", pp. 125-146 in Diewert, W.E., B.M. Balk, D. Fixler, K.J. Fox and A.O. Nakamura, Price and Productivity Measurement: Volume 1: Housing, Victoria: Trafford Press.

Genesove, D (2003) , "The Nominal Rigidity of Apartment Rents", The Review of Economics and Statistics 85 (4), 844-853.

Gilman, S. (1939), Accounting Concepts of Profit, New York: The Rolland Press Co.

Goodhart, C. (2001), "What Weights should be Given to Asset Prices in the Measurement of Inflation?”, The Economic Journal 111 (June), F335-F356.

Griliches, Z. (1971), "Introduction: Hedonic Price Indexes Revisited", pp. 3-15 in Price Indexes and Quality Change, Z. Griliches (ed.), Cambridge MA: Harvard University Press.

Gudnason, R. and G. Jonsdottir (2011), "Owner Occupied Housing in the Icelandic CPI," pp. 147-150 in Diewert, W.E., B.M. Balk, D. Fixler, K.J. Fox and A.O. Nakamura, Price and Productivity Measurement: Volume 1: Housing, Victoria: Trafford Press.

Hall, R.E. (1971), "The Measurement of Quality Change from Vintage Price Data", pp. 240-271 in Price Indexes and Quality Change, Z. Griliches (ed.), Cambridge MA: Harvard University Press.

Hall, R.E. and D.W. Jorgenson (1967), "Tax Policy and Investment Behavior", American Economic Review 57, 391-414.

Harper, M.J., E.R. Berndt and D.O. Wood (1989), "Rates of Return and Capital Aggregation Using Alternative Rental Prices”, pp. 331-372 in Technology and Capital Formation, D. W. Jorgenson and R. Landau (eds.), The MIT Press, Cambridge, MA. 
Heston, A. and A.O. Nakamura (2011), Reported Prices and Rents of Housing: Reflections of Costs, Amenities or Both?", pp. 117-124 in Diewert, W.E., B.M. Balk, D. Fixler, K.J. Fox and A.O. Nakamura, Price and Productivity Measurement: Volume 1: Housing, Victoria: Trafford Press.

Hicks, J. R. (1946), Value and Capital, Second Edition, Oxford: Clarendon Press.

Hill, R.J. (2013), "Hedonic Price Indexes for Residential Housing: A Survey, Evaluation and Taxonomy", Journal of Economic Surveys 27, 879-914.

Hill, R.J., M. Scholz, C. Shimizu and M. Steurer (2018), "An Evaluation of the Methods used by European Countries to compute their Official House Price Indices", Economie et Statistique / Economics and Statistics Numbers 500-502, 221-238.

Hill, R.J., M. Steurer and S.R. Waltl (2017), "Owner Occupied Housing in the CPI and Its Impact On Monetary Policy During Housing Booms and Busts", Graz Economic Paper 2018-12, Department of Public Economics, University of Graz, Graz, Austria.

Hoffmann, J. and C. Kurz (2002), "Rent Indices for Housing in West Germany: 1985 to 1998", Discussion Paper 01/02, Economic Research Centre of the Deutsche Bundesbank, Frankfurt.

Hotelling, H. (1925), “A General Mathematical Theory of Depreciation”, Journal of the American Statistical Association 20, 340-353.

Hulten, C.R. (1990), "The Measurement of Capital", pp. 119-158 in Fifty Years of Economic Measurement, E. R. Berndt and J. E. Triplett (eds.), Chicago: the University of Chicago Press.

Hulten, C.R. (1996), "Capital and Wealth in the Revised SNA", pp. 149-181 in The New System of National Accounts, J.W. Kendrick (ed.), New York: Kluwer Academic Publishers.

Hulten, C.R. and F.C. Wykoff (1981a), "The Estimation of Economic Depreciation using Vintage Asset Prices", Journal of Econometrics 15, 367-396.

Hulten, C.R. and F.C. Wykoff (1981b), "The Measurement of Economic Depreciation", pp. 81-125 in Depreciation, Inflation and the Taxation of Income from Capital, C.R. Hulten (ed.), Washington D.C.: The Urban Institute Press.

Hulten, C.R. and F.C. Wykoff (1996), "Issues in the Measurement of Economic Depreciation: Introductory Remarks", Economic Inquiry 34, 10-23. 
ILO, Eurostat, IMF, OECD, UNECE and the World Bank (2004), Consumer Price Index Manual: Theory and Practice, Peter Hill (ed.), Geneva: International Labour Office.

Ivancic, L., W.E. Diewert and K.J. Fox (2011), "Scanner Data, Time Aggregation and the Construction of Price Indexes", Journal of Econometrics 161, 24-35.

Jorgenson, D.W. (1989), "Capital as a Factor of Production”, pp. 1-35 in Technology and Capital Formation, D.W. Jorgenson and R. Landau (eds.), Cambridge MA: The MIT Press.

Jorgenson, D.W. (1996), “Empirical Studies of Depreciation”, Economic Inquiry 34, 2442.

Katz, A.J. (1983), "Valuing the Services of Consumer Durables", The Review of Income and Wealth 29, 405-427.

Koev, E. and J.M.C. Santos Silva (2008), "Hedonic Methods for Decomposing House Price Indices into Land and Structure Components", unpublished paper, Department of Economics, University of Essex, England, October.

Krsinich, F. (2016), “The FEWS Index: Fixed Effects with a Window Splice', Journal of Official Statistics 32, 375-404.

Lebow, D.E. and J.B. Rudd (2003), "Measurement Error in the Consumer Price Index: Where do we Stand?", Journal of Economic Literature 41, 159-201.

Lewis, R. and A. Restieaux (2015), Improvements to the Measurement of Owner Occupiers' Housing Costs and Private Housing Rental Prices, Newport, UK: Office for National Statistics.

Malpezzi, S., L. Ozanne and T. Thibodeau (1987), "Microeconomic Estimates of Housing Depreciation", Land Economics 63, 372-385.

Marshall, A. (1898), Principles of Economics, Fourth Edition, London: The Macmillan Co.

Matheson, E. (1910), The Depreciation of Factories and their Valuation, Fourth Edition, London: E. \& F.N. Spon.

McMillen, D.P. (2003), "The Return of Centralization to Chicago: Using Repeat Sales to Identify Changes in House Price Distance Gradients", Regional Science and Urban Economics 33, 287-304.

OECD (2001), Measuring Productivity: Measurement of Aggregate and Industry-Level Productivity Growth, Paris: OECD. 
Office for National Statistics (2010), Consumer Price Indexes Technical Manual:2010 Edition, Newport, U.K.: Office for National Statistics.

Office for National Statistics (2016), CPIH Compendium, Newport, U.K.: Office for National Statistics.

Office for National Statistics (2017), Household Costs Indices: Methodology, Newport, U.K.: Office for National Statistics.

Office for National Statistics (2018), Measures of Owners Occupiers' Housing Costs, UK: April to June 2018, Newport, U.K.: Office for National Statistics.

Peasnell, K.V. (1981), “On Capital Budgeting and Income Measurement”, Abacus 17:1, 52-67.

Prais, S.J. (1959), "Whose Cost of Living?", The Review of Economic Studies 26, 126134.

Rambaldi, A.N., R.J. McAllister, K. Collins and C.S. Fletcher (2010), "Separating Land from Structure in Property Prices: A Case Study from Brisbane Australia", School of Economics, The University of Queensland, St. Lucia, Queensland 4072, Australia.

Rambaldi, A.N, and C.S. Fletcher (2014), "Hedonic Imputed Property Price Indexes: The Effects of Econometric Modeling Choices", Review of Income and Wealth 60:S2, S423-S448.

Schreyer, P. (2001), OECD Productivity Manual: A Guide to the Measurement of Industry-Level and Aggregate Productivity Growth, Paris: OECD.

Schreyer, P. (2009), Measuring Capital, Statistics Directorate, National Accounts, STD/NAD(2009)1, Paris: OECD.

Schwann, G.M. (1998), "A Real Estate Price Index for Thin Markets", Journal of Real Estate Finance and Economics 16:3, 269-287.

Shimizu, C., W.E. Diewert, K. Nishimura and T. Watanabe (2012), "The Estimation of Owner Occupied Housing Indexes using the RPPI: The Case of Tokyo", Meeting of the Group of Experts on Consumer Price Indices, Geneva, May 28.

Shimizu, C., K. Nishimura and T. Watanabe (2010a), "Housing Prices in Tokyo: A Comparison of Hedonic and Repeat Sales Measures", Journal of Economics and Statistics 230, 792-813.

Shimizu, C.,K.G. Nishimura and T. Watanabe (2010b), "Nominal Rigidity of Housing Rent", Financial Review 106:1, 52-68. 
Shimizu, C., H. Takatsuji, H. Ono and K. G. Nishimura (2010), "Structural and Temporal Changes in the Housing Market and Hedonic Housing Price Indices," International Journal of Housing Markets and Analysis, 3(4), 351-368.

Shimizu, C. and T. Watanabe (2011), "Nominal Rigidity of Housing Rent", Financial Review 106:1, 52-68.

Silver, M.S. (2018), "How to Measure Hedonic Property Price Indexes Better", EURONA 1/2018, 35-66.

Solomons, D. (1961), "Economic and Accounting Concepts of Income", The Accounting Review 36, 374-383.

Statistics Portugal (Instituto Nacional de Estatistica) (2009), “Owner-Occupied Housing: Econometric Study and Model to Estimate Land Prices, Final Report", paper presented to the Eurostat Working Group on the Harmonization of Consumer Price Indices", March 26-27, Luxembourg: Eurostat.

Suzuki, M., Y. Asami and C. Shimizu (2018), "Unit-Level Long-Run Dynamics of 'Sticky' Housing Rents", unpublished paper, Department of Urban Engineering, The University of Tokyo Email: suzuki@ua.t.u-tokyo.ac.jp

Verbrugge, R. (2008), “The Puzzling Divergence of Rents and User Costs, 1980-2004", Review of Income and Wealth 54:4, 671-699.

Walras, L. (1954), Elements of Pure Economics, translated by W. Jaffe (first published in 1874), London: George Allen and Unwin.

White, K.J. (2004), Shazam: User's Reference Manual, Version 10, Vancouver, Canada: Northwest Econometrics Ltd. 